UC-25 Metallurgy and Ceramics (TID-4500, 15th Ed.)

Contract No. W-7405-eng-92

\title{
PROGRESS ON THE USE OF GAS-PRESSURE BONDING FOR FABRICATING LOW-COST CERAMIC, CERMET, AND DISPERSION FUELS \\ Phase II Report on AEC Fuel-Cycle Program
}

Edited by

Stan J. Paprocki

Work done by

Donald L. Keller

Edwin S. Hodge

Charles B. Boyer

John B. Fox

Donald E. Kizer

Stanley W. Porembka

November 7, 1960

BATTELLE MEMORIAL INSTITUTE

$505 \mathrm{King}$ Avenue

Columbus 1, Ohio 


\section{DISCLAIMER}

This report was prepared as an account of work sponsored by an agency of the United States Government. Neither the United States Government nor any agency Thereof, nor any of their employees, makes any warranty, express or implied, or assumes any legal liability or responsibility for the accuracy, completeness, or usefulness of any information, apparatus, product, or process disclosed, or represents that its use would not infringe privately owned rights. Reference herein to any specific commercial product, process, or service by trade name, trademark, manufacturer, or otherwise does not necessarily constitute or imply its endorsement, recommendation, or favoring by the United States Government or any agency thereof. The views and opinions of authors expressed herein do not necessarily state or reflect those of the United States Government or any agency thereof. 


\section{DISCLAIMER}

Portions of this document may be illegible in electronic image products. Images are produced from the best available original document. 
ABSTRACT . . . . . . . . . . . . . . . . . . . . 1

INTRODUCTION . . . . . . . . . . . . . . . . . . . . 1

GAS-PRESSURE-BONDING TECHNIQUE . . . . . . . . . . . . . . . 2

MATERIALS . . . . . . . . . . . . . . . . . . . . . . . . . . . 2

COMPACTION STUDIES OF UO $\mathrm{UO}_{2}$. . . . . . . . . . . . . . . . . . . 8

Cold Pressing . . . . . . . . . . . . . . . . . 8

Effectiveness of Binder Additions . . . . . . . . . . . 10

Oxide Mixtures .. . . . . . . . . . . . . . . 10

Particle-Size Effects ................. . . 13

Other Compaction Methods . . . . . . . . . . . . . . 13

Tamp Packing . . . . . . . . . . . . . . 15

Centrifuging .................. . . . . 15

Ultrasonic Packing . . . . . . . . . . . . . . 17

Metal-Faced Compacts . . . . . . . . . . . . . 17

Slurry Methods for $\mathrm{UO}_{2}$ Compacting. . . . . . . . . . 18

Presintering . . . . . . . . . . . . . . . . 19

Discussion of Compaction Methods . . . . . . . . . . . . 19

STOICHIOMETRY STUDY . . . . . . . . . . . . . . . . 20

CERMET PREPARATION . . . . . . . . . . . . . . . . . . 23

EVALUATION OF STAINLESS STEEL BONDS. . . . . . . . . . . . . . . . 24

Cleaning and Assembly of Components . . . . . . . . . . . . 24

Effects of Mechanical Surface Preparation . . . . . . . . . . 25

EVALUATION OF PRESSURE-BONDED UO $\mathrm{UO}_{2}$. . . . . . . . . . . . . 25

Density and Structure of Pressure-Bonded Uranium Dioxide. . . . . . 25

Individual Oxides . . . . . . . . . . . . . 30

Oxide Mixtures .. . . . . . . . . . . . . . . . 35

Permeation of Helium at Room Temperature . . . . . . . . . . 40

Thermal Conductivity . . . . . . . . . . . . . . . 42

Apparatus and Method . . . . . . . . . . . . . 45

Results . . . . . . . . . . . . . . . 45

EVALUATION OF PRESSURE-BONDED CERMETS . . . . . . . . . . . . . 47

GAS-PRESSURE-BONDED FUEL-ELEMENT DESIGNS . . . . . . . . . . . . 50 
Rod-Type Elements . . . . . . . . . . . . . . . 51

Cylindrical-Rod Design. . . . . . . . . . . . . 51

Problems Associated With Gas-Pressure Bonding . . . . . 52

Effect of Compaction Method on Element Uniformity . . . . 59

Design Modifications ... . . . . . ...... 63

Preliminary Requirements for a Stable Cylindrical-Rod

Configuration................ 63

Corrugated-Rod Design. . . . . . . . . . . . 63

Compartmented-Rod Design. . . . . . . . . . . . 69

Tubular Elements . . . . . . . . . . . . . . . . 74

Flat-Plate Elements. . . . . . . . . . . . . . . . 77

Preliminary Studies . . . . . . . . . . . . . 77

Edge-Welded Flat Plates . . . . . . . . . . . 80

Flat-Plate Fuel Assemblies. . . . . . . . . . . . 80

Modified Flat-Plate Design . . . . . . . . . . 88

CONCLUSIONS . . . . . . . . . . . . . . . . . . . . . 88

FUTURE WORK . . . . . . . . . . . . . . . . . . . . . . 90

REFERENCES . . . . . . . . . . . . . . . . . . . . . 9 91 


\title{
PROGRESS ON THE USE OF GAS-PRESSURE BONDING FOR FABRICATING LOW-COST CERAMIC, CERMET, AND DISPERSION FUELS
}

\author{
Phase II Report on AEC Fuel-Cycle Program
}

Edited by Stan J. Paprocki

\begin{abstract}
Uranium dioxide clad with Type 304 stainless steel has been fabricated into rod, tubular, and flat-plate shapes by the gas-pressure-bonding process. Modifications of these basic designs have included compartmented rods, corrugated rods, and compartmented plates. The cold-compacting behavior in methods other than direct cold pressing and the pressure-bonding behavior of seven commercial oxides and various mixtures have been defined.
\end{abstract}

Through the selection of initial oxides and compacting procedures, final oxide densities of 86 to 99.5 per cent of theoretical have been achieved. It has been noted that the oxides tend to approach stoichiometry during the pressurebonding process. Permeability measurements of high-density pressure-bonded uranium dioxide have resulted in values which were within the blank rate of measuring apparatus, indicating equivalence to high-density sintering oxides. Thermal-conductivity measurements on similar materials are also consistent with high-density oxide as prepared by pressing and sintering.

Of the oxides investigated, mixtures of ceramic and fused oxides appear to offer the most promise in achieving low-cost fuel elements through the pressurebonding process. Such mixtures containing from 30 to $60 \mathrm{w} / \mathrm{o}$ ceramic oxide provide a high initial pressed density and also permit achieving a high final density. Both oxides are low-cost materials.

The preparation and pressure bonding of uranium dioxide-stainless steel cermets were also briefly studied, yielding materials of densities up to 96.5 per cent of theoretical. Modulus-of-rupture and thermal-conductivity measurements were also obtained on these materials.

\section{INTRODUCTION}

In support of the Fuel-Cycle Development Program of the U. S. Atomic Energy Commission, Battelle is investigating the gas-pressure-bonding technique as a method for producing low-cost quality fuel elements. The basic approach of the program has been to achieve both fuel densification and cladding bonding in a single pressure-bonding cycle. Uranium dioxide ceramic, cermet, and dispersion fuels with stainless steel cladding are under study. To date the program emphasis has been placed on the ceramic fuel system since it appears to have the potential for the widest application. Also, it is anticipated that the techniques developed in this case can be applied to the other systems with a minimum of further development.

This report presents the progress achieved in Phase II of the Battelle program. This phase of the investigation involved two general areas of study, namely uranium dioxide powder compaction and the pressure-bonding characteristics of stainless-clad 
uranium dioxide assemblies. The uranium dioxide study was concerned with the development of optimum methods for preparing the oxide with sufficient green density for pressure bonding. The objective of the pressure-bonding portion of this phase of the program was to establish the effects of the oxide parameters, assembly design, and bonding parameters on the characteristics of the densified oxide. In conjunction with this area of study various fuel-element designs were also evaluated.

\section{GAS-PRESSURE-BONDING TECHNIQUE}

The gas-pressure-bonding technique developed by Battelle utilizes a cladding process in which the components to be bonded are sealed in a pressuretight evacuated container and then heated at an elevated temperature in an autoclave containing gas at high pressure. The components are fabricated to final size, inspected and cleaned prior to assembly into the metallic container. In the bonding process the pressure is uniformly transmitted through the container to the assembled components, thus forcing the mating surfaces into intimate contact. The combined action of the high gas pressure and elevated temperature promotes diffusion between components to produce bonded structures. Generally, a temperature above the recrystallization temperature of the materials to be bonded is selected in order to achieve grain growth across the original interfaces and thus produce bond strengths consistent with that of the parent materials.

The gas-pressure-bonding process as utilized in the present study has many unique advantages not possessed by other fabrication techniques. Complex shapes can be produced with extremely close dimensional control. Since many components can be bonded in a single operation, the process represents a low-cost fabrication technique. Also, where powder core products are employed the simultaneous densification and cladding of the core is possible. The technique is extremely flexible in that it can be adapted to a variety of systems including metallic, dispersion, cermet, and ceramic materials.

The pressure-bonding equipment utilized in this study is of a relatively simple design but incorporates several unique features. Three high-pressure autoclaves, two measuring $9 \mathrm{in}$. in ID by $4 \mathrm{ft}$ long and the third $14 \mathrm{in}$. in ID by $6 \mathrm{ft}$ long, are available for this study. The pressure vessels are of the cold-wall design, incorporating a resistance heater located within the center of the vessel. Ceramic-fiber material is tightly packed around the heater to insulate it from the autoclave wall. The vessels are sealed at both ends by heads employing the use of a modified Bridgeman closure, which can be readily opened for loading and unloading of specimens. Though all electrical and thermocouple leads, pressure inlet and outlet, and safety-disk assembly are located within the head, they have been designed so they can be quickly disconnected to gain access to the interior of the autoclave.

\section{MATERIALS}

The uranium dioxide powders used in this study represent seven different commercially available types. These powders were selected so that it would be possible to 
establish the pressure-bonding behavior of $\mathrm{UO}_{2}$ powders of widely varying characteristics. The seven types of powders employed are as follows:

(1) Mallinckrodt ceramic

(2) Mallinckrodt dense ceramic

(3) Mallinckrodt high-fired

(4) Mallinkrodt special dense

(5) Mallinkrodt spherical

(6) Numec high-fired

(7) Spencer fused.

At the outset of Phase I of the present program the characteristics of the various powder types were defined. (1) The results of microscopic analyses of the individual powders, which are presented in Tables 1 and 2 , demonstrate the wide variation of characteristics in the powders chosen for study. Further variance is shown in the particle-size distributions, which are presented in Figure 1. With respect to the particle-size distributions, it was desired that the as-received size distributions be utilized since they would represent a considerably lower cost as compared with powders requiring special sizing operations.

TABLE 1. MICROSCOPIC DETERMINATION OF DIRECT VISUAL POROSITY AND CRYSTAL SIZE OF UO 2 POWDERS

\begin{tabular}{|c|c|c|c|}
\hline Sample and Size & $\begin{array}{l}\text { Porosity by } \\
\text { Direct Visual Count, } \\
\text { volume per cent }\end{array}$ & $\begin{array}{c}\text { Calculated Equivalent } \\
\text { Water Absorption, } \\
\text { volume per cent }\end{array}$ & $\begin{array}{c}\text { Average } \\
\text { Crystal Size } \\
\text { of the } \mathrm{UO}_{2} \text { Phase, } \mu \\
\end{array}$ \\
\hline $\mathrm{MCW}$ ceramic $\mathrm{UO}_{2}$ (minus 325 mesh) & $<0.01$ & Zero & 0.6 \\
\hline $\mathrm{MCW}$ dense ceramic $\mathrm{UO}_{2}$ (minus 325 mesh) & 0.2 & 0.05 & 0.9 \\
\hline MCW high-fired $\mathrm{UO}_{2}$ (minus 400 mesh) & 0.42 & 0.1 & 14.9 \\
\hline Numec high-fired $\mathrm{UO}_{2}$ (minus 325 mesh) & 1.9 & 0.5 & 9.4 \\
\hline $\mathrm{MCW}$ special dense $\mathrm{UO}_{2}$ (minus 40 mesh) & 1.38 & 0.35 & 2.1 \\
\hline MCW spherical $\mathrm{UO}_{2}$ (minus 200 plus 325 mesh) & 1.6 & 0.4 & 3.7 \\
\hline Spencer fused $\mathrm{UO}_{2}$ (minus 20 mesh) & $<0.01$ & Zero & 178.0 \\
\hline
\end{tabular}

The seven uranium dioxide powders considered in this investigation also represent a wide range of initial costs, which would be reflected in the over-all costs of the final fuel element. These costs are dependent on the extent of processing required in the manufacture of the individual materials. In this respect, the ceramic grade of oxide is the lowest cost powder and the special dense grade is the most expensive. The dense ceramic and high-fired grades represent an intermediate cost because of limited additional processing. The fused oxide, which is processed by a different route, can be regarded as an intermediate-cost oxide.

Type 304 stainless steel was utilized as the cladding material throughout the investigation. In view of possible future efforts to minimize cladding with regard to

(1) References at end. 
TABLE 2. MICROSCOPIC EXAMINATION OF SEVEN DIFFERENT SAMPLES OF UO 2 POWDERS AS RECEIVED FROM COMMERCIAL SUPPLIERS

\begin{tabular}{|c|c|c|c|}
\hline \multirow[b]{2}{*}{ Sample } & \multicolumn{2}{|c|}{ Visual Volume Phase Composition by Direct-Area-Count Method } & \multirow{2}{*}{$\begin{array}{l}\text { Variation in the } \\
\text { Index of Refraction } \\
\text { of Phases }\end{array}$} \\
\hline & Phase Identity & $\begin{array}{l}\text { Average, } \\
\text { volume per cent }\end{array}$ & \\
\hline \multirow[t]{2}{*}{$\begin{array}{l}\text { Mallinckrodt ceramic grade } \\
\text { (minus } 200 \text { mesh) } \mathrm{UO}_{2}\end{array}$} & $\begin{array}{l}\text { Extremely fine grained, very finely cryptocrystalline, } \\
\text { nodular, grape-cluster type of } \mathrm{UO}_{2} \text { aggregates. The } \\
\text { average grain size was approximately } 0.8 \mu \text { in } \\
\text { diameter. }\end{array}$ & $\begin{array}{l}99.5 \\
\text { plus }\end{array}$ & $\begin{array}{l}\text { Isotropic, } \\
\mathrm{N}=2.34_{\mathrm{Li}} \pm 0.01_{\mathrm{Li}} \\
\mathrm{N}>2.33_{\mathrm{Li}} \text { but below } \\
\quad 2.35_{\mathrm{Li}}\end{array}$ \\
\hline & $\begin{array}{l}\text { Scattered traces of impurities. No enriching secondary } \\
\text { phase appeared to be present. }\end{array}$ & Traces & -- \\
\hline \multirow[t]{2}{*}{$\begin{array}{l}\text { Mallinckrodt dense ceramic } \\
\text { grade } \mathrm{UO}_{2}\end{array}$} & $\begin{array}{l}\text { Isotropic, coarsely crystalline grains and particles of } \\
\mathrm{UO}_{2} \text { phase. }\end{array}$ & 87.7 & $\begin{array}{l}\text { Isotropic, } \\
\qquad \mathrm{N}=2.34_{\mathrm{Li}} \pm 0.01_{\mathrm{Li}}\end{array}$ \\
\hline & $\begin{array}{l}\text { Isotropic, tiny "pin points" of a secondary, bonding } \\
\text { phase appeared to be present. The secondary phase } \\
\text { was probably glass in structure. }\end{array}$ & 12.3 & Isotropic, $\mathrm{N}>2.35_{\mathrm{Li}}$ \\
\hline \multirow[t]{2}{*}{$\begin{array}{l}\text { Mallinckrodt high-fired } \\
\text { grade (minus } 400 \text { mesh) }\end{array}$} & $\begin{array}{l}\text { Isotropic, coarsely crystalline grains and particles of } \\
\mathrm{UO}_{2} \text { phase. Many of the grains were broken } \\
\text { portions of a single crystal. }\end{array}$ & 92.3 & $\begin{array}{l}\text { Isotropic, } \\
\qquad \mathrm{N}=2.34_{\mathrm{Li}} \pm 0.01_{\mathrm{Li}}\end{array}$ \\
\hline & $\begin{array}{l}\text { Black, opaque, interstitial stringers of a secondary, } \\
\text { cementing phase appeared to be present. No } \\
\text { birefringence was observed in the secondary- } \\
\text { phase portion. }\end{array}$ & 7.7 & $\begin{array}{l}\text { Black, opaque, in } \\
\text { transmitted light }\end{array}$ \\
\hline \multirow[t]{2}{*}{$\begin{array}{l}\text { NUMEC high-fired grade } \\
\text { (minus } 325 \text { mesh) } \mathrm{UO}_{2}\end{array}$} & $\begin{array}{l}\text { Isotropic, coarsely crystalline grains and particles of } \\
\mathrm{UO}_{2} \text { phase. Temperature of calcination was high } \\
\text { enough to produce anhedral crystal grains. Rectan- } \\
\text { gular shapes, polygon shapes, and octahedrons were } \\
\text { present. This appeared'to be a calcined high- } \\
\text { temperature type of } \mathrm{UO}_{2} \text { powder. }\end{array}$ & 95.4 & $\begin{array}{l}\text { Isotropic, } \\
\qquad \mathrm{N}=2.34_{\mathrm{Li}} \pm 0.01_{\mathrm{Li}}\end{array}$ \\
\hline & $\begin{array}{l}\text { Tiny "pin points" of a secondary, cementing phase } \\
\text { were present. }\end{array}$ & 4.6 & Isotropic, $\mathrm{N}>2.35_{\mathrm{Li}}$ \\
\hline \multirow[t]{2}{*}{$\begin{array}{l}\text { Mallinckrodt special dense } \\
\text { grade } \mathrm{UO}_{2}\end{array}$} & $\begin{array}{l}\text { Isotropic, microcrystalline type of crystalline } \mathrm{UO}_{2} \\
\text { powder. }\end{array}$ & 89.1 & $\begin{array}{l}\text { Isotropic, } \\
\qquad \mathrm{N}=2.34_{\mathrm{Li}} \pm 0.01_{\mathrm{Li}}\end{array}$ \\
\hline & $\begin{array}{l}\text { Isotropic, "pin points" of a secondary cementing } \\
\text { phase were present. A few black, opaque, } \\
\text { inclusions of secondary phase were also present. }\end{array}$ & 10.9 & Isotropic, $\mathrm{N}>2.35_{\mathrm{Li}}$ \\
\hline $\begin{array}{l}\text { Mallinckrodt spherical shot } \\
\text { (minus } 200 \text { plus } 325 \text { mesh) }\end{array}$ & $\begin{array}{l}\text { Isotropic, coarsely crystalline grains and coalescent } \\
\text { crystalline particles of } \mathrm{UO}_{2} \text { phase were seen. } \\
\text { Nodular, grape-cluster type of aggregate particles } \\
\text { were also noted. }\end{array}$ & 90.6 & $\begin{array}{l}\text { Isotropic, } \\
\qquad \mathrm{N}=2.34_{\mathrm{Li}} \pm 0.01_{\mathrm{Li}}\end{array}$ \\
\hline
\end{tabular}


5

TABLE 2. (Continued)

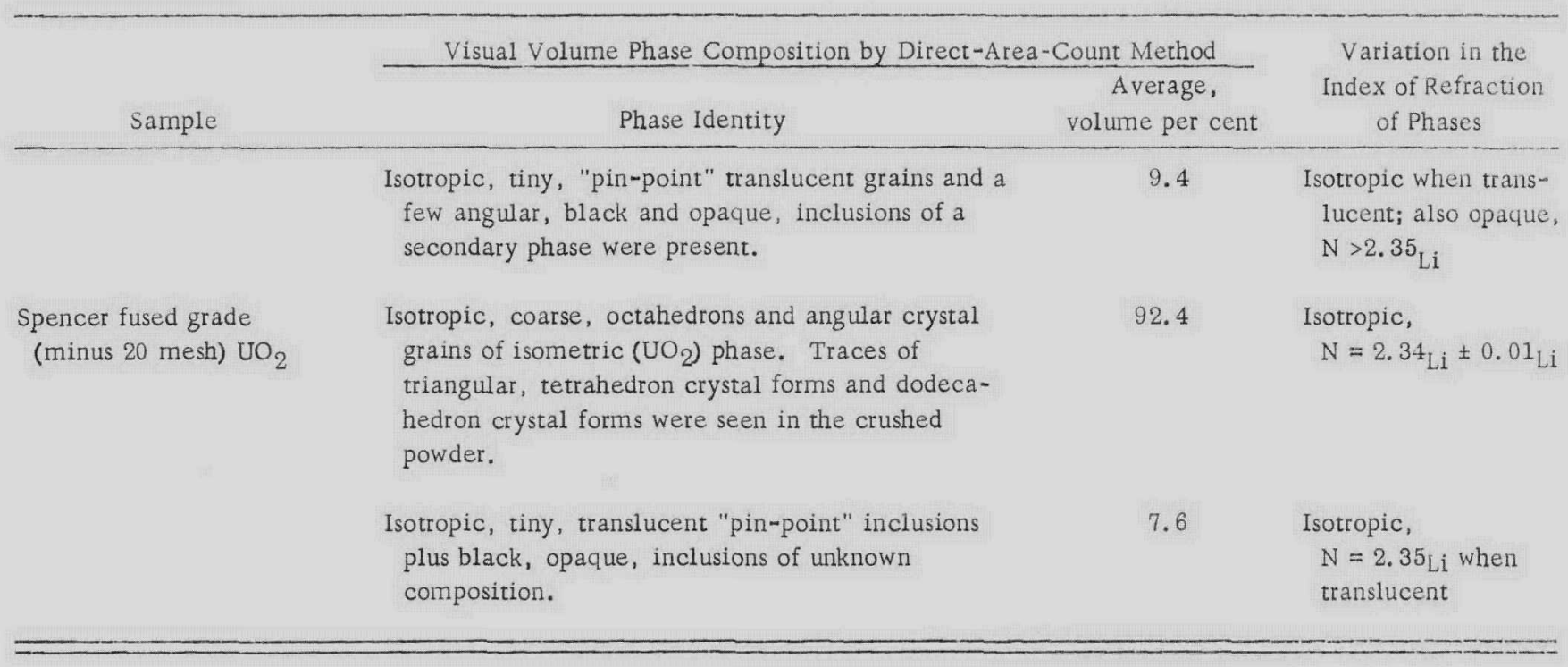




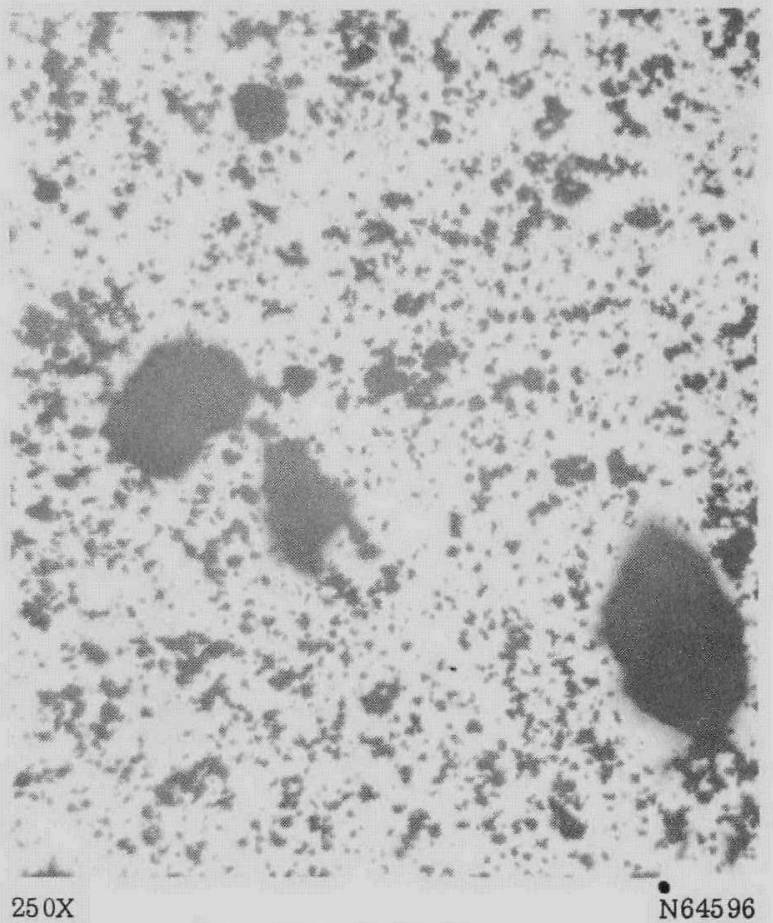

a. Ceramic Grade

(Minus 325 Mesh)

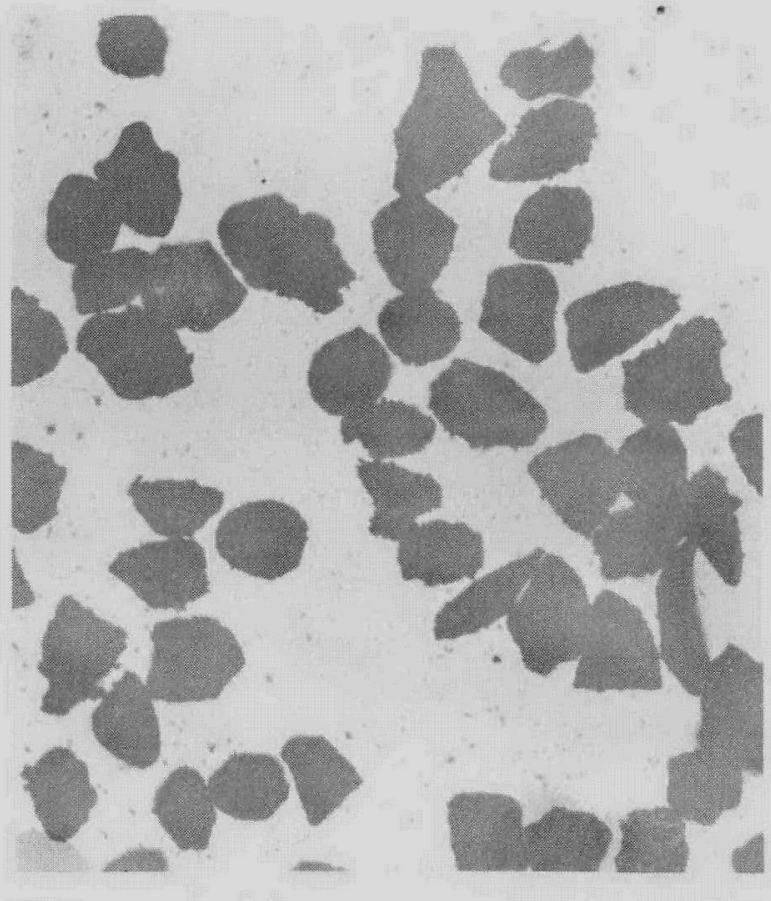

c. Spherical Grade

(Minus 200 Plus 325 Mesh)

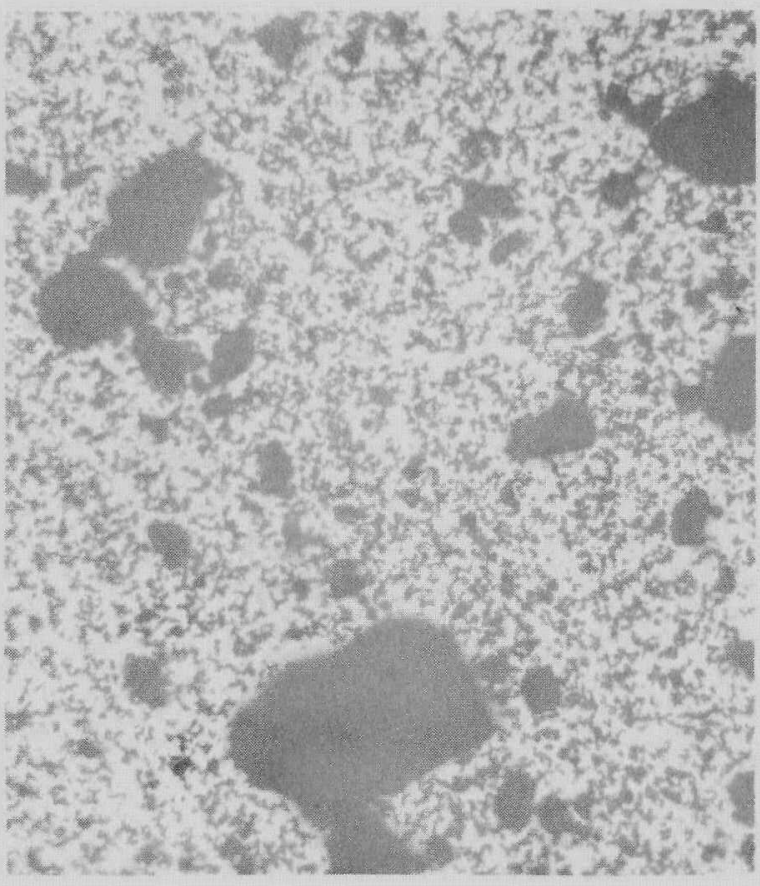

$250 \mathrm{X}$

b. Dense Ceramic Grade

(Minus 325 Mesh)

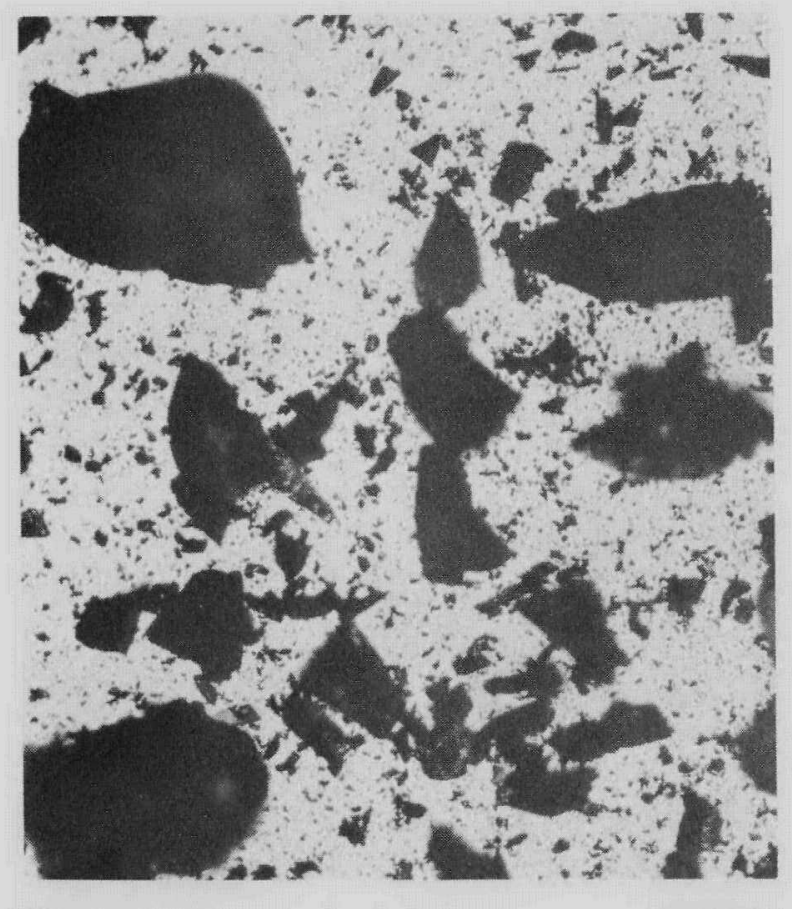

$50 \mathrm{X}$

d. Fused Grade

(Minus $20 \mathrm{Mesh}$ )
N64599 


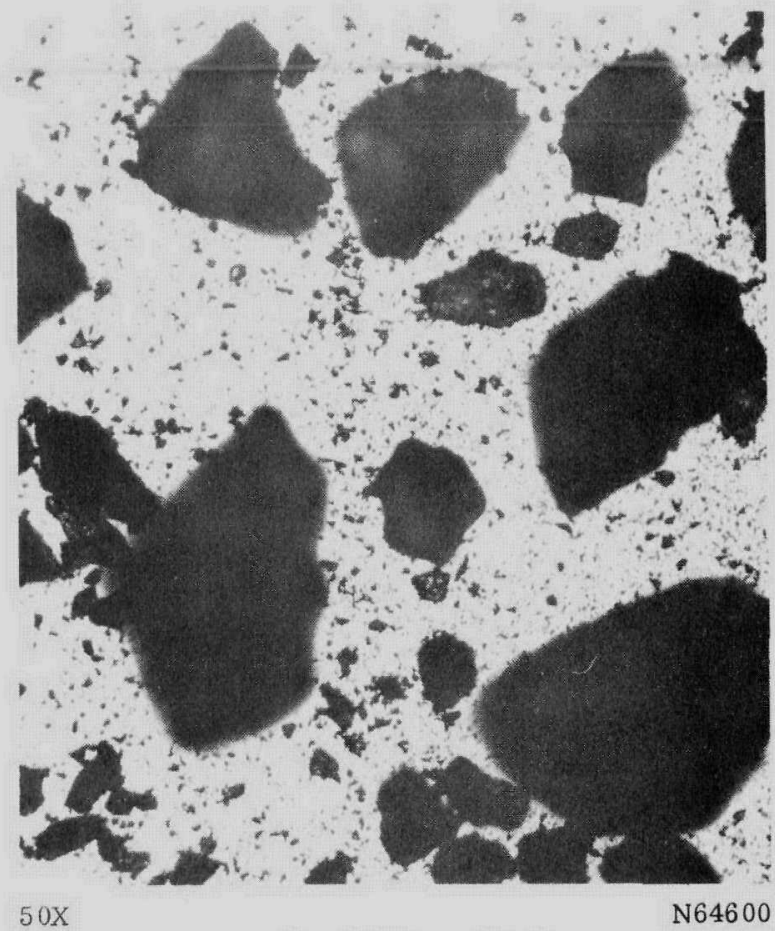

e. Special Dense Grade

(Minus 40 Mesh)

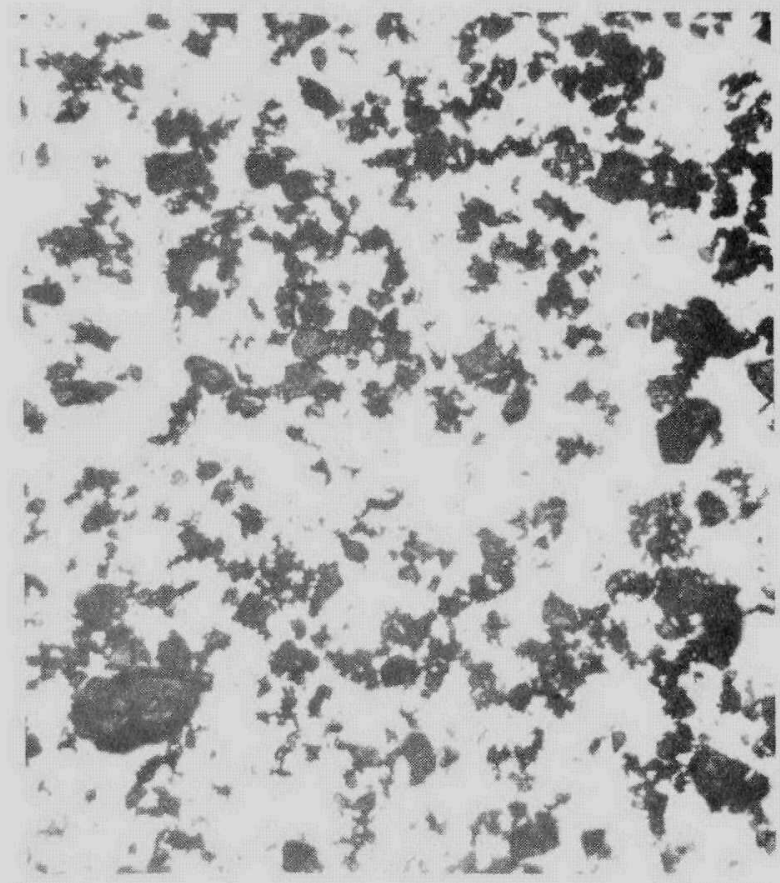

$250 \mathrm{X}$

N64597

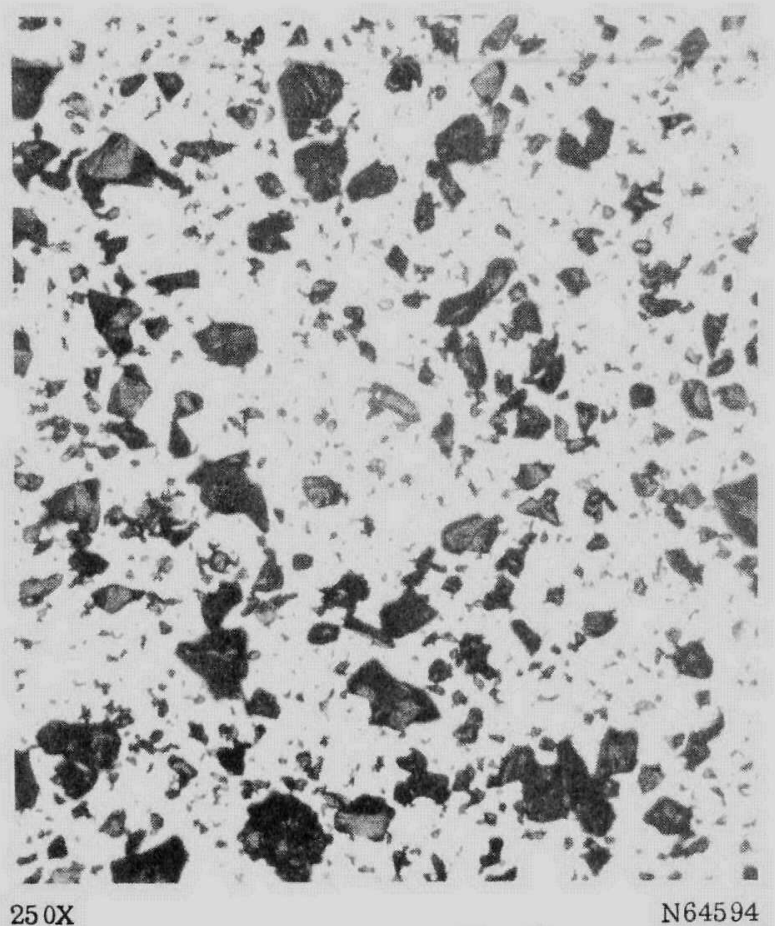

f. MCW High-Fired Grade

(Minus 400 Mesh)

FIGURE 1. AS-RECEIVED MICROSTRUCTURES OF VARIOUS COMMERCI AL UO $\mathrm{UO}_{2}$ POWDERS

Powders were photographed on a ground glass plate, and thus some of the particles are out of focus. g. Numec High-Fired Grade

(Minus 325 Mesh) 
neutron economy, the cladding thicknesses studied were restricted to 10 to $20 \mathrm{mils}$. Tubing and strip sizes incorporated in this investigation represented readily available commercial sizes. In final usage, however, it is intended that a low-carbon grade of Type 304 stainless will be required to minimize sensitization effects due to the slow cool during the pressure-bonding cycle.

\section{COMPACTION STUDIES OF UO2}

Studies of the cold-compacting characteristics of the various uranium dioxide powders were continued during the present phase of the program. Several oxide types, particularly the ceramic grade, have been treated extensively in other investigations with respect to pressing and sintering behavior. (2) In Phase I, the cold-pressing behavior of the seven powders was established, and for the purpose of review the results are plotted in Figure 2. These compacting results, in conjunction with the early pressure-bonding experiments, indicated that green oxide densities of 70 per cent of theoretical or greater were required to restrict cladding deformation during densification and produce a symmetrical final product. In view of subsequent data this limit has been revised to 75 per cent of theoretical density. A variation in activity of the powder during pressure bonding was also noted with the low-green-density ceramic grade oxide achieving the highest density after the bonding cycle. In contrast, the fused and special dense oxides, which pressed to high green densities, exhibited little densification during the bonding cycle. Subsequent compaction studies were therefore directed toward achieving high green densities with potential bonding activity through the optimization of binders, utilization of mixtures, and special particle sizing. In view of the desirability to minimize or possibly eliminate binder additions, tamp packing, centrifuging, ultrasonic packing, and nickelfacing powder techniques were also investigated. More recently, processing of dewaxed pellets from specially dried uranium dioxide slurries containing binder was studied.

\section{Cold Pressing}

Perhaps the most conventional method for producing high-green-density uranium dioxide cores for pressure bonding is the cold-pressing process. In earlier work this procedure was used almost exclusively, and the results indicated that further studies were required to optimize the materials and process for the present pressure-bonding technique. It was noted that a considerable variation in pressed density resulted from the selection of type and amount of binder addition in cold pressing; therefore, an investigation was initiated to optimize the amount of several binder materials. In view of the behavior demonstrated by various materials in previous pressure-bonding tests, it appeared that combinations of these properties through mixing offered promise of achieving both the desired compacting behavior and the pressure-bonding characteristics. The optimization of particle sizing appeared to be desirable, since close packing of particles would represent a high green density and an increased number of point contacts for bonding by diffusion in the terminal process. 


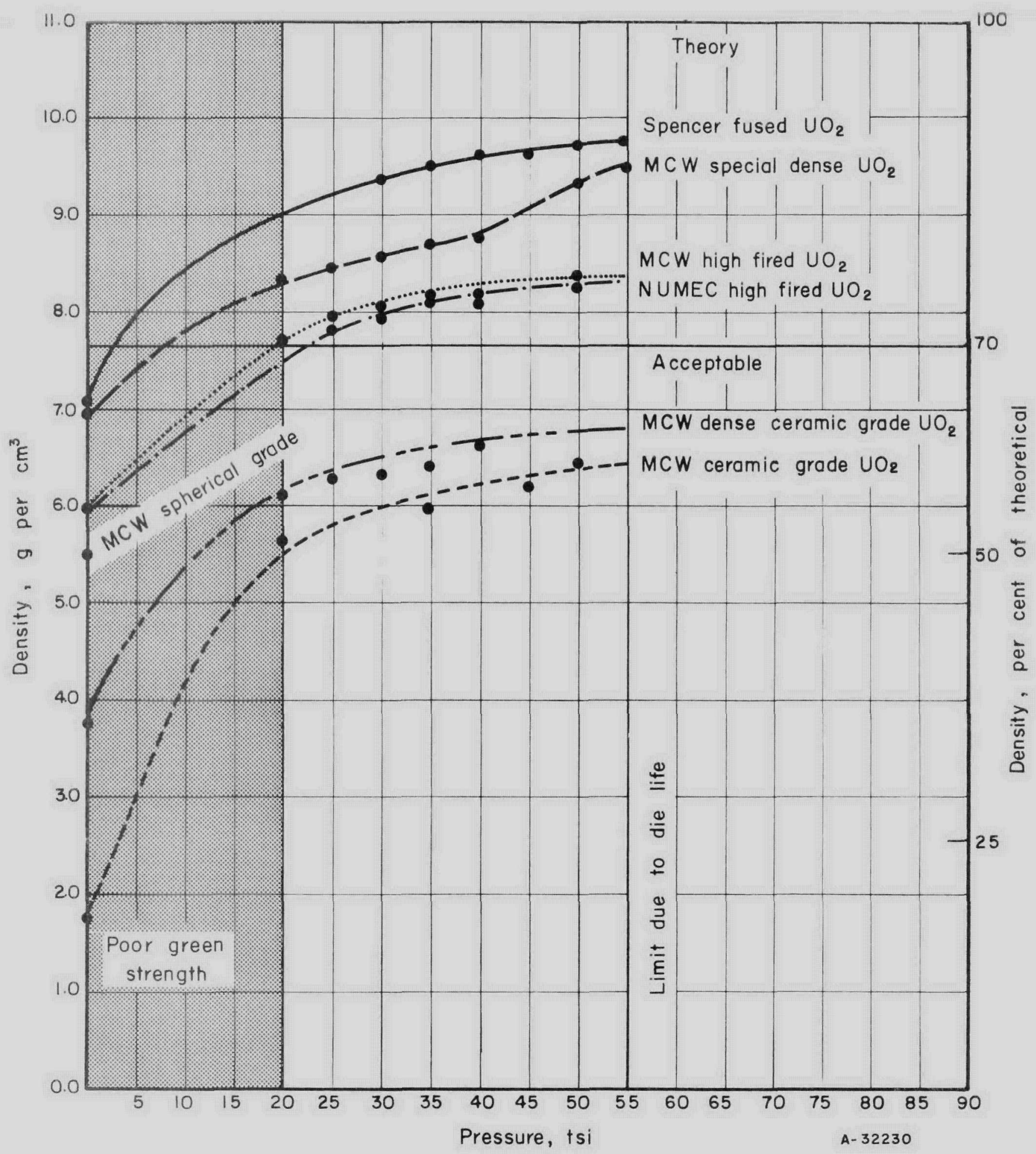

FIGURE 2. EFFECT OF COMPACTING PRESSURE ON GREEN DENSITY OBTAINED WITH VARIOUS $\mathrm{UO}_{2}$ POWDERS 
Effectiveness of Binder Additions

Uranium dioxide powders have poor cohesive properties and thus require an effective internal binder to provide the necessary green strength for handling. This binder must exhibit properties that will not hinder the resulting compacts during subsequent pressurc bonding, namely, the binder should increase the basic green density of compacts when added in small amounts. It must also lend strength to the compacts so that they may be readily handled and loaded into tubes or flat-plate assemblies while maintaining well-defined edges. It is desired that the binder be ashless and have a low boiling point in order that it can be removed prior to pressure bonding without leaving contaminants within the core.

Various binders were included in this study; however, the majority of the effortwas devoted to the Ceremul "C" and Carbowax 6000 binder materials. The results of this investigation utilizing pressures ranging from 10 to 55 tsi are summarized in Table 3 . The use of a Carbowax 6000-methyl alcohol solution produced noteworthy results in that pressures as low as 10 tsi produced sound high-density compacts of the fused oxide. This is in contrast to the minimum compacting pressure of 20 to $25 \mathrm{tsi}$ required with other oxides and other binder materials. This particular binder also produced superior loading and handling qualities as compared with compacts mixed with other binders. In general, it was noted that good handling characteristics were also achieved with polyvinyl alcohol and Ceremul "C".

A portion of this study concerned the optimization of Ceremul " $\mathrm{C}$ " and Carbowax 6000 additions to fused oxide in compacts pressed at 40 and $50 \mathrm{tsi}$. The results whichare also included in Table 3 show that $1 \mathrm{w} / 0$ Ceremul "C" or $3 \mathrm{w} / 0$ Carbowax 6000 produced the maximum cold-pressed densities. In subsequent pressure bonding of these compacts, densities of 95.8 and 93.9 per cent of theoretical were achieved. These results demonstrate the effectiveness of binder selection and control on the green-pressed density which in turn will affect the final density and uniformity of the pressure-bonded oxide.

\section{Oxide Mixtures}

Since it is desirable to achieve high green densities with uranium dioxide which will demonstrate sinterability during the pressure-bonding cycle, mixtures of a highdensity oxide and an "active" oxide were considered for further investigation. The major portion of the effort was devoted to mixtures of the fused oxide which imparted a high green density and a ceramic grade oxide which imparted the sinterability required to achieve a high final density. The cold-pressing characteristics of these mixtures are summarized in Table 4. It can be seen from these data that the addition of up to $40 \mathrm{w} / \mathrm{o}$ ceramic oxide to either the fused or special dense oxide resulted in only a minor decrease in cold-pressed density, and the mixtures ultimately pressure bonded to densities up to 99.5 per cent of theoretical. It appears that in these cases the fine ceramic grade particles tended to locate in the interstices of the larger fused or special dense particles. During subsequent pressure bonding the ceramic grade oxide then densified to nearly theoretical density, acting as a binder for the fused oxide or special dense oxide particles which initially were nearly theoretical density. Those mixtures containing fused uranium dioxide exhibited a higher final density than those containing special dense $\mathrm{UO}_{2}$ because the fused oxide possessed the higher initial density. It is particularly noteworthy that mixtures of fused and ceramic oxides consistently resulted 
TABLE 3. COMPACTING OF UO 2 USING VARIOUS BINDERS

\begin{tabular}{|c|c|c|c|c|c|c|c|c|c|c|c|c|}
\hline \multicolumn{3}{|c|}{ Description of Powder } & \multirow{2}{*}{\multicolumn{10}{|c|}{ Calculated Density at Stated Compacting Pressure, g per $\mathrm{cm}^{3}$}} \\
\hline \multicolumn{2}{|c|}{ Fuel } & \multirow[b]{2}{*}{ Binder Employed } & & & & & & & & & & \\
\hline Grade of $\mathrm{UO}_{2}$. & Mesh Size & & 10 TSI & 15 TSI & 20 TSI & 25 TSI & $30 \mathrm{TSI}$ & 35 TSI & 40 TSI & 45 TSI & 50 TSI & 55 TSI \\
\hline \multirow[t]{6}{*}{ Ceramic } & -325 & $2 \mathrm{w} / \mathrm{o}$ paraffin and benzene & -- & -- & 5.75 & -- & 5.97 & 6.28 & -- & -- & - & - \\
\hline & & 2 w/o methyl cellulose & -- & -- & 5.73 & $-\cdot$ & 6.40 & 5.97 & -- & 6.12 & 6.20 & -- \\
\hline & & 2 w/o Ceremul "C" & -- & -- & 5.21 & -- & 5.82 & -- & 5.76 & -- & -. & - \\
\hline & & 2 w/o ethylene glycol & -. & -- & 6.25 & -- & 6.11 & - & 6.34 & -- & -- & -- \\
\hline & . & 2 w/o camphor and alcohol & -- & - & 5.86 & -- & -- & 6.09 & -- & 6.30 & 6.39 & -- \\
\hline & & $2 \mathrm{w} / \mathrm{o}$ polyvinyl alcohol & -- & -- & 5.84 & -- & -- & 6.17 & -- & 6.20 & 6.47 & - \\
\hline \multirow[t]{2}{*}{ High fired } & -325 & 2 w/o camphor and alcohol & -- & -- & 7.40 & 7.86 & 7.84 & 7.96 & 8.14 & -- & 8.06 & - \\
\hline & & 2 w/o Ceremul "C" & -- & -- & 7.71 & 7.80 & 7.90 & 8.07 & 8.05 & -- & 8.12 & -. \\
\hline \multirow[t]{2}{*}{ Special dense } & -40 & 2 w/o Ceremul "C" & -- & -- & 8.33 & 8.52 & 8.60 & 8.64 & 8.75 & -- & 9.34 & 9.47 \\
\hline & & 2 w/o camphor and alcohol & -. & -- & 7.78 & 8.29 & 8.35 & 8.48 & 8.53 & -- & 8.67 & 8.75 \\
\hline \multirow[t]{2}{*}{ Dense ceramic } & -325 & $2 \mathrm{w} / \mathrm{o}$ camphor and alcohol & -- & -- & 6.17 & 6.31 & 6.38 & 6.49 & 6.59 & -- & -. & -. \\
\hline & & 2 w/o Ceremul "C" & -- & -- & 6.08 & 6.24 & 6.33 & 6.38 & -- & -- & -. & -- \\
\hline \multirow[t]{2}{*}{ High fired } & -400 & 2 w/o camphor and alcohol & -- & -- & 7.54 & 8.04 & 7.89 & 8.05 & 8.11 & -- & 8.29 & 8.34 \\
\hline & & 2 w/o Ceremul "C" & -- & -- & -- & 7.93 & 8.04 & 8.14 & 8.15 & -- & 8.34 & -- \\
\hline \multirow[t]{10}{*}{ Spencer fused } & -20 & $2 \mathrm{w} / \mathrm{o}$ Ceremul "C" & -- & -- & -- & 9.38 & -- & 9.50 & 9.62 & 9.61 & 9.70 & 9.75 \\
\hline & & 2 w/o Carbowax 6000 and methyl alcohol & 8.66 & 8.90 & 9.08 & 9.19 & 9.30 & 9.35 & 9.39 & 9.22 & 9.33 & 9.40 \\
\hline & & $1 / 2$ w/o Ceremul "C" & -. & -- & -- & -- & -- & -- & 9.39 & 9.47 & 9.55 & -- \\
\hline & & $1 \mathrm{w} / \mathrm{o}$ Ceremul "C" & -. & -- & -. & -. & -. & -- & 9.55 & 9.59 & 9.61 & -- \\
\hline & & $2 \mathrm{w} / \mathrm{o}$ Ceremul "C" & -- & -- & -- & -. & -- & -- & 8.96 & 9.10 & 9.12 & - \\
\hline & & $3 \mathrm{w} / \mathrm{o}$ Ceremul "C" & -- & -- & -- & -. & -- & - & 8.77 & 8.96 & 8.82 & - \\
\hline & & $1 / 2$ w/o Carbowax 6000 and methyl alcohol & - & -- & - & -. & -- & - & 9.23 & 9.30 & 9.36 & -. \\
\hline & & $1 \mathrm{w} / 0$ Carbowax 6000 and methyl alcohol & - & -- & -- & - & -- & $\cdots$ & 9.29 & 9.47 & 9.45 & $\cdots$ \\
\hline & & $2 \mathrm{w} / 0$ Carbowax 6000 and methyl alcohol & - & -- & - & -. & - & - & 9.37 & 9.42 & 9.45 & -. \\
\hline & & $3 \mathrm{w} / 0$ Carbowax 6000 and methyl alcohol & -- &.- & - & -. & -- & $-\cdot$ & 9.44 & 9.54 & 9.51 & -. \\
\hline
\end{tabular}




\begin{tabular}{|c|c|c|c|c|c|c|c|c|}
\hline \multirow[b]{3}{*}{ Description of $\mathrm{UO}_{2}$ Powder } & \multirow{2}{*}{\multicolumn{3}{|c|}{$\begin{array}{l}\text { Density at Stated Compact- } \\
\text { ing Pressure, g per } \mathrm{cm}^{3} \\
\end{array}$}} & \multicolumn{3}{|c|}{ Pressure Bonding Conditions } & \multicolumn{2}{|c|}{$\begin{array}{l}\text { Typical Pressure- } \\
\text { Bonded Density }\end{array}$} \\
\hline & & & & \multirow{2}{*}{$\begin{array}{c}\text { Time, } \\
\text { hr }\end{array}$} & \multirow{2}{*}{$\begin{array}{l}\text { Tempera- } \\
\text { ture, } \mathrm{F}\end{array}$} & \multirow{2}{*}{$\begin{array}{c}\text { Pressure, } \\
\text { psi }\end{array}$} & \multirow[b]{2}{*}{$\mathrm{G}$ per $\mathrm{Cm}^{3}$} & \multirow{2}{*}{$\begin{array}{c}\text { Per Cent of } \\
\text { Theoretical(a) }\end{array}$} \\
\hline & 40 TSI & 45 TSI & 50 TSI & & & & & \\
\hline $75 \mathrm{w} / \mathrm{o}$ fused $(-20+325)$ and $25 \mathrm{w} / 0$ ceramic $(-325)$ & 9.07 & 9.10 & 8.79 & 3 & 2100 & 10,000 & 10.6 & 96.7 \\
\hline $75 \mathrm{w} / \mathrm{o}$ fused $(-20+325)$ and $25 \mathrm{w} / 0$ ceramic $(-325)$ & 8.75 & 8.75 & 8.50 & 3 & 2100 & 10,000 & 10.1 & 92.2 \\
\hline $80 \mathrm{w} / \mathrm{o}$ fused $(-20+325)$ and $20 \mathrm{w} / \mathrm{o}$ dense ceramic $(-325)$ & 8.25 & 8.76 & 8.84 & 3 & 2100 & 10,000 & 10.1 & 92.2 \\
\hline 75 w/o special dense $(-40+325)$ and 25 w/o ceramic $(-325)$ & 8.59 & 8.55 & 8.29 & 3 & 2100 & 10,000 & 9.92 & 90.5 \\
\hline $75 \mathrm{w} / \mathrm{o}$ special dense $(-40+325)$ and $25 \mathrm{w} / \mathrm{o}$ dense ceramic $(-325)$ & 8.21 & 8.17 & 8.59 & 3 & 2100 & 10,000 & 9.75 & 89.0 \\
\hline $75 \mathrm{w} / \mathrm{o}$ fused $(-20+325)$ and $25 \mathrm{w} / \mathrm{o}$ high fired $(-400)$ & 9.29 & 9.42 & 9.44 & 3 & 2100 & 10,000 & 9.74 & $88.9^{(b)}$ \\
\hline $75 \mathrm{w} / 0$ fused $(-100+325)$ and $25 \mathrm{w} / 0$ high fired $(-400)$ & 8.99 & 9.06 & 8.62 & (c) & - & -- & -- & -- \\
\hline $70 \mathrm{w} / \mathrm{o}$ fused $(-20+200), 20 \mathrm{w} / \mathrm{o}$ ceramic $(-200+325)$, and $10 \mathrm{w} / \mathrm{o}$ high fired $(-400)$ & 8.65 & 8.60 & 8.60 & 3 & 2100 & 10,000 & 10.4 & 94.9 \\
\hline $90 \mathrm{w} / \mathrm{o}$ fused $(-20)$ and $10 \mathrm{w} / \mathrm{o}$ ceramic $(-325)$ & 8.50 & 8.66 & 8.73 & 3 & 2100 & 10,000 & 10.1 & 92.2 \\
\hline $85 \mathrm{w} / \mathrm{o}$ fused $(-20)$ and $15 \mathrm{w} / \mathrm{o}$ ceramic $(-325)$ & 8.28 & 8.46 & 8.66 & 3 & 2100 & 10,000 & 9.78 & 89.2 \\
\hline $80 \mathrm{w} / \mathrm{o}$ fused $(-20)$ and $20 \mathrm{w} / \mathrm{o}$ ceramic $(-325)$ & 8.03 & 8.40 & 8.61 & 3 & 2100 & 10,000 & 10.3 & 94.0 \\
\hline $90 \mathrm{w} / \mathrm{o}$ special dense $(-40)$ and $10 \mathrm{w} / \mathrm{o}$ ceramic $(-325)$ & 8.27 & 8.38 & 8.53 & 3 & 2100 & 10,000 & 10.1 & 92.2 \\
\hline $85 \mathrm{w} / \mathrm{o}$ special dense $(-40)$ and $15 \mathrm{w} / \mathrm{o}$ ceramic $(-325)$ & 8.21 & 8.16 & 8.17 & 3 & 2100 & 10,000 & 10.3 & 94.0 \\
\hline $80 \mathrm{w} / \mathrm{o}$ special dense $(-40)$ and $20 \mathrm{w} / \mathrm{o}$ ceramic $(-325)$ & 7.92 & 7.97 & 8.29 & 3 & 2100 & 10,000 & 10.1 & 92.2 \\
\hline $75 \mathrm{w} / \mathrm{o}$ fused $(-325)$ and $25 \mathrm{w} / \mathrm{o}$ ceramic $(-325)$ & & & 8.14 & 3 and 3 & $\begin{array}{l}2100 \\
2300\end{array}$ & 10,000 & & \\
\hline $65 \mathrm{w} / \mathrm{o}$ fused $(-325)$ and $35 \mathrm{w} / \mathrm{o}$ ceramic $(-325)$ & -- & -- & 8.16 & 3 and 3 & $\begin{array}{l}2100 \\
2300\end{array}$ & 10,000 & & \\
\hline $50 \mathrm{w} / \mathrm{o}$ fused $(-325)$ and $50 \mathrm{w} / \mathrm{o}$ ceramic $(-325)$ & -- & -- & $7.41^{(d)}$ & 3 and 3 & $\begin{array}{l}2100 \\
2300\end{array}$ & 10,000 & 10.9 & 99.5 \\
\hline $25 \mathrm{w} / \mathrm{o}$ fused $(-20)$ and $75 \mathrm{w} / \mathrm{o}$ ceramic $(-325)$ & -- & -- & $7.32^{(\mathrm{d})}$ & 3 & 2100 & 10,000 & 10.9 & 99.5 \\
\hline $70 \mathrm{w} / \mathrm{o}$ fused $(-20)$ and $30 \mathrm{w} / \mathrm{o}$ ceramic $(-325)$ & -- & - & 8.66 & 3 & 2100 & 10,000 & 10.7 & 97.8 \\
\hline $60 \mathrm{w} / \mathrm{o}$ fused $(-20)$ and $40 \mathrm{w} / \mathrm{o}$ ceramic $(-325)$ & -- & -- & 8.14 & 3 & 2100 & 10,000 & 10.7 & 97.8 \\
\hline $50 \mathrm{w} / \mathrm{o}$ fused $(-20)$ and $50 \mathrm{w} / \mathrm{o}$ ceramic $(-325)$ & -- & -- & 7.84 & (c) & -- & -- & -- & -- \\
\hline $40 \mathrm{w} / \mathrm{o}$ fused $(-20)$ and $60 \mathrm{w} / \mathrm{o}$ ceramic $(-325)$ & -- & -- & 7.64 & (c) & -- & -- & -- & -- \\
\hline $25 \mathrm{w} / \mathrm{o}$ fused $(-100)$ and $75 \mathrm{w} / \mathrm{o}$ ceramic $(-325)$ & -- & -- & $6.94(d)$ & 3 & 2100 & 10,000 & 10.9 & 99.5 \\
\hline $50 \mathrm{w} / \mathrm{o}$ fused $(-100)$ and $50 \mathrm{w} / \mathrm{o}$ ceramic $(-325)$ & -- & -- & $7.31(\mathrm{~d})$ & 3 & 2100 & 10,000 & 10.9 & 99.5 \\
\hline $25 \mathrm{w} / \mathrm{o}$ fused $(-200)$ and $75 \mathrm{w} / \mathrm{o}$ ceramic $(-325)$ & -- & -- & $6.94^{(d)}$ & 3 & 2100 & 10,000 & 10.9 & 99.5 \\
\hline $50 \mathrm{w} / \mathrm{o}$ fused $(-200)$ and $50 \mathrm{w} / \mathrm{o} \mathrm{ceramic}(-325)$ & -- & -- & $7.11^{(d)}$ & 3 & 2100 & 10,000 & 10.4 & 95.0 \\
\hline
\end{tabular}

(a) Pycnometer value unless stated otherwise.

(c) Failed in welding.

(b) Calculated density.

(d) Not acceptable from standpoint of deformation and cladding warpage that will follow. 
in final densities greater than 95 per cent of theoretical when the ceramic oxide content was in excess of $25 \mathrm{w} / 0$.

Of the mixtures investigated the range of compositions of fused oxide with from 30 to $60 \mathrm{w} / 0$ ceramic grade oxide appeared to offer the most promise. This combination represents a low-cost uranium dioxide material since two low-cost oxides in the as-received form can be utilized. This combination of oxides permits the achievement of both high green densities (to $8.14 \mathrm{~g}$ per $\mathrm{cm}^{3}$ ) and high final densities (to $10.7 \mathrm{~g}$ per $\mathrm{cm}^{3}$ ) with little difficulty in processing. The data in Table 4 also indicate that a smaller particle-size distribution also yielded high densities, which would minimize surfaceroughness effects.

\section{Particle-Size Effects}

Another approach to attaining high green densities by cold pressing involved the study of the effects of oxide particle size and particle-size distribution on cold compacting. It was anticipated that if close-packed aggregates could be achieved through particle control the resulting deformation on pressure bonding would be reduced, and bonding would be established by increased point contacts and diffusion. Materials used in this study were the fused and special dense grades of uranium dioxide. The coldpressed densities of size fractions of the individual powder and compacted ideal cubic and rhombohedral size distributions are given in Table 5. The best results over the entire range of compacting pressures were attained with the ideal rhombodedral particle-size distribution which also produced the highest final density (96. 7 per cent of theoretical) after pressure bonding for $3 \mathrm{hr}$ at $2100 \mathrm{~F}$ and $10,000 \mathrm{psi}$. At the higher compacting pressures noteworthy results were obtained with the as-received fused oxide and the ideal cubic distribution of the fused oxide. These sizings, particularly that of the calculated rhombohedral distribution, yielded compacts of appreciable green strength. The effect of particle size on the pressure-bonded densities is also indicated for the fused and special dense oxides. From the results it appears that in both cases a size fraction of minus 140 plus 200 mesh has yielded the highest final densities.

Although high green densities were possible by utilizing the aforementioned mixtures and sizings, binder additions were still required. Such binders necessitated removal either prior to assembly of the fuel configuration or prior to pressure bonding the assembled units. The former resulted in spalling of the compacts, whereas the latter procedure resulted in movement of the fine particles to the stainless steel interfaces to be bonded during the pressure-bonding cycle. Presently efforts are in progress to minimize these effects and also study compacting techniques which do not require binder additions.

\section{Other Compaction Methods}

In view of the high densities attainable with several uranium dioxide powders at low compacting pressures and the desirability of eliminating binders, compaction methods other than conventional cold pressing were considered in the present investigation. It appeared possible that the 75 per cent of theoretical density considered as the minimum required for acceptable deformation behavior during pressure bonding could be achieved through packing techniques which would not require the use of binder materials. 
TABLE 5. EFFECT OF PARTICLE SIZE ON COLD-PRESSED DENSITIES OF UO ${ }_{2}$ POWDERS

\begin{tabular}{|c|c|c|c|c|c|c|c|c|c|c|c|c|}
\hline \multirow[b]{3}{*}{ Description of $\mathrm{UO}_{2}$ Powder } & \multirow{2}{*}{\multicolumn{10}{|c|}{ Density at Stated Compacting Pressure, g per $\mathrm{cm}^{3}$}} & \multicolumn{2}{|c|}{$\begin{array}{l}\text { Density of Pressure- } \\
\text { Bonded Oxide }\end{array}$} \\
\hline & & & & & & & & & & & \multirow{2}{*}{$\begin{array}{l}\text { Density, } \\
\text { G per } \mathrm{Cm}^{3}\end{array}$} & \multirow{2}{*}{$\begin{array}{l}\text { Per Cent of } \\
\text { Theoretical(b) }\end{array}$} \\
\hline & $10 \mathrm{TSI}$ & 15 TSI & $20 \mathrm{TSI}$ & 25 TSI & $30 \mathrm{TSI}$ & 35 TSI & 40 TSI & 45 TSI & 50 TSI & $55 \mathrm{TSI}$ & & \\
\hline $\begin{array}{l}\text { Spencer fused }(1.25 \mathrm{w} / \mathrm{o}-325,6.25 \mathrm{w} / \mathrm{o} \\
-150+200 \text {, and } 92.50 \mathrm{w} / \mathrm{o}-60+80)(\mathrm{c})\end{array}$ & -- & -- & -- & $7.66^{(\mathrm{d})}$ & -- & -- & 9.41 & 9.39 & 9.45 & 9.46 & 9.60 & $87.6^{(e)}$ \\
\hline $\begin{array}{l}\text { MCW special dense }(1.25 \mathrm{w} / \mathrm{o}-325,6.25 \mathrm{w} / \mathrm{o} \\
-150+200 \text {, and } 92.50 \mathrm{w} / \mathrm{o}-60+80)(\mathrm{c})\end{array}$ & -- & -- & -- & 8.49 & -- & -- & 8.79 & 8.74 & 8.81 & 8.84 & 9.19 & $83.7(c)$ \\
\hline $\begin{array}{l}\text { Fused }(1.25 \mathrm{w} / \mathrm{o}-325,6.25 \mathrm{w} / \mathrm{o}-150+200 \text {, } \\
\text { and } 92.50 \mathrm{w} / \mathrm{o}-60+80)(\mathrm{c})\end{array}$ & -- & -- & -- & -- & -- & -- & 9.02 & 9.19 & 9.20 & -- & 9.81 & 89.5 \\
\hline $\begin{array}{l}\text { Special dense }(1.25 \mathrm{w} / \mathrm{o}-325,6.25 \mathrm{w} / \mathrm{o} \\
-150+200 \text {, and } 92.50 \mathrm{w} / \mathrm{o}-60+80)^{(\mathrm{c})}\end{array}$ & -- & -- & -- & -- & -- & -- & 8.44 & 8.56 & 8.69 & -- & 9.94 & 90.7 \\
\hline Fused (ideal rhombehedrial distribution $(f)$ & 8.74 & 8.87 & 9.06 & 9.08 & 9.16 & 9.26 & 9.28 & 9.35 & 9.36 & -- & 10.6 & 96.7 \\
\hline Fused $(-100)$ & -- & -- & -- & -- & -- & -- & 8.64 & 8.68 & 8.82 & 8.85 & 9.74 & 88.9 \\
\hline Fused $(-20)$ & -- & -- & -- & 9.38 & -- & 9.50 & 9.62 & 9.61 & 9.70 & 9.75 & 9.83 & $89.8(e)$ \\
\hline Fused $(-80+100)$ & -- & -- & -- & 8.90 & 8.98 & 9.03 & 9.02 & 9.12 & 9.21 & -- & 10.3 & 94.0 \\
\hline Fused $(-100+140)$ & -- & -- & -- & 8.73 & 8.82 & 8.95 & 9.01 & 9.10 & 9.11 & -- & 10.4 & 94.9 \\
\hline Fused $(-140+200)$ & - & -- & -- & 8.60 & 9.03 & 8.81 & 9.42 & 8.48 & 8.46 & -- & 10.1 & 92.2 \\
\hline Fused $(-200+325)$ & -- & -- & -- & 8.43 & 8.48 & 8.58 & -- & 8.65 & 8.84 & -- & (g) & - \\
\hline Fused $(-325)$ & -- & -- & -- & 8.16 & 8.16 & 8.35 & 8.27 & 8.46 & 8.58 & -- & 9.04 & 82.5 \\
\hline Special dense $(-80+100)$ & -- & -- & -- & 8.18 & 8.34 & 8.40 & 8.43 & 8.51 & 8.63 & -- & 9.75 & 89.0 \\
\hline Special dense $(-100+140)$ & -- & -- & -- & 8.16 & 8.27 & 8.33 & 8.46 & 8.52 & 8.71 & -- & 9.83 & 89.7 \\
\hline Special dense $(-140+200)$ & -- & -- & -- & 8.04 & 8.18 & 8.29 & 8.24 & 8.45 & -- & -- & 10.1 & 92.2 \\
\hline Special dense $(-200+325)$ & -- & -- & -- & 7.92 & 8.08 & 8.16 & 8.31 & -- & -- & -- & 9.85 & 89.9 \\
\hline
\end{tabular}

(a) All samples pressure bonded for $3 \mathrm{hr}$ at $2100 \mathrm{~F}$ and 10,000 psi.

(b) Pycnometer measurements unless otherwise stated.

(c) Ideal cubic distribution.

(d) Not dense enough.

(e) Galculated density.

(f) $74.5 \mathrm{w} / \mathrm{o}-42+48,5.3 \mathrm{w} / \mathrm{o}-110+115,1.7 \mathrm{w} / \mathrm{o}-200+250,2.9 \mathrm{w} / \mathrm{o}-250+270,2.0 \mathrm{w} / \mathrm{o}-270+325$, and $13.6 \mathrm{w} / \mathrm{o}-325$.

(g) Failed in welding. 
Such packing methods included tamp packing, centrifuging, and ultrasonic packing. Several pressing techniques involving the use of nickel slurry-coated dies and the preparation of special oxide slurries for dewaxing procedures were also included in this portion of the program.

Tamp Packing

The most direct approach to achieving a packed powder product is the tamp-packing procedure. This technique consists of filling a tube with small increments of powder and repeatedly tamping the powders into place with a flat-end tool. This procedure is repeated until the tube is completely filled with powder. The method eliminates the need of a compacting operation and the use of binder materials in processing such assemblies; however, it represents a rather time-consuming procedure which would ultimately require automation to be economically feasible.

The green densities and final pressure-bonded densities attainable with the various grades of uranium dioxide and several mixtures by use of the procedure have been established. Representative values for these materials are presented in Table 6. From these results it is evident that densities of 70 per cent of theoretical and greater were achieved only with the fused and special dense oxides. In these cases the tamp-packed densities represent an increase of only 5 to 6 per cent of the tap density of the as-received materials. In general, high final densities were achieved with the tamp-packed powders after pressure bonding, with values ranging from 85.8 to 99.5 per cent of theoretical density.

Radiographs of the bonded assemblies indicated that uniform uranium dioxide cores were obtained, with no evidenceof cleavage or other defects. Dimensional uniformity of the final shapes was dependent on the amount of densification occurring during pressure bonding. Where corrugated configurations were utilized the resulting shapes were more uniform due to the symmetry of deformation.

\section{Centrifuging}

Centrifuging of uranium dioxide powders as a possible means for low-cost powder packing prior to pressure bonding was also briefly investigated. This procedure required centrifuging graduated, conical glass tubes filled with approximately $15 \mathrm{ml}$ of the various oxide powders at a variety of speeds in an effort to establish conditions which would optimize the packed density for the respective powders. All experiments were performed on an International centrifuging unit permitting speeds from 1200 to $4500 \mathrm{rpm}$ and centrifugal forces of from 290 to $3200 \mathrm{G}$. With the weight of $\mathrm{UO}_{2}$ contained in the experimental tubes, speeds of only up to $2850 \mathrm{rpm}$ were attainable. Centrifuging times were maintained at $3 \mathrm{~min}$, which was considered ample to locate the powder particles in their final compacted form.

Powder compacting by centrifuging was investigated for the seven commercial grades of uranium dioxide and for three oxide mixtures. The densities achieved by this technique over the range of speeds permitted by the experimental equipment are reported in Table 7. In general, no advantage over the tamp-packing technique was noted, and in only one case was a packed density equivalent to that attainable by tamp packing found. In this instance a mixture of $75 \mathrm{w} / \mathrm{o}$ fused oxide and $25 \mathrm{w} / 0$ high-fired oxide resulted in a final density of 68 per cent of theoretical. It is also evident from the data that increased densities were obtained with increasing centrifuging speeds, with an apparent maximizing in the ranges of 2500 to $2850 \mathrm{rpm}$. 
TABLE 6. RESULTS OF EXPERIMENTS WITH TAMP PACKING OF UO 2

\begin{tabular}{|c|c|c|c|c|c|c|c|}
\hline \multirow[b]{2}{*}{ Tube } & \multirow[b]{2}{*}{ Description of $\mathrm{UO}_{2}$} & \multicolumn{2}{|c|}{ Density of Green Compact } & \multicolumn{2}{|c|}{ Bonding Conditions (a) } & \multicolumn{2}{|c|}{ Pressure-Bonded Density } \\
\hline & & $\mathrm{G}$ per $\mathrm{Cm}^{3}$ & $\begin{array}{l}\text { Per Cent of } \\
\text { Theoretical }\end{array}$ & $\begin{array}{c}\text { Time, } \\
\text { hr }\end{array}$ & $\begin{array}{c}\text { Temperature, } \\
\text { F }\end{array}$ & $\mathrm{G}$ per $\mathrm{Cm}^{3}$ & $\begin{array}{l}\text { Per Cent of } \\
\text { Theoretical }\end{array}$ \\
\hline PB-22 & Ceramic $(-325)$ & $2.14^{(\mathrm{b})}$ & 19.6 & 4 & 2100 & 10.8 & 98.5 \\
\hline $\mathrm{PB}-27$ & Ceramic $(-325)$ & $2.14^{(b)}$ & 19.6 & 3 & 2200 & 10.9 & 99.45 \\
\hline $\mathrm{PB}-62$ & High-fired $(-325)$ & 6.00 & 54.7 & 3 & 2100 & 10.1 & 92.4 \\
\hline $\mathrm{PB}-7$ & Fused $(-20)$ & 7.69 & 70.0 & 3 & 2100 & 9.93 & 90.6 \\
\hline $\mathrm{PB}-67$ & Fused $(-20)$ & 7.69 & 70.0 & 3 & 2100 & 10.1 & 92.4 \\
\hline $\mathrm{PB}-73$ & $75 \mathrm{w} / \mathrm{o}$ fused $(-20)$ and $25 \mathrm{w} / \mathrm{o}$ ceramic $(-325)$ & $6.47^{(b)}$ & 59.1 & 3 & 2100 & 10.4 & 95.0 \\
\hline $\mathrm{PB}-15$ & $75 \mathrm{w} / \mathrm{o}$ fused $(-20+325)$ and $25 \mathrm{w} / \mathrm{o}$ high fired $(-400)$ & $7.44^{(b)}$ & 68.0 & 3 & 2100 & 9.50 & 86.7 \\
\hline $\mathrm{PB}-66$ & $50 \mathrm{w} / \mathrm{o}$ fused $(-325)$ and $50 \mathrm{w} / \mathrm{o}$ ceramic $(-325)$ & -- & -- & 3 & 2100 & 10.4 & 95.0 \\
\hline $\mathrm{PB}-47$ & Special dense $(-40)$ & 6.95 & 63.4 & 3 & 2100 & 9.82 & 89.6 \\
\hline SD-1 & Special dense $(-40)$ & 8.43 & 77.0 & 3 & 2100 & 9.40 & 85.8 \\
\hline PB-1 & Special dense $(-40+325)$ and 25 w/o ceramic $(-325)$ & 7.04 & 64.1 & 3 & 2100 & 10.41 & 95.1 \\
\hline PB-2 & Special dense $(-40+325)$ and 25 w/o ceramic $(-325)$ & 7.05 & 64.3 & 3 & 2100 & 10.40 & 95.4 \\
\hline
\end{tabular}

(a) All specimens bonded at 10,000 psi.

(b) Density not measured as the material was packed into a corrugated tube; tap density is inserted for comparison. 
TABLE 7. PACKING OF UO 2 POWDER OBT AINED BY CENTRIF UGING EXPERIMENTS

\begin{tabular}{|c|c|c|c|c|c|}
\hline \multirow[b]{2}{*}{ Type of $\mathrm{UO}_{2}$} & \multicolumn{5}{|c|}{ Density After Treatment Shown, g per $\mathrm{cm}^{3}$} \\
\hline & $\begin{array}{c}\text { Tap } \\
\text { Density }\end{array}$ & $\begin{array}{r}3 \mathrm{Min} \text { at } \\
1500 \mathrm{RPM} \\
\end{array}$ & $\begin{array}{r}3 \text { Min at } \\
2000 \text { RPM } \\
\end{array}$ & $\begin{array}{r}3 \mathrm{Min} \text { at } \\
2500 \mathrm{RPM} \\
\end{array}$ & $\begin{array}{c}3 \text { Min at } \\
2650 \text { to } 2850 \text { RPM } \\
\end{array}$ \\
\hline Ceramic grade $(-325)$ & 2.14 & -- & -- & -- & 2.62 \\
\hline Dense ceramic grade $(-325)$ & 3.29 & -- & -- & -- & 3.53 \\
\hline Numec high fired $(-325)$ & 4.58 & -- & -- & -- & 5.64 \\
\hline MCW high fired $(-400)$ & 4.90 & 5.34 & 5.40 & 5.47 & 5.47 \\
\hline MCW spherical $(-200+325)$ & 5.02 & 5.12 & 5.18 & 5.22 & 5.22 \\
\hline MCW special dense $(-40)$ & 5.13 & 5.68 & 5.68 & 5.73 & 5.73 \\
\hline Spencer fused $(-20)$ & 6.17 & 6.30 & 6.30 & 6.30 & 6.30 \\
\hline $75 \mathrm{w} / \mathrm{o}$ special dense $(-20)$ and $25 \mathrm{w} / \mathrm{o}$ ceramic $(-325)$ & 6.48 & 6.48 & 6.57 & 6.57 & 6.57 \\
\hline $75 \mathrm{w} / 0$ fused $(-20)$ and $25 \mathrm{w} / 0$ ceramic $(-325)$ & 5.59 & 5.67 & 5.74 & 5.84 & 5.84 \\
\hline $75 \mathrm{w} / 0$ fused $(-20)$ and $25 \mathrm{w} / 0$ high fired $(-400)$ & 7.20 & 7.35 & 7.35 & 7.43 & 7.43 \\
\hline
\end{tabular}

The results of these tests indicate that powder-bridging effects prevented the attainment of high packed densities in the range of centrifuging speeds covered. It appears that the initial compacting locks the particles into position and the combined bridging and particle friction prevent further movement of the particles. In view of the low densities achieved with existing equipment no efforts were initiated to obtain new equipment for the purpose of continuing tests at higher centrifuging speeds.

\section{Ultrasonic Packing}

A preliminary study of the effects of ultrasonic vibration on the compaction of various types and mixtures of uranium dioxide was also undertaken. This method appeared to be a potential packing method since it offered the possibility of achieving packing by vibration without the use of binders. It was anticipated that the powder particles when set in motion by ultrasonic vibration would seek a maximum packing density with the smaller particles locating themselves at the interstices of larger particles. The experimental methods considered in this study include both the ultrasonic vibration of a powder-filled tube and the ultrasonic vibration of a tool directly in contact with the powder. Both techniques are currently being investigated, and the relative merits of the two approaches cannot be assessed with the data so far obtained. In conjunction with this work, studies of vibratory packing of the more active oxide types and mixtures have been initiated. The investigation of both systems should permit a wide range of frequencies for study.

\section{Metal-Faced Compacts}

Initial tests on coating uranium dioxide compacts with nickel during the compacting operation show the technique has considerable promise as a cold-pressing method utilizing a minimum of binder material. This coating is accomplished by using a mixture of fine nickel particles dispersed in ethylene glycol as a die lubricant. The oxide powder is loaded into the die cavity without a binder, and, on pressing, the ductile nickel is deformed into the compacted oxide thus providing a smooth coating and mechanical locking at the resulting compact surface. Since the small amount of binder required for this process is located only at the surface it is readily removed on subsequent binderremoval or outgassing operations. Finished compacts as prepared by this method to date were coated with from 0.008 to 0.010 in. of nickel. 
Compacting experiments with both the high-fired and special dense grades of uranium dioxide have yielded good results. Green densities of 73.8 and 79.6 per cent of theoretical were attained in compacting the respective powders by this method. No spalling effects of the oxide compacts were noted in subsequent handling and degassing operations required for assembling pressure-bonding composites. Radiographs of the pressure-bonded assemblies indicate no adverse effects of the nickel coatings.

Analyses of the initial compacts prepared in this study showed a total nickel content of $9.1 \mathrm{w} / \mathrm{o}$. In final usage it would be required that the metal content be minimized because of its thermal-neutron capture cross section. It is anticipated such reduction can be accomplished by controlling the composition of the slurry-type die lubricant. This compaction method would require considerable development to be economically feasible as a production process. Present efforts involve the further study of pressure bonding nickel-coated compacts and also an investigation of stainless steel powdercoated compacts. 、

\section{Slurry Methods for $\mathrm{UO}_{2}$ Compacting}

A brief study of slurry methods for preparing uranium dioxide prior to cold pressing has been completed. This study was initiated as an effort to achieve a more uniform distribution of binder in the blended oxide powders and thereby achieve better compacting and handling characteristics with the individual oxide materials. The binder materials considered in these experiments included polyvinyl alcohol, ethyl alcohol, paraffin, and Carbowax 6000. The combined effects of procedure and binder materials were established for various types of uranium dioxide, and the results were compared with the more conventional powder-preparation procedure for cold pressing.

The major advantage of the slurry procedure lies in the fact that it permits a more uniform coating of the powder particles with the binder material. In this method the dry powders are first mixed in a V-type Kelly blender to minimize segregation of particle sizes or types. The binder is then added in an amount depending on the binder material and the oxide powders to be compacted. In most cases the amount of binder required is approximately $2 \mathrm{w} / \mathrm{o}$. After further dry mixing the blended material is placed in a mixing bowl, and a solvent is added to the extent that a slurry is produced. This slurry is then mixed while drying under an external heat source, thus resulting in a powder mass in which each particle is coated with the binder. Such powders have much less tendency to segregate on subsequent handling.

Powders prepared in this manner yield high-strength green compacts with welldefined edges and smooth surfaces. To retain these properties after binder removal it is necessary to control the dewaxing operation to the extent that the binder is removed very slowly. In general, compacts prepared by this technique were superior to those produced by the more conventional techniques. As to the effects of this procedure with respect to the type of oxide compacted, all materials did not compact satisfactorily. The small particle-size distributions did not result in good compacts, an effect which was noted in previous compaction studies. Good results were obtained with coarse distributions of fused oxides, ceramic powders, special dense grades, and various mixtures containing the ceramic grade of oxide. 


\section{Presintering}

A brief investigation was undertaken to determine the feasibility of increasing the compacted densities of pellets through the use of a high-temperature dewaxing operation. With this treatment, it appeared possible to achieve some densification while effecting the removal of binder material. Consequently compacts of the various powders were presintered at $2000,2100,2200$, and $2300 \mathrm{~F}$ for periods of 1,2 , and $4 \mathrm{hr}$. Only in the case of the ceramic grade oxide was a significant density increase achieved. Depending on the presintering conditions, density increases of up to 6 per cent were attained; however, this increase still fell far short of the 75 per cent of theoretical density required for the pressure-bonding operation. All other grades of oxide showed no density changes in the range of presintering conditions covered in this experiment.

\section{Discussion of Compaction Methods}

The powder-compacting techniques described previously have demonstrated the ranges of initial and final uranium dioxide densities that are possible through the selection of oxide material and compacting methods. In regard to successful pressure bonding, it is required that green densities in excess of 75 per cent of theoretical be obtained and that the material possess the potential to achieve a desired range of densities on pressure bonding. It has been shown that the required initial densities can be achieved in many cases with oxide materials that will ultimately exhibit densities of from 88 to 99.5 per cent of theoretical. It is anticipated that materials having final densities from 96 to 99.5 per cent of theoretical may possess unique irradiation properties; therefore, considerable effort has been directed toward the development of the combination of materials and processes which produce such final densities. $(3,4)$

Since the present study concerns the development of low-cost high-quality fuel elements, it has been necessary to evaluate both the materials and processes with regard to cost. The ceramic grade of uranium dioxide represents the lowest cost oxide considered in this investigation; therefore, its use either as an individual oxide or as a component in oxide mixtures offers a decided cost advantage. The high activity of this oxide and high ultimate densities in both applications offers a definite process advantage. Perhaps the most promising oxide materials to date are mixtures of fused oxide and 30 to $60 \mathrm{w} / 0$ ceramic oxide. These mixtures require some further optimization as to particle sizes. Other oxide mixtures of the same system and also the high-fired grade of oxide alone have demonstrated the potential for fulfilling the pressure-bonding requirements and over-all program objectives.

In compacting the various oxide materials prior to pressure bonding it is desirable to achieve a high density with a low-cost process. In this respect cold-pressing techniques, although well developed, are inherently expensive and represent a large portion of the processing cost. Consequently, considerable study was performed on other compacting methods. Of these methods the ultrasonic and vibratory techniques presently being developed for powder applications offer considerable promise with respect to attaining the required compacted densities with active oxide materials that can subsequently achieve extremely high bonding densities. Present studies at Hanford(5) have demonstrated the usefulness of vibratory packing coarse sizings of fused and special dense oxides. More recent efforts at Aeroprojects $(6)$ concerning ultrasonic packing of 
fine-grained alumina have shown considerable promise in achieving high packing densities in substantial lengths. Since these two methods would further reduce the over-all processing costs of high-density uranium dioxide fuel elements, further investigation concerning a more detailed study has been initiated with respect to the ceramic oxide, ceramic-fused mixtures, and high-fired oxides.

\section{STOICHIOMETRY STUDY}

A review of the behavior of various uranium dioxides, representing various initial oxygen/uranium ratios, on pressure bonding demonstrated that the final products tend to return to stoichiometry. The sinterability displayed by the oxide appears to be related to the degree of initial off-stoichiometry during pressure-bonding cycles at $1600 \mathrm{~F}$ to $2200 \mathrm{~F}$ and $10,000 \mathrm{psi}$. Similar effects have been reported in the literature dealing with the effects of uranium dioxide stoichiometry on hot pressing and elevated-temperature creep behavior. $(7,8)$ Representative values from the present study demonstrating this effect are given in Table 8. Analyses of the cladding material in selected cases showed no significant oxygen increase, thus indicating the excess oxygen was removed from the fuel configuration.

Ceramic grade oxides which have been found to be the most active oxides in this investigation generally range in composition from $\mathrm{UO}_{2.05}$ to $\mathrm{UO}_{2}$. 12. The excess oxygen can be regarded as confined within the lattice and contained in minor phases of $\mathrm{U}_{4} \mathrm{O}_{9}$ and $\mathrm{U}_{3} \mathrm{O}_{8}$. The general characteristics of such oxides are a low green-pressed density and a high final pressure-bonded density, a combination which results in considerable deformation of the bonded assembly. Other types of oxides such as the fused, special dense, and high-fired grades which are initially stoichiometric exhibit good pressing characteristics but limited activity on pressure bonding. It was, therefore, considered desirable to study the effects of excess oxygen on the characteristics of the dense grades of uranium dioxide with the objective of achieving off-stoichiometric powders which would exhibit both good cold-pressing and pressure-bonding behavior. It would also be necessary for such a material to return to stoichiometry in the final product in order that good fission-gas-retention properties would be demonstrated in irradiation.

A study was initiated to determine the cold-compacting and pressure-bonding characteristics of off-stoichiometry special dense and fused uranium dioxides. These oxides represented the highest density particles with the best cold-compacting densities as established in previous investigations in this program. Excess oxygen was added to these materials by flash roasting in air at temperatures ranging from 350 to $950 \mathrm{~F}$, with the fused oxide requiring the higher roasting temperatures. The results of these tests are plotted in Figure 3. It is interesting to note that the fused oxide appears resistant to oxidation for times of 1 and $2 \mathrm{~min}$ at temperatures up to $800 \mathrm{~F}$. This effect may be partly due to the heating time required to equilibrate the over-all temperature of the powder mass with that of the furnace. The wide difference between the oxidation behavior of the special dense and fused grades is evident in the plot. The values reported indicate an experimental scatter of approximately 2 per cent due to the experimental and analytical combined errors.

Having established the flash-roasting parameters for these oxides, present studies are concerned with the compacting and pressure-bonding behavior of the oxides at 
TABLE 8. STOICHIOMETRY CHANGES DURING PRESSURE BONDING OF VARIOUS UO ${ }_{2}$ POWDERS

\begin{tabular}{|c|c|c|c|c|c|c|c|c|c|}
\hline \multirow[b]{3}{*}{ Tube } & \multirow[b]{3}{*}{ Type of $\mathrm{UO}_{2}$ Powder } & \multirow[b]{3}{*}{ Binder } & \multicolumn{5}{|c|}{ Analysis Before Bonding } & \multicolumn{2}{|c|}{ Analysis After Bonding } \\
\hline & & & \multirow[b]{2}{*}{$\begin{array}{c}\text { Uranium, } \\
\mathrm{w} / \mathrm{O} \\
\end{array}$} & \multirow{2}{*}{$\begin{array}{c}\text { Oxygen/ } \\
\text { Uranium } \\
\text { Ratio }\end{array}$} & \multicolumn{3}{|c|}{ Bonding Conditions } & \multirow[b]{2}{*}{$\begin{array}{c}\text { Uranium, } \\
\mathrm{w} / \mathrm{O}\end{array}$} & \multirow{2}{*}{$\begin{array}{c}\text { Oxygen/ } \\
\text { Uranium } \\
\text { Ratio }\end{array}$} \\
\hline & & & & & $\begin{array}{c}\text { Time, } \\
\text { hr }\end{array}$ & $\begin{array}{c}\text { Temperature, } \\
\mathrm{F} \\
\end{array}$ & $\begin{array}{c}\text { Pressure, } \\
\text { psi }\end{array}$ & & \\
\hline $\mathrm{PB}-20$ & MCW special dense $(-40)$ & $\begin{array}{l}\text { Carbowax } \\
6000-\mathrm{MEOH}\end{array}$ & 88.14 & 2.00 & 4 & 2100 & 10,000 & 88.07 & 2.02 \\
\hline $\mathrm{PB}-21$ & Spencer fused $(-20)$ & $6000-\mathrm{MEOH}$ & 88.15 & 2.00 & 4 & 2100 & 10,000 & 88.15 & 2.00 \\
\hline PB -22 & MCW ceramic $(-325)$ & 6000-MEOH & 87.72 & 2.08 & 4 & 2100 & 10,000 & 88.09 & 2.01 \\
\hline $\mathrm{PB}-23$ & MCW ceramic $(-325)$ & $6000-\mathrm{MEOH}$ & 87.72 & 2.08 & 3 & 2200 & 10,000 & 88.13 & 2.00 \\
\hline $\mathrm{PB}-24$ & MCW special dense $(-40)$ & None & 88.14 & 2.00 & 4 & 2100 & 10,000 & 88.10 & 2.01 \\
\hline $\mathrm{PB}-25$ & Spencer fused $(-20)$ & None & 88.15 & 2.00 & 4 & 2100 & 10,000 & 88.14 & 2.00 \\
\hline $\mathrm{PB}-26$ & MCW ceramic $(-325)$ & None & 87.72 & 2.08 & 4 & 2100 & 10,000 & 88.10 & 2.01 \\
\hline $\mathrm{PB}-27$ & MCW ceramic $(-325)$ & None & 87.72 & 2.08 & 3 & 2200 & 10,000 & 88.12 & 2.01 \\
\hline $34 \mathrm{~S}$ & MCW special dense $(-200+325)$ & Ceremul "C" & 88.14 & 2.00 & 3 & 2100 & 10,000 & 88.19 & 1.99 \\
\hline $34 \mathrm{~B}$ & MCW special dense $(-140+200)$ & Ceremul "C" & 88.14 & 2.00 & 3 & 2100 & 10,000 & 88.20 & 1.99 \\
\hline $35 \mathrm{~B}$ & MCW special dense $(-80+100)$ & Ceremul "C" & 88.14 & 2.00 & 3 & 2100 & 10,000 & 88.17 & 2.00 \\
\hline $36 \mathrm{~S}$ & Spencer fused $(-80+100)$ & Ceremul "C" & 88.15 & 2.00 & 3 & 2100 & 10,000 & 88.22 & 1.99 \\
\hline $37 \mathrm{~B}$ & Spencer fused $(-325)$ & Ceremul "C" & 88.15 & 2.00 & 3 & 2100 & 10,000 & 88.19 & 1.99 \\
\hline $38 \mathrm{~B}$ & MCW special dense $(-100+140)$ & Ceremul "C" & 88.14 & 2.00 & 3 & 2100 & 10,000 & 88.15 & 2.00 \\
\hline $40 S$ & $80 \mathrm{w} / \mathrm{o}$ fused (as received) and $20 \mathrm{w} / \mathrm{o}$ ceramic $(-325)$ & Ceremul "C" & - & -- & 3 & 2100 & 10,000 & 88.14 & 2.00 \\
\hline $40 \mathrm{~B}$ & $90 \mathrm{w} / \mathrm{o} \mathrm{special}$ dense $(-40)$ and $10 \mathrm{w} / \mathrm{o}$ ceramic $(-325)$ & Ceremul "C" & -- & -- & 3 & 2100 & 10,000 & 88.06 & 2.02 \\
\hline $41 \mathrm{~S}$ & $85 \mathrm{w} / \mathrm{o}$ special dense $(-40)$ and $15 \mathrm{w} / \mathrm{o}$ ceramic $(-325)$ & Ceremul "C" & -- & -- & 3 & 2100 & 10,000 & 88.17 & 2.00 \\
\hline \multirow[t]{2}{*}{$48 \mathrm{~S}$} & MCW ceramic $(-325)$ & Ceremul "C" & 87.72 & 2.08 & 3 & 1600 & 8,000 & & 2.04 \\
\hline & & & & & 3 a & 1700 & 8,000 & & \\
\hline $57 \mathrm{~S}$ & MCW ceramic $(-325)$ & Ceremul "C" & 87.72 & 2.08 & $3^{a}$ & 2100 & 10,000 & & 2.03 \\
\hline$-\infty$ & MCW dense ceramic $(-140)$ & None & 87.81 & 2.07 & -- & -- & -- & -- & -- \\
\hline -- & MCW spherical $(-200+325)$ & None & 88.16 & 2.00 & - & - & -- & -- & -- \\
\hline-- & Numec high fired $(-325)$ & None & 88.17 & 2.00 & $\cdots$ & -- & - & -- & -- \\
\hline-- & MCW high fired $(-400)$ & None & 88.14 & 2.00 & - & -- & -- & -- & -- \\
\hline
\end{tabular}




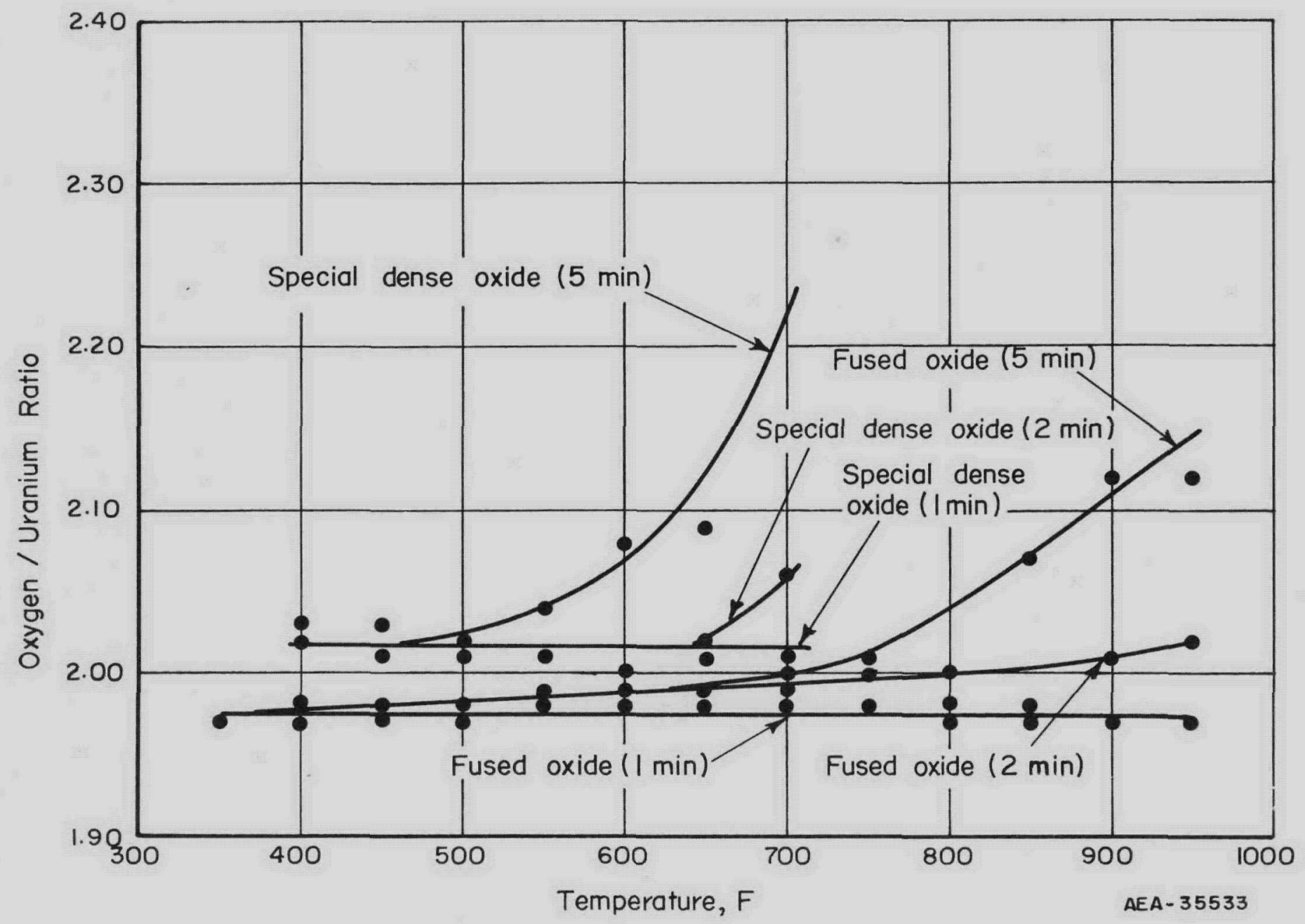

FIGURE 3. EFFECT OF FLASH ROASTING ON UO ${ }_{2}$ STOICHIOMETRY 
various oxygen/uranium ratios. Microscopic analyses are also planned in order to establish the manner in which the excess oxygen is contained in these materials. Preliminary observations indicate no particle fracturing due to the heat treatment.

\section{CERMET PREPARATION}

Stainless steel-uranium dioxide cermets, particularly those with high oxide loadings, are attractive as reactor fuels because of their potentially high thermal conductivity. This effect is achieved in a structure where the stainless steel, although the minor constituent, forms a continuous network to provide a thermal path for heat removal during reactor operation. Such fuel systems would result in lower fuel temperatures and, consequently, reduced fission-gas release. In view of the desirability of such fuels, a brief investigation was undertaken to establish the feasibility of densifying and cladding cermets by gas-pressure bonding.

As a first step in the preparation of stainless steel-uranium dioxide cermets, it was necessary to develop a blending and pressing technique which would assure uniform dispersion of the two phases. In the initial efforts, segregation was evident, apparently due to the differences in density and particle size of the two constituents. Binder materials, including ethylene glycol, Ceremul "C", and camphor and alcohol, were studied in an effort to achieve more uniform dispersions in the blended powders. Of the materials investigated, the camphor-and-alcohol binder produced the bestblending action when used in conjunction with a standard V-type mixer. In this procedure, the binder material and $\mathrm{UO}_{2}\left(3 \mathrm{~cm}^{3}\right.$ of a solution of 1 oz of camphor in $600 \mathrm{~cm}^{3}$ of methyl alcohol per $100 \mathrm{~g}$ of $\mathrm{UO}_{2}$ ) are stirred, dried, and the resulting blend sized through a 100-mesh screen to fragment any agglomeration. The sized $\mathrm{UO}_{2}$ and stainless steel powder is then blended for $1 \mathrm{hr}$ in the $\mathrm{V}$-type mixer prior to adding $1 \mathrm{~cm}^{3}$ of the camphor-alcohol solution per $100 \mathrm{~g}$ of $\mathrm{UO}_{2}$. After the binder addition, the material is blended for an additional $2 \mathrm{hr}$.

Cold pressing of the stainless steel-uranium dioxide cermet mixtures was generally accomplished at $30 \mathrm{tsi}$. This pressure was selected since pressures to 50 tsi resulted in very little density increase but did produce greater die wear. Compacts produced in this manner were found to generally possess adequate green strength for loading and sealing into stainless steel tubes. With respect to platelet compacts, considerable difficulty was encountered in achieving compacts with good handling characteristics. Generally, such compacts showed poor definition of edges and a tendency to crumble readily on handling.

To study the effects of pressure-bonding parameters on the densification of these cermets, assemblies were pressure-bonded for $3 \mathrm{hr}$ at 10,000 psi at temperatures ranging from 2000 to $2400 \mathrm{~F}$. For these experiments, the compacted cermets were loaded into stainless steel tubes measuring $0.470 \mathrm{in.}$ in ID with 0.015 -in. walls, dewaxed while contained in the tubes, evacuated, and sealed. The material resulting from these tests also provided sufficient stock for establishing mechanical and physical properties of the cermets considered in this work. 
Various methods for conditioning stainless steel surfaces prior to pressure bonding have been investigated. Since this process involves only a slight metal deformation in achieving bonding, the initial surface preparation and cleaning have a significant effect on the final bond quality. In previous studies with other materials, such as Zircaloy-2, the surface preparation and cleaning methods were found to be extremely critical. (9, 10,11) However, the present study concerning stainless steel bonds shows that in this case bonding is much less sensitive to the initial procedures.

\section{Cleaning and Assembly of Components}

During the course of this study, a cleaning technique for both the stainless steel components and container material has been developed. After mechanical preparation, the stainless steel components are degreased in alcohol, pickled in a 10 volume per cent nitric acid- 2 volume per cent hydrofluoric acid aqueous solution for $2 \mathrm{~min}$ at 120 to $140 \mathrm{~F}$, and then rinsed in cold running water. All metal components, including the pressure-bonding container, are then subjected to the developed washing and cleaning cycle, which is as follows:

(1) Placed in trichlorethylene vapor bath $(5 \mathrm{~min})$

(2) Scrubbed in methyl ethyl ketone

(3) Scrubbed in 200-proof alcohol

(4) Placed in 200-proof ultrasonic bath (5 min)

(5) Scrubbed in a hot Alcanox solution (180 F)

(6) Rinsed in cold running water

(7) Placed in 200-proof ultrasonic bath (5 $\mathrm{min}$ )

(8) Rinsed in cold running water

(9) Rinsed in hot water (180 F)

(10) Blown dry with filtered air.

Immediately after drying, the components are assembled into their respective pressure bonding container and then Heliarc welded to form a pressuretight assembly. The assembled unit is then leak tested, either by pressurizing with helium under water or by utilizing a helium leak-detector unit. In those cases where binder removal of the contained uranium dioxide cores is required, the assembly is evacuated while heating for $1 / 2 \mathrm{hr}$ at $1200 \mathrm{~F}$. All composite units are ultimately placed on an evacuation manifold and outgassed to $5 \times 10^{-3} \mathrm{~mm}$ of mercury prior to final sealing before the bonding operation. 
Effects of Mechanical Surface Preparation

In previous Phase I studies involving the development of optimum pressurebonding conditions for producing Type 304 stainless steel bonds, both mechanical and as-rolled surfaces were considered. (9) With such surfaces excellent bond structures and bond strengths were achieved with a pressure-bonding cycle of $3 \mathrm{hr}$ at $2100 \mathrm{~F}$ and $10,000 \mathrm{psi}$. However, the results obtained in this series of experiments indicated that a more complete study of mechanical surface-preparation methods would be desirable.

During the present phase of the program a further study was conducted concerning the effects of various surface-preparation methods on the quality of Type 304 stainless steel bonds resulting from the pressure-bonding operation. Flat-plate specimens measuring 1 by $1 \mathrm{in}$. were prepared from two sheets of thicknesses measuring 0.010, 0.020 , or $0.075 \mathrm{in.}$ Mechanical surface-preparation techniques involved in these tests concerned surfaces which were as rolled, belt abraded, milled, and vacuum annealed. These were gas-pressure bonded for periods of $3 \mathrm{hr}$ at 2000 and $2100 \mathrm{~F}$ at 10,000 psi, except for the milled surface, which was bonded only at $2100 \mathrm{~F}$. The specimens were evaluated by metallographic observation and by peel and bend tests, as reported in Table 9. Photomicrographs of typical sections taken of these different bond interfaces are shown in Figure 4. From the results of these specimens and others prepared during this study, it appears that gas-pressure bonding at $2100 \mathrm{~F}$ for $3 \mathrm{hr}$ at 10,000 psi of specimens with either as-rolled, belt-abraded, or milled surfaces can produce consistently strong Type 304 stainless steel bonds, while attaining the essential densification of the $\mathrm{UO}_{2}$.

\section{EVALUATION OF PRESSURE-BONDED UO 2}

In order to more completely evaluate the gas-pressure-bonding technique as a means for fabricating low-cost fuel elements, it was necessary to establish the characteristics of the various uranium dioxides as processed by this method. In this regard, the final oxides were examined with respect to their density and structural features in order that some idea as to their acceptability as reactor fuels could be obtained. To further evaluate the reactor potential of such fuels, studies of the permeability and thermal conductivity of selected pressure-bonded oxides were also initiated. With the data from these tests, a more direct comparison with uranium dioxide as processed by the more conventional pressing and sintering techniques can be drawn.

$\underline{\text { Density and Structure of Pressure-Bonded Uranium Dioxide }}$

The density and metallographic evaluation of the specimens gas-pressure-bonded in this study revealed widely varying characteristics in the massive uranium dioxide produced from both powders and powder mixtures. The initial characteristics of the seven types of uranium dioxide powders and various powder mixtures used are given in previous sections of this report. The general densities and structures achieved in pressure bonding these materials are summarized in Table 10. Further comments upon their characteristics follow. 
TABLE 9. EVALUATION OF THE EFFECTS OF SURFACE PREPARATION ON THE QUALITY OF TYPE 304 STAINLESS STEEL BONDS

Type of Surface

As rolled

Surface Preparation of Components

Components degreased in alcohol and rinsed in cold water, given 2-min pickle in an aqueous solution of 10 parts nitric acid heated to $120 \mathrm{~F}$ followed by cold-water rinse, given detergent washes and hotwater rinses, then dried by filtered air

Belt abraded

Surfaces belt abraded with a 60 -grit SiC abrasive belt to a surface finish of 20 to $25 \mu$ in., then degreased, pickled, washed, and rinsed as the as-rolled specimens cold water and then vacuum annealed at $2100 \mathrm{~F}$ for $1 \mathrm{hr}$; no further treatment was given

Milled

Gas-Pressure-Bonding

Temperature(a) $\mathrm{F}^{\mathrm{F}}$

Surfaces machined to a finish of 30 to $40 \mu$ in. then degreased, pickled, washed, and rinsed as the as-rolled specimens
2000

Evaluation Comments

Bonds did not fail during bend and peel tests; metallographic examination revealed only a 25 per cent grain growth across the interface

Bonds did not fail during bend and peel tests; metallographic examination revealed 90 to 100 per cent grain growth across the interface

Bonds did not fail during bend and peel tests; metallographic examination revealed slight contamination and 25 to

30 per cent grain growth across the interface

Bonds withstood the bend and peel tests; metallographic examination revealed slight contamination and 95 per cent grain growth across the interface

Bonds did not fracture during bend and pee tests; metallographic examination revealed slight contamination and only a 20 per cent grain growth across the bond interface

Bonds withstood the bend and peel tests; metallographic examination revealed

60 to 70 per cent grain growth across the bond interface
Bonds withstood the bend and peel tests; metallographic examination revealed 90 per cent grain growth with slight contamination at the interface

(a) Bonded $3 \mathrm{hr}$ at 10,000 psi. 


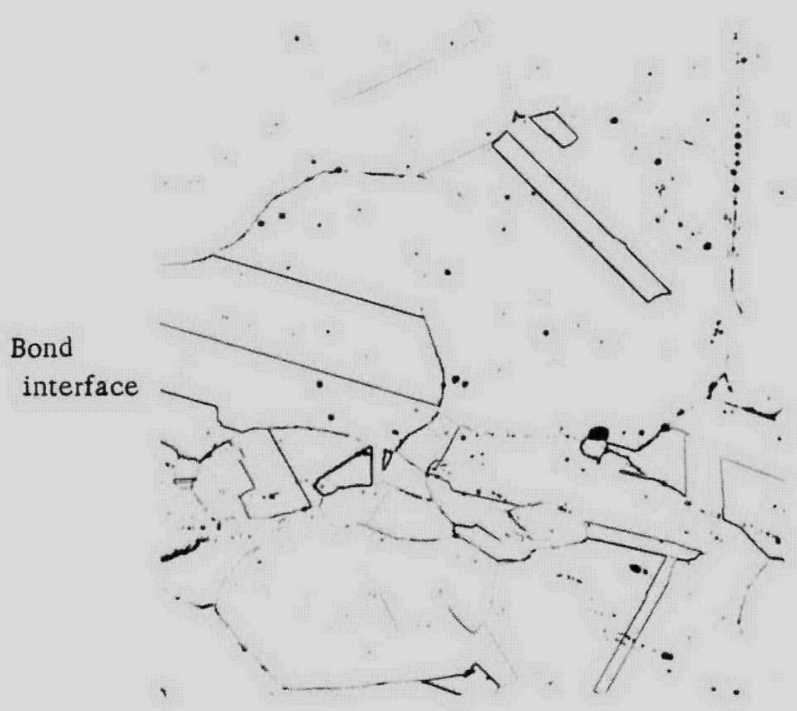

$250 \mathrm{X}$

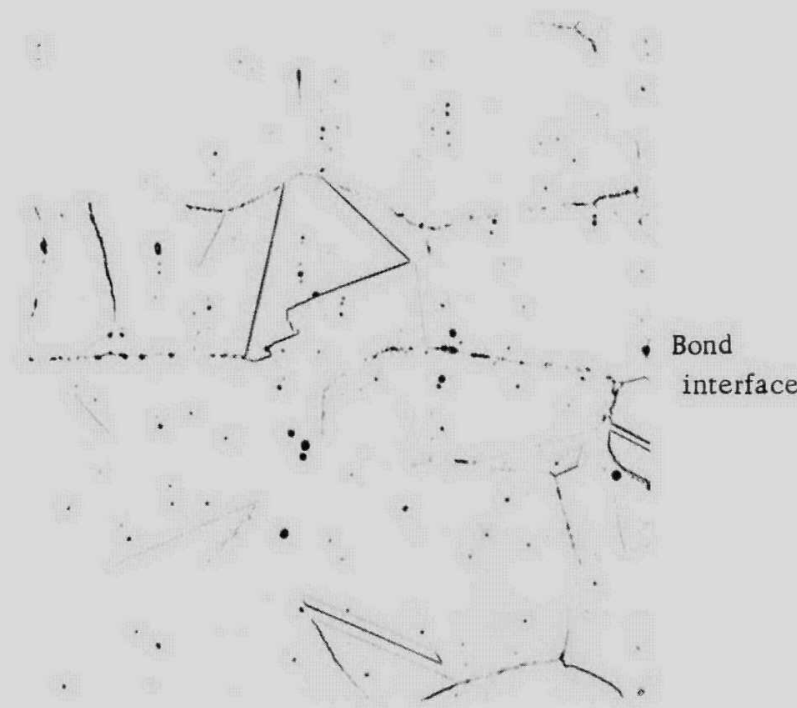

$250 \mathrm{X}$
RM15172
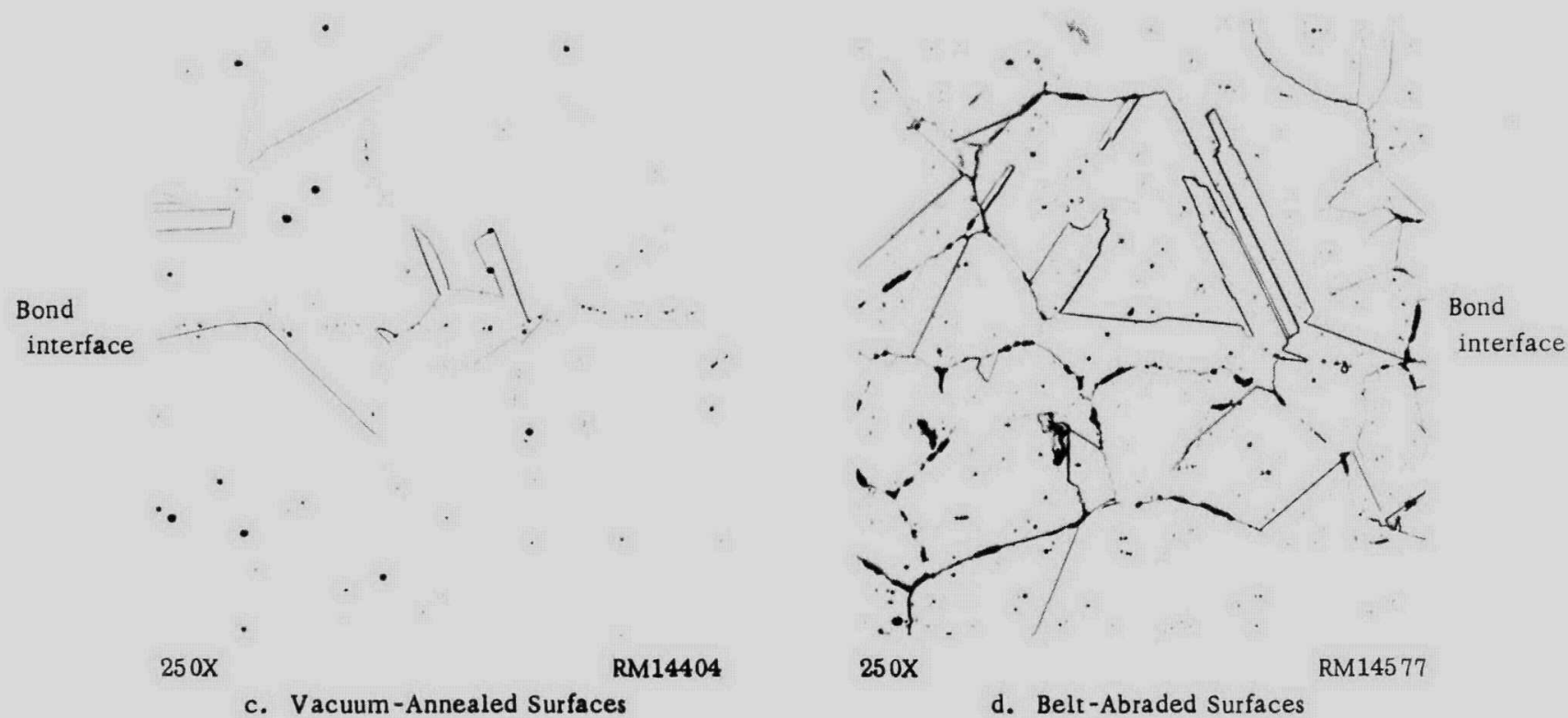

$250 \mathrm{X}$

d. Belt-Abraded Surfaces

FIGURE 4. BOND INTERF ACES OBTAINED IN GAS-PRESSURE BONDING TYPE 304 ST AINLESS STEEL SURF ACES PREPARED BY DIFFERENT METHODS

All specimens were bonded at $2100 \mathrm{~F}$ for $3 \mathrm{hr}$ at $10,000 \mathrm{psi}$. 
TABLE 10. EVALUATION OF PRESSURE-BONDED UO ${ }_{2}$

\begin{tabular}{|c|c|c|c|c|c|}
\hline $\begin{array}{l}\text { Description of Powder } \\
\text { or Powder Mixture }\end{array}$ & $\begin{array}{l}\text { Range of Cold-Pressed } \\
\text { Densities Used for } \\
\text { Pressure Bonding, } \\
\text { per cent of theoretical }\end{array}$ & $\begin{array}{l}\text { Range of Tamp-Packed } \\
\text { Densities Used for } \\
\text { Pressure Bonding, } \\
\text { per cent of theoretical }\end{array}$ & $\begin{array}{l}\text { Pressure-Bonding } \\
\text { Temperature(a), } \\
\text { F }\end{array}$ & $\begin{array}{l}\text { Density Achieved by } \\
\text { Pressure Bonding, } \\
\text { per cent of theoretical }\end{array}$ & Comments \\
\hline Mallinckrodt ceramic grade & $\begin{array}{c}54.8-58.3 \\
-- \\
-- \\
54.8-58.3 \\
78(d)\end{array}$ & $\begin{array}{l}-- \\
19.0-20.0 \\
19.0-20.0 \\
-- \\
--\end{array}$ & $\begin{array}{l}2100 \\
2100 \\
2200 \\
1600 \text { and } \\
1700 \text { (c) } \\
2100\end{array}$ & $\begin{array}{l}98.5^{(\mathrm{b})} \\
98.5^{(\mathrm{b})} \\
99.5^{(\mathrm{b})} \\
96.7^{(\mathrm{b})} \\
96.9^{(\mathrm{b})}\end{array}$ & $\begin{array}{l}\text { An "active" oxide that deformed well upon pressure } \\
\text { bonding; high densities with little porosity were } \\
\text { achieved }\end{array}$ \\
\hline Mallinckrodt dense ceramic & - & - & - & -- & $\begin{array}{l}\text { Not pressure bonded; pellets were friable and } \\
\text { difficult to handle }\end{array}$ \\
\hline $\begin{array}{l}\text { Mallinckrodt and Numec } \\
\text { high fired }\end{array}$ & $\begin{array}{l}72.7-76.1 \\
72.7-76.1\end{array}$ & -- & $\begin{array}{l}2100 \\
2100 \text { and } \\
2300 \text { (c) }\end{array}$ & $\begin{array}{l}90.3-93.2(e) \\
93.1-95.8^{(e)}\end{array}$ & $\begin{array}{l}\text { Though high cold-pressed densities were achieved } \\
\text { this oxide did not appear to move well during } \\
\text { pressure bonding; particles exhibited a 1ack of } \\
\text { grain growth and were susceptible to pull-out } \\
\text { when polishing }\end{array}$ \\
\hline Mallinckrodt special dense & $\begin{array}{c}75.6-80.3 \\
75.6-80.3 \\
--\end{array}$ & $\begin{array}{l}-- \\
-- \\
54.9-63.4\end{array}$ & $\begin{array}{l}2100 \\
2300 \\
2100\end{array}$ & $\begin{array}{l}83.9-90.7(e) \\
93.1 \text { (b) } \\
85.7-89.6^{(e)}\end{array}$ & $\begin{array}{l}\text { There appeared to be only point-to-point bonding } \\
\text { with the oxide particles themselves remaining } \\
\text { porous; little movement during pressure bonding }\end{array}$ \\
\hline Spencer fused & $\begin{array}{c}77.2-84.7 \\
84.6-85.0 \\
--\end{array}$ & $\begin{array}{c}-- \\
-- \\
53.8-69.4\end{array}$ & $\begin{array}{l}2100 \\
2300 \\
2100\end{array}$ & $\begin{array}{l}82.5-94.0^{(e)} \\
\quad 94.9 \\
83.5-88.9^{(e)}\end{array}$ & $\begin{array}{l}\text { The high-density brittle particles bridged against } \\
\text { each other, leaving large amounts of void space; } \\
\text { only point bonding occured; many of the larger } \\
\text { particles fractured during pressure bonding }\end{array}$ \\
\hline Mallinckrodt spherical & - & - & -- & - & $\begin{array}{l}\text { Not pressure bonded; the cost of this oxide was } \\
\text { considered excessive for this program }\end{array}$ \\
\hline $\begin{array}{l}\text { Fused and ceramic mixture } \\
25 \mathrm{w} / 0 \text { ceramic } \\
25 \mathrm{w} / 0 \text { ceramic } \\
40 \mathrm{w} / 0 \text { ceramic } \\
50 \mathrm{w} / 0 \text { ceramic } \\
75 \mathrm{w} / 0 \text { ceramic }\end{array}$ & $\begin{array}{c}72.0-83.5 \\
74.4-75.2 \\
74.5 \\
67.0-72.0 \\
63.0-67.1\end{array}$ & $\begin{array}{l}-- \\
-- \\
-- \\
--\end{array}$ & $\begin{array}{l}2100 \\
2300 \\
2100 \\
2100 \\
2100\end{array}$ & $\begin{array}{l}92.2-96.7(e) \\
96.7 \\
97.8 \\
99.0-99.5^{(e)} \\
99.0-99.5^{(e)}\end{array}$ & $\begin{array}{l}\text { These mixtures of a highly dense oxide with an } \\
\text { "active" oxide deformed well upon pressure } \\
\text { bonding; very high densities with little porosity } \\
\text { were achieved }\end{array}$ \\
\hline
\end{tabular}


TABLE 10. (Continued)

\begin{tabular}{|c|c|c|c|c|c|}
\hline $\begin{array}{l}\text { Description of Powder } \\
\text { or Powder Mixture }\end{array}$ & $\begin{array}{l}\text { Range of Cold-Pressed } \\
\text { Densities Used for } \\
\text { Pressure Bonding, } \\
\text { per cent of theoretical }\end{array}$ & $\begin{array}{l}\text { Range of Tamp-Packed } \\
\text { Densities Used for } \\
\text { Pressure Bonding, } \\
\text { per cent of theoretical }\end{array}$ & $\begin{array}{l}\text { Pressure-Bonding } \\
\text { Temperature }{ }^{(a)} \text {, } \\
\text { F }\end{array}$ & $\begin{array}{l}\text { Density Achieved by } \\
\text { Pressure Bonding, } \\
\text { per cent of theoretical }\end{array}$ & Comments \\
\hline $\begin{array}{l}75 \text { w/o special dense and } 25 \text { w/o } \\
\text { ceramic grade }\end{array}$ & $72.2-78.5$ & - & 2100 & $89.0-92.2^{(\mathrm{e})}$ & $\begin{array}{l}\text { The special dense oxide particles remained } \\
\text { porous, giving the core a rather low final density }\end{array}$ \\
\hline $\begin{array}{l}75 \text { w/o high fired and } 25 \mathrm{w} / \mathrm{o} \\
\text { ceramic grade }\end{array}$ & $68.5-71.4$ & -. & $\begin{array}{r}2100 \text { and } \\
2300 \text { (c) }\end{array}$ & $92.9-95.0^{(e)}$ & $\begin{array}{l}\text { The cores appeared sound but metallographic } \\
\text { examination revealed high porosity }\end{array}$ \\
\hline $\begin{array}{l}75 \mathrm{w} / \mathrm{o} \text { fused and } 25 \mathrm{w} / \mathrm{o} \mathrm{high} \\
\text { fired }\end{array}$ & $78.5-86.8$ & -- & 2100 & 88.9 & $\begin{array}{l}\text { Little movement upon pressure bonding; particles } \\
\text { appeared to position themselves, but there was } \\
\text { little to no bonding }\end{array}$ \\
\hline Fused and dense ceramic mixtures & & & & & The dense ceramic oxide did not fill in voids \\
\hline $25 \mathrm{w} / \mathrm{o}$ ceramic & $77.6-79.9$ & -- & 2100 & 92.2 & formed by the fused oxide; bridging of the fused \\
\hline $20 \mathrm{w} / \mathrm{o}$ ceramic & $75.3-80.6$ & -- & 2100 & 92.2 & oxide was noticed \\
\hline $\begin{array}{l}75 \mathrm{w} / \mathrm{o} \text { special dense and } 25 \mathrm{w} / \mathrm{o} \\
\text { dense ceramic }\end{array}$ & $74.5-78.5$ & -- & 2100 & 89.0 & $\begin{array}{l}\text { Little movement during pressure bonding; core } \\
\text { had low density with high porosity }\end{array}$ \\
\hline
\end{tabular}

(a) All specimens were bonded $3 \mathrm{hr}$ at 10,000 psi.

(b) Average density achieved.
(c) This specimen was pressure bonded twice.
(d) Mallinckrodt pressed and dewaxed pellets.

(e) Range of densities achieved. 
Individual Oxides

Ceramic grade uranium dioxide powder obtained from Mallinckrodt was the most "active" oxide investigated in this study. It was found that this oxide consolidated readily during pressure bonding, achieving a high density either from tamp-packed or greenpressed core loadings. Metallographic studies revealed bonding between particles with very little porosity, as shown in Figures 5 and 6. Grain growth, such as illustrated in Figure 7, was evident when increased time or temperature over the desired $3 \mathrm{hr}$ at $2100 \mathrm{~F}$ at 10,000 psi was used. These cores did appear to crack more frequently than any of the other oxide cores bonded. This effect was attributed to the excessive cladding movement required because of the lower starting density. High densities were achieved with this oxide at temperatures as low as $1700 \mathrm{~F}$; however, the resulting material exhibited a very fine grain structure that had nonuniform etching characteristics. In general, ceramic grade uranium dioxide powders alone do not appear practical for the pressure-bonding process, due to their low initial density and high activity during the process. This combination of characteristics usually leads to defects in the final bonded components.

No specimens containing Mallinckrodt dense ceramic pellets were pressure bonded during this investigation. In the initial work the green-pressed pellets of this oxide were extremely friable and difficult to handle. As a result of their compacting characteristics, they were excluded from further study.

High-fired uranium dioxide powders obtained from Numec and Mallinckrodt were found similar in pressure-bonding characteristics. Good green-pressed densities were achieved with both oxides; however, they exhibited an intermediate densification behavior when pressure bonded. The best density obtained in the present program with highfired oxides was 95.8 per cent of theoretical after pressure bonding in successive cycles of $3 \mathrm{hr}$ at 10,000 psi at both 2100 and $2300 \mathrm{~F}$. There appeared to be some bonding between particles in the resulting oxide, but many voids were also present, as shown in the photomicrograph in Figure 8. The particles in the core were susceptible to pull-out when polishing for metallographic study; however, bulk strength was evident since sizable pieces were obtained for thermal-conductivity study. In view of the lack of structural integrity after pressure bonding, this oxide was removed from consideration.

Pellets containing Mallinckrodt special dense powders could be green pressed to rather high densities, between 75.6 to 80.3 per cent of theoretical. However, when pressure bonded, these compacts densified very little with respect to the starting density even at the high temperatures. In the final structures there appeared to be only pointto-point bonding between particles, causing a slight bridging effect. The particles themselves remained porous as noted in the photomicrographs in Figures 9 and 10. to these results and the fairly high cost of this oxide it was eliminated from further consideration.

As with special dense oxide, the Spencer fused oxide also yielded high greenpressed densities, in this case ranging from 77.2 to 85 per cent of theoretical. This oxide, however, densified very little upon pressure bonding. The fused particles were essentially fully dense, being very brittle and demonstrating no plasticity on pressure bonding. As can be observed in the photomicrographs in Figures 11, 12, and 13, the particles exhibited a marked tendency to bridging and thus wedged themselves into place, restraining further movement. Such effects resulted in structures consisting of large amounts of void area. With the fused powder, selective particle sizing had little effect 


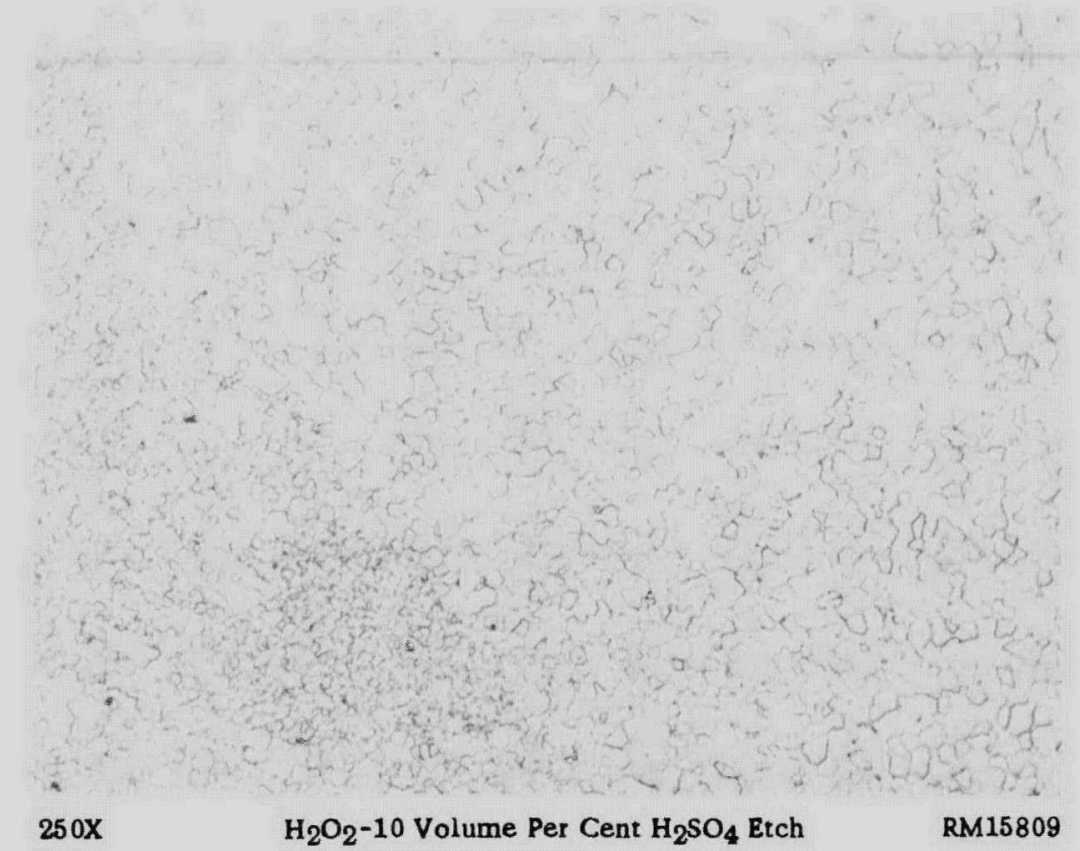

FIGURE 5. MICROSTRUCTURE OF A COLD-PRESSED CERAMIC UO 2 CORE GAS-PRESSURE BONDED AT 2100 F FOR 3 HR AT 10,000 PSI

Starting pellets were MCW ceramic grade (minus 325 mesh) cold pressed to 55.5 to 58.3 per cent of theoretical density. Final density was 98.5 per cent of theoretical with an oxygen/uranium ratio of 2.03 .

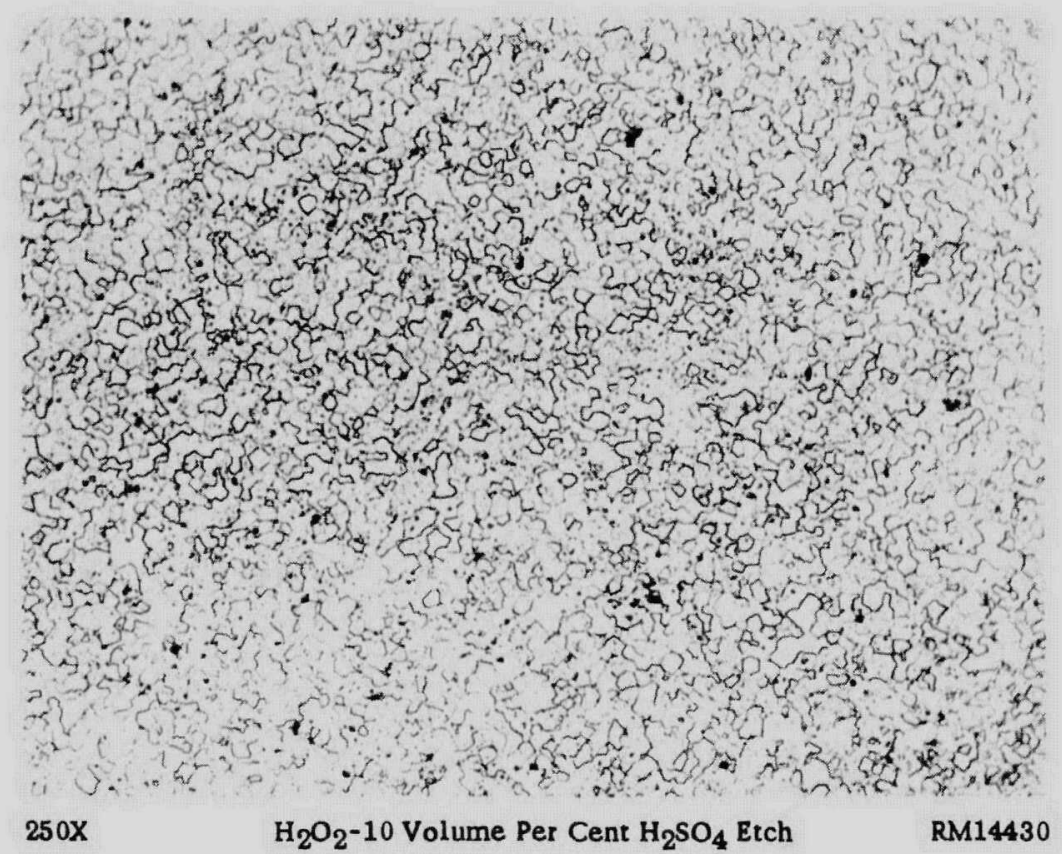

FIGURE 6. MICROSTRUCTURE OF A CERAMIC UO 2 CORE GAS-PRESSURE BONDED AT 2100 F FOR 3 HR AT 10,000 PSI AFTER COLD PRESSING AND PARTIALLY SINTERING

Starting pellets were MCW ceramic grade pressed and dewaxed to a density of 78. 0 per cent of theoretical. Final density was 96.9 per cent of theoretical. 


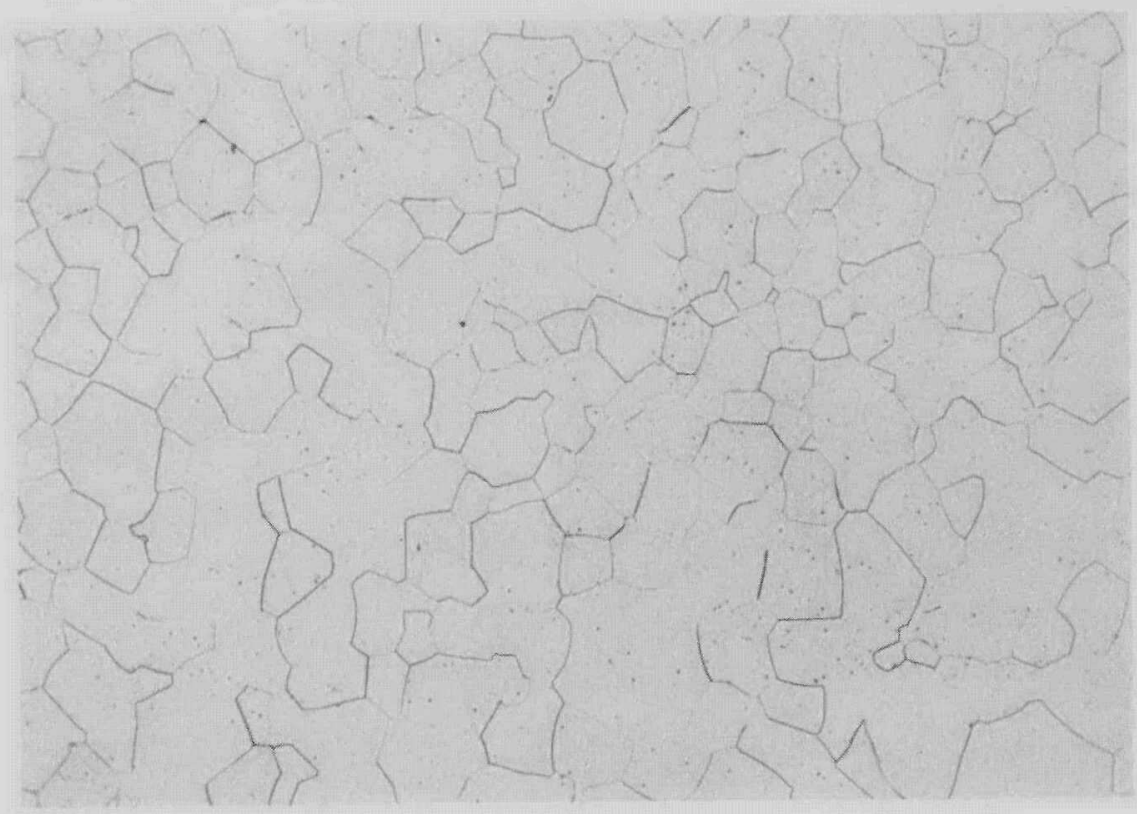

FIGURE 7. MICROSTRUCTURE OF A T AMP-PACKED CERAMIC UO 2 CORE GAS-PRESSURE BONDED AT 2200 F FOR 3 HR AT 10, 000 PSI

Starting from tamp-packed MCW ceramic grade (minus 325 mesh) of a theoretical density of 19.6 per cent, the final density was 99.5 per cent of theoretical with an oxygen/ uranium ratio of 2.01 .

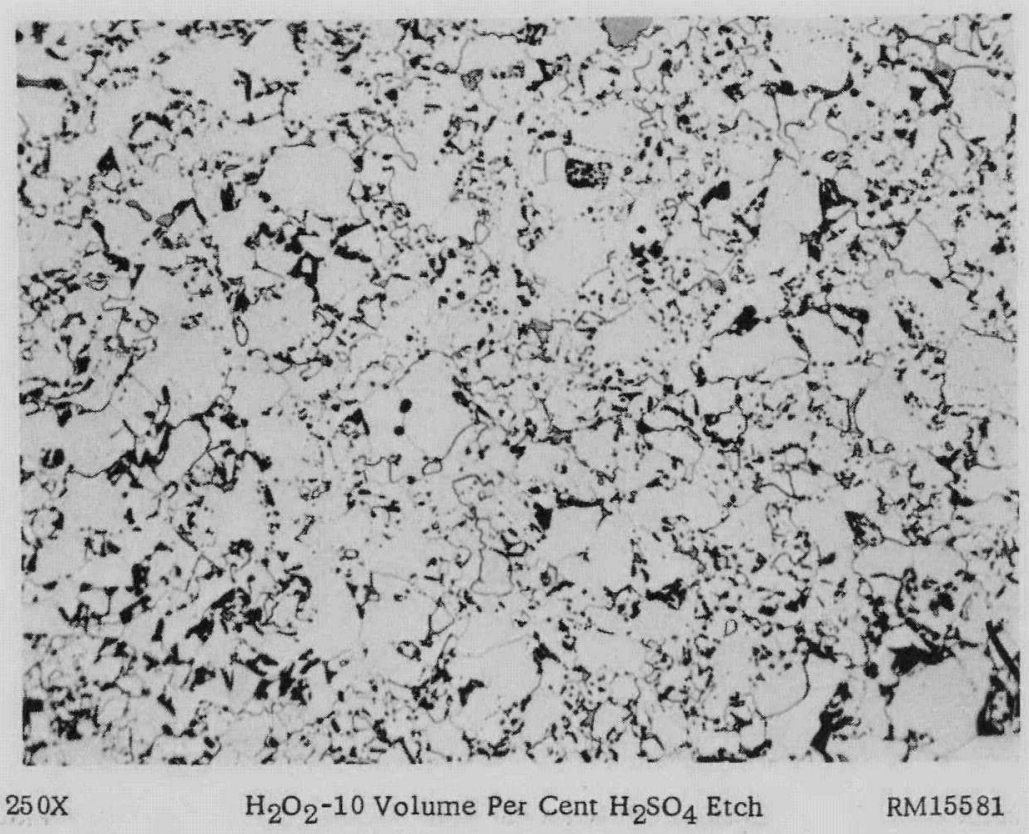

FIGURE 8. MICROSTRUCTURE OF A HIGH-FIRED UO ${ }_{2}$ CORE GAS-PRESSURE BONDED AT $2100 \mathrm{~F}$ FOR 3 HR AT 10,000 PSI AND REBONDED AT 2300 F FOR 3 HR AT 10, 000 PSI

The starting material was $\mathrm{MCW}$ high-fired minus 400 -mesh $\mathrm{UO}_{2}$ cold pressed to a density 72.7 per cent of theoretical. The final density was 95.8 per cent of theoretical with an oxygen/uranium ratio of 2.01. Similar results were obtained with Numec high-fired oxide. 


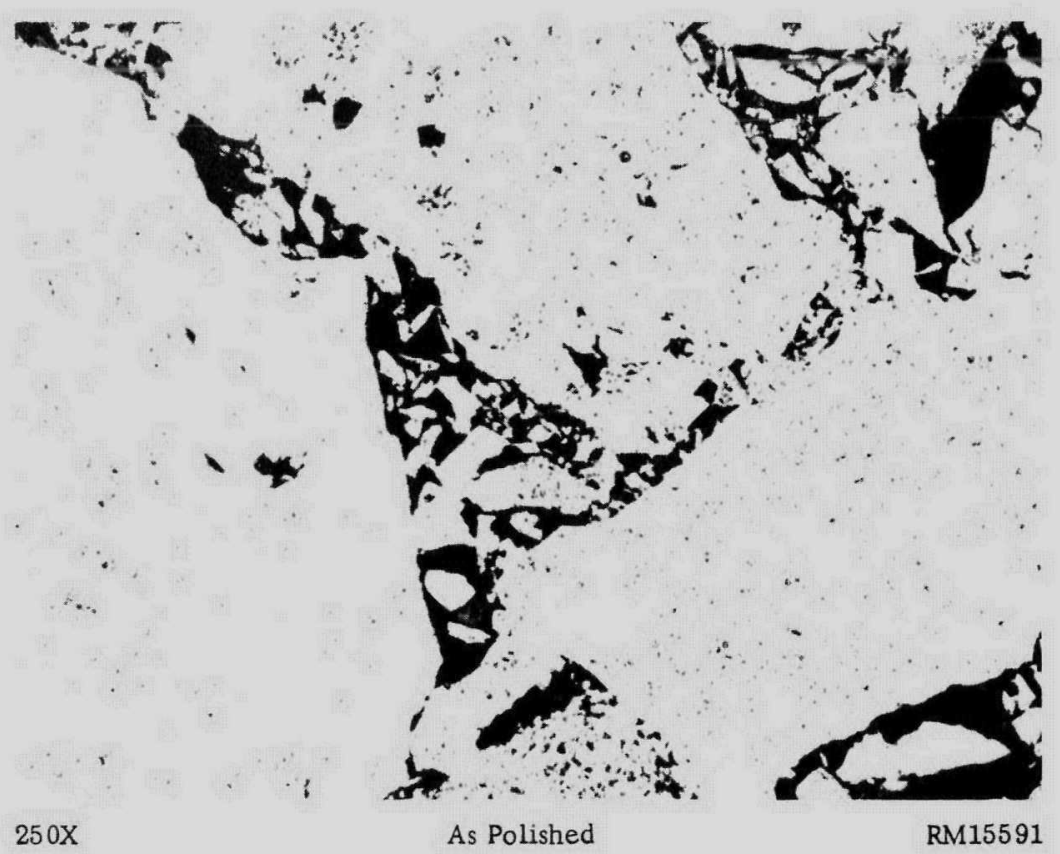

FIGURE 9. MICROSTRUCTURE OF A TAMP-PACKED SPECI AL DENSE UO ${ }_{2}$ CORE GAS-PRESSURE BONDED AT 2100 F FOR 3 HR AT 10,000 PSI

Starting material was $\mathrm{MCW}$ special dense (minus 40 mesh) $\mathrm{UO}_{2}$ tamp packed to a starting density of 63.4 per cent of theoretical. Final density was 89.6 per cent of theoretical.

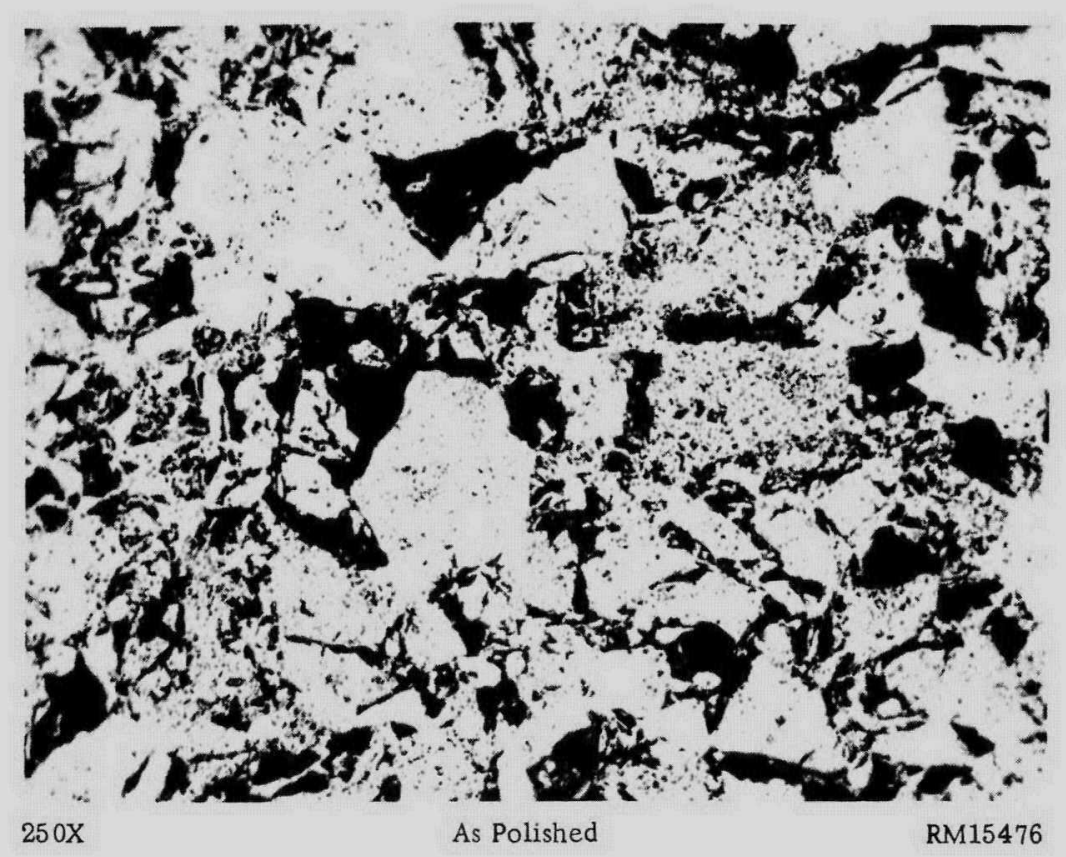

FIGURE 10. MICROSTRUCTURE OF A COLD-PRESSED SPECIAL DENSE UO ${ }_{2}$ CORE GAS-PRESSURE BONDED AT 2100 F FOR 3 HR AT 10,000 PSI

Starting material was MCW special dense minus 200 plus $325-$ mesh $\mathrm{UO}_{2}$ cold pressed to a 73.3 per cent theoretical density. The final density was 89.9 per cent of theoretical with an oxygen/uranium ratio of 1.99 . 


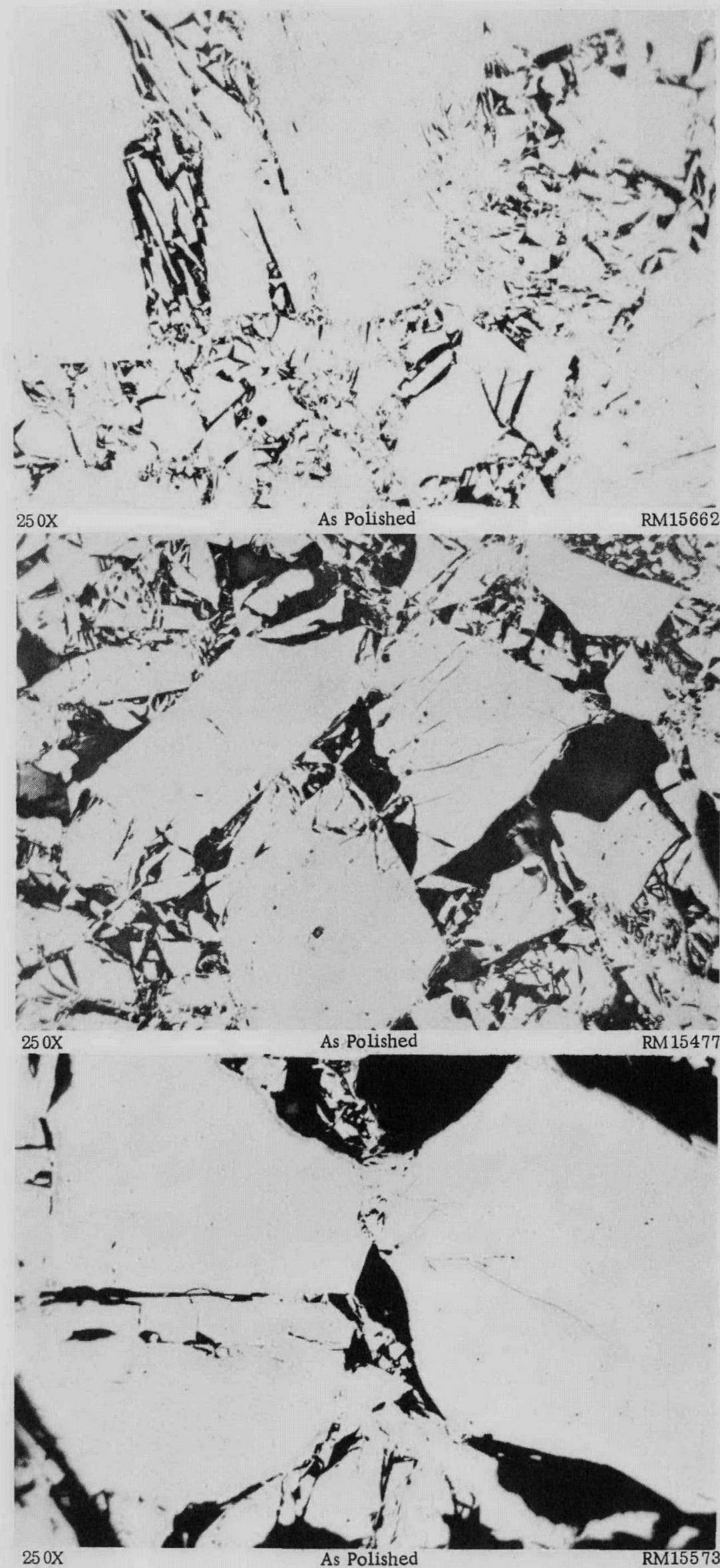

FIGURE 11. MICROSTRUCTURE OF A FUSED UO CORE GAS-PRESSURE BONDED AT 2300 F FOR 3 HR AT 10,000 PSI

Starting material was Spencer fused (minus 20 mesh) $\mathrm{UO}_{2}$ cold pressed to a starting theoretical density of 84.6 to 85.0 per cent. Final density was 94.9 per cent of theoretical.

FIGURE 12. MICROSTRUCTURE OF A FUSED UO2 CORE GAS-PRESSURE BONDED AT 2100 F FOR 3 HR AT 10,000 PSI

Starting material was Spencer fused minus 100 plus 140 -mesh $\mathrm{UO}_{2}$ cold pressed to a density of 82.2 to 83.1 per cent of theoretical. Final density was 91.0 per cent of theoretical with an oxygen/uranium ratio of 1.99 .

FIGURE 13. MICROSTRUCTURE OF A FUSED UO ${ }_{2}$ CORE OF SPECIAL SIZE DISTRIBUTION GAS-PRESSURE BONDED AT 2100 F FOR 3 HR AT 10, 000 PSI

The starting material was Spencer fused $\mathrm{UO}_{2}$ (ideal cubic packing mixture) cold pressed to a density of 82.3 to 83.9 per cent of theoretical. Final density was 89.5 per cent of theoretical. 
upon the final density achieved. It was noted that some particles were fractured during the pressing and bonding operations, as illustrated in Figure 13, but this crushing effect did not create enough fines to fill the void areas. As an individual oxide for core loadings, the fused oxide does not appear practical for pressure-bonding use at the temperatures and pressures being investigated in the present program.

No specimens were pressure bonded containing Mallinckrodt spherical oxide due to the cold-pressing behavior demonstrated in earlier tests. Results of compaction studies showed no marked improvement over powders which were far less expensive.

\section{Oxide Mixtures}

The mixture of fused and ceramic grade oxides represents a combination of a highly dense oxide to achieve a high compacting density and an active oxide to achieve sinterability. From the range of compositions investigated, it appears that those containing from 30 to $60 \mathrm{w} / 0$ ceramic grade oxide offer the most promise. Final structures of the oxide mixtures are shown in the photomicrographs in Figures 14, 15, and 16. In these combinations of oxides both high green densities and high final densities were obtained. It should be noted in the photomicrographs in Figures 17 and 18 that there was not enough ceramic grade oxide in the $75 \mathrm{w} / 0$ fused- $25 \mathrm{w} / 0$ ceramic grade mixture to prevent fused particles from bridging. In this case, the bridging effect prevented the ceramic grade oxide from filling all void areas and achieving full density. A metallographic study of those specimens containing higher concentrations of the ceramic oxide revealed a very firm core with virtually no cracks or voids. The resulting structures consisted of high-density fused particles completely surrounded by a high-density ceramic oxide matrix. This combination of oxides appears to offer the best characteristics at the lowest cost for use in the pressure-bonding process.

The mixture of ceramic grade and special dense oxides formed an apparently solid mass with no visible cracks when pressure bonded at $2300 \mathrm{~F}$ for $3 \mathrm{hr}$ at 10,000 psi. As revealed in the photomicrograph in Figure 19, the particles of special dense oxide remained porous after bonding. The final densities and over-all structural characteristics were not as attractive as the fused-ceramic mixtures; therefore, no further work on this mixture was undertaken.

Cores prepared with the mixture of high-fired and ceramic oxides appeared to be uniform. The initial compacting density was below that desired, and, as revealed in the photomicrograph in Figure 20, the porosity in the final structure was quite high.

The mixture of fused and high-fired oxides was also found to densify very little on pressure bonding. The particle positioning in this case also exhibited the bridging effect; therefore, poor densities were obtained. Little or no particle bonding was observed.

The fused-dense ceramic mixtures investigated revealed good green-pressed densities, but little further consolidation when pressure bonded. The dense ceramic did not fill in the areas around the fused particles, thus large void areas were present in the cores. At the temperatures used, this oxide mixture was considered unsatisfactory.

High green-pressed densities were ichieved with the speciai dense-dense cerainic mixiure. The pressure-bonder cores demonstrated litiis promise in that they were below the desired density and, consequently, very porous. 


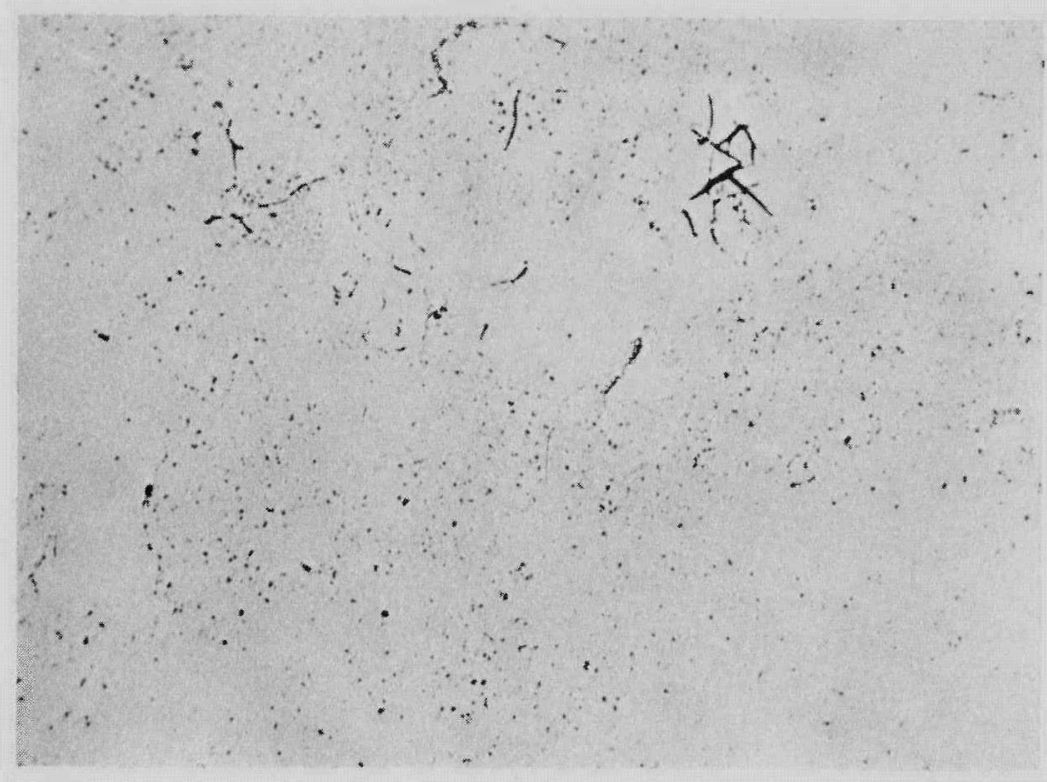

$250 \mathrm{X}$

RM16318

a. Etched in $\mathrm{H}_{2} \mathrm{O}_{2}-10$ Volume Per Cent $\mathrm{H}_{2} \mathrm{SO}_{4}$ Solution

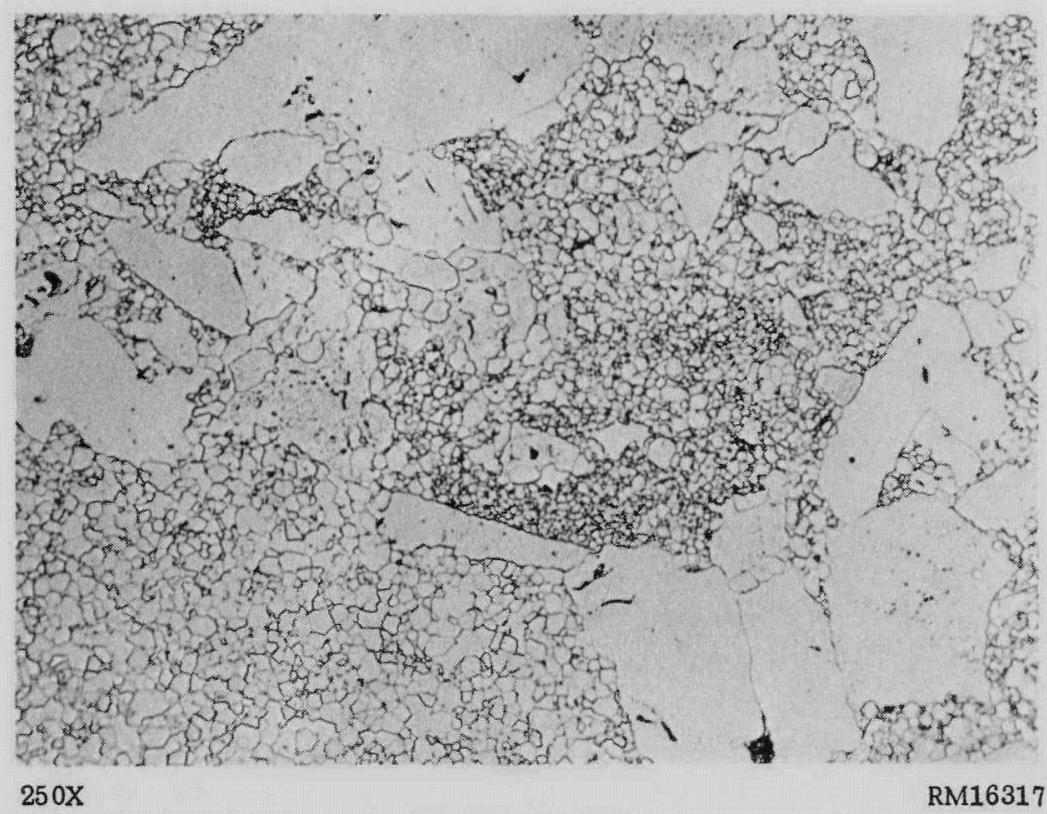

b. Unetched

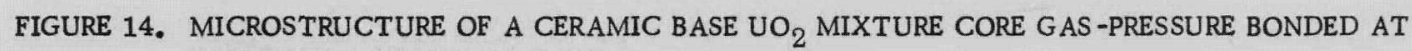
2100 F FOR 3 HR AT 10, 000 PSI

Starting material was a mixture of $25 \mathrm{w} / 0$ Spencer fused (minus 100 mesh) and $75 \mathrm{w} / \mathrm{o} \mathrm{MCW}$ ceramic grade (minus 325 mesh) $\mathrm{UO}_{2}$ cold pressed to a starting density of 60.0 to 63.5 per cent of theoretical. Final density was 99.5 per cent of theoretical. 


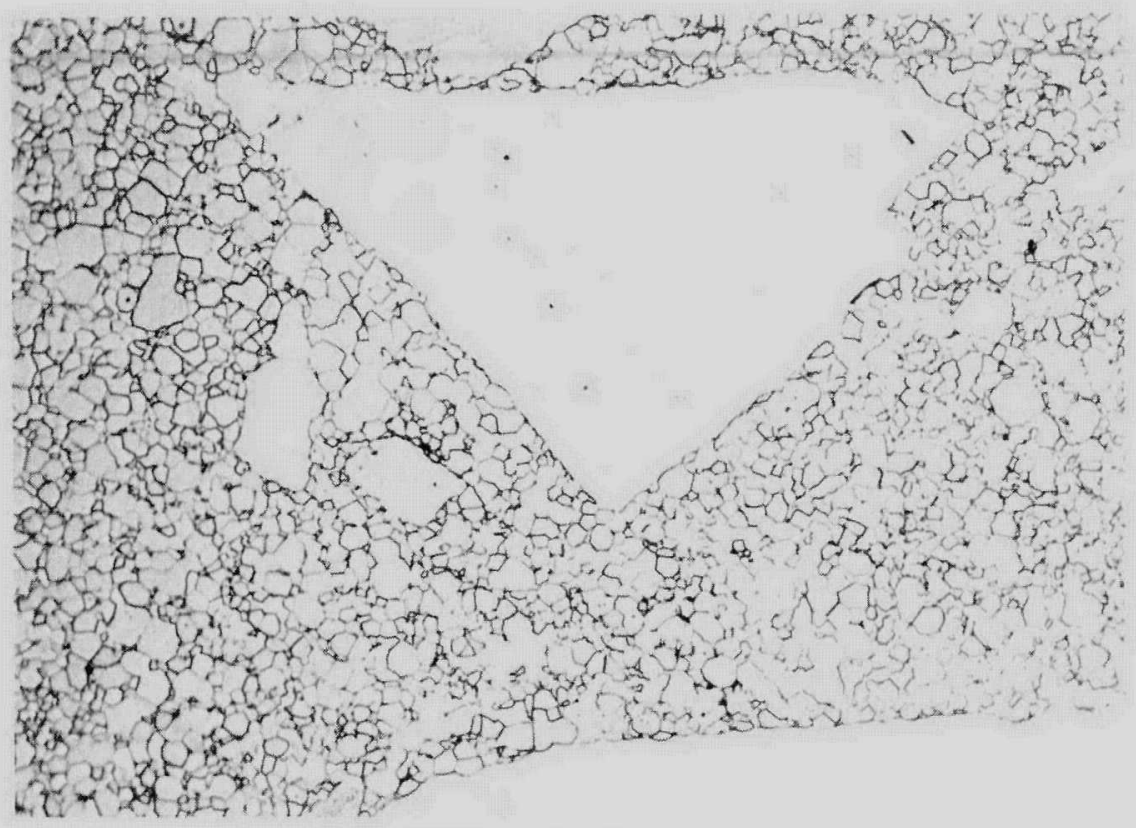

$250 \mathrm{X}$

$\mathrm{H}_{2} \mathrm{O}_{2}-10$ Volume Per Cent $\mathrm{H}_{2} \mathrm{SO}_{4}$ Etch

RM16069

FIGURE 15. MICROSTRUCTURE OF AN AS-RECEIVED CERAMIC BASE UO ${ }_{2}$ MIXTURE CORE GAS-PRESSURE BONDED AT 2100 F FOR 3 HR AT 10,000 PSI

Starting material was a mixture of $25 \mathrm{w} / \mathrm{o}$ Spencer fused (minus 20 mesh) and $75 \mathrm{w} / \mathrm{o} \mathrm{MCW} \mathrm{ceramic}$ grade (minus 325 mesh) $\mathrm{UO}_{2}$ cold pressed to a starting density of 63.0 to 67.1 per cent of theoretical. Final density was 99.5 per cent of theoretical.

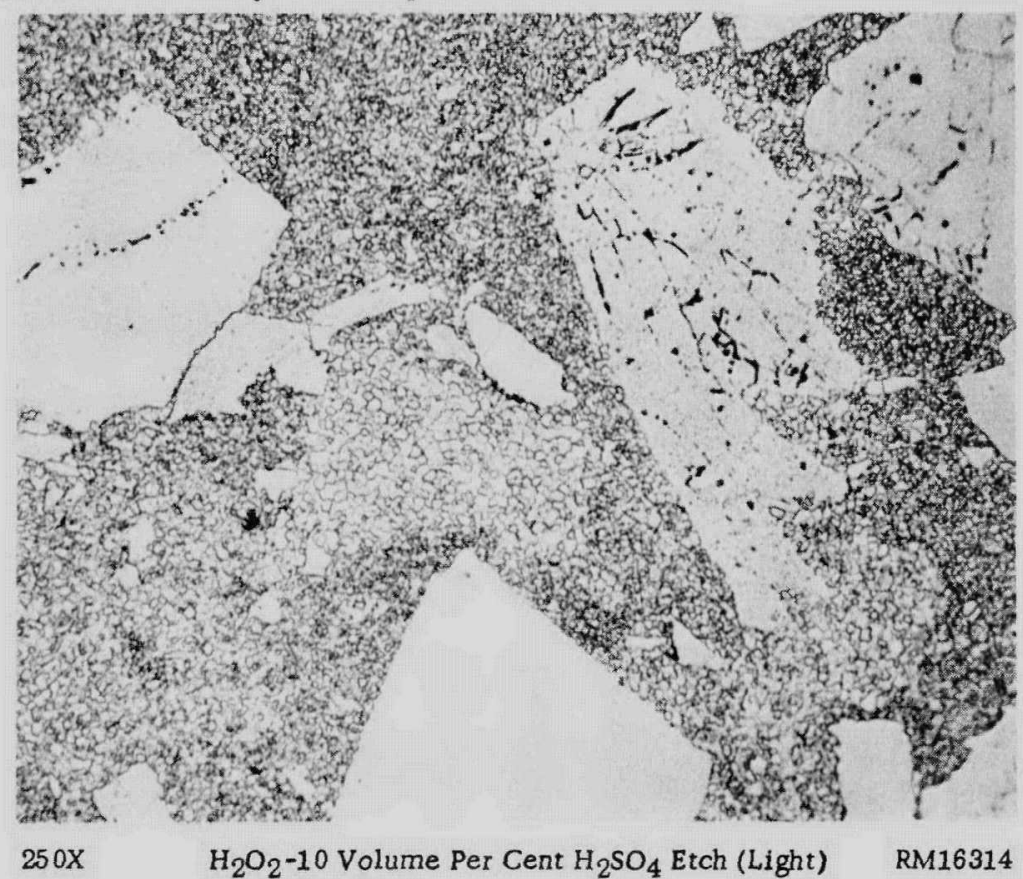

FIGURE 16. MICROSTRUCTURE OF A 50 w/o CERAMIC - 50 w/o FUSED UO ${ }_{2}$ CORE GAS -PRESSURE BONDED AT 2100 F FOR 3 HR AT 10,000 PSI

Starting material was a mixture of $50 \mathrm{w} / \mathrm{o}$ Spencer fused (minus $100 \mathrm{mesh}$ ) and $50 \mathrm{w} / \mathrm{o} \mathrm{MCW}$ ceramic grade (minus 325 mesh) $\mathrm{UO}_{2}$ cold pressed to a starting density of 67.0 to 72.0 per cent of theoretical. Final density was 99.5 per cent of theoretical. 


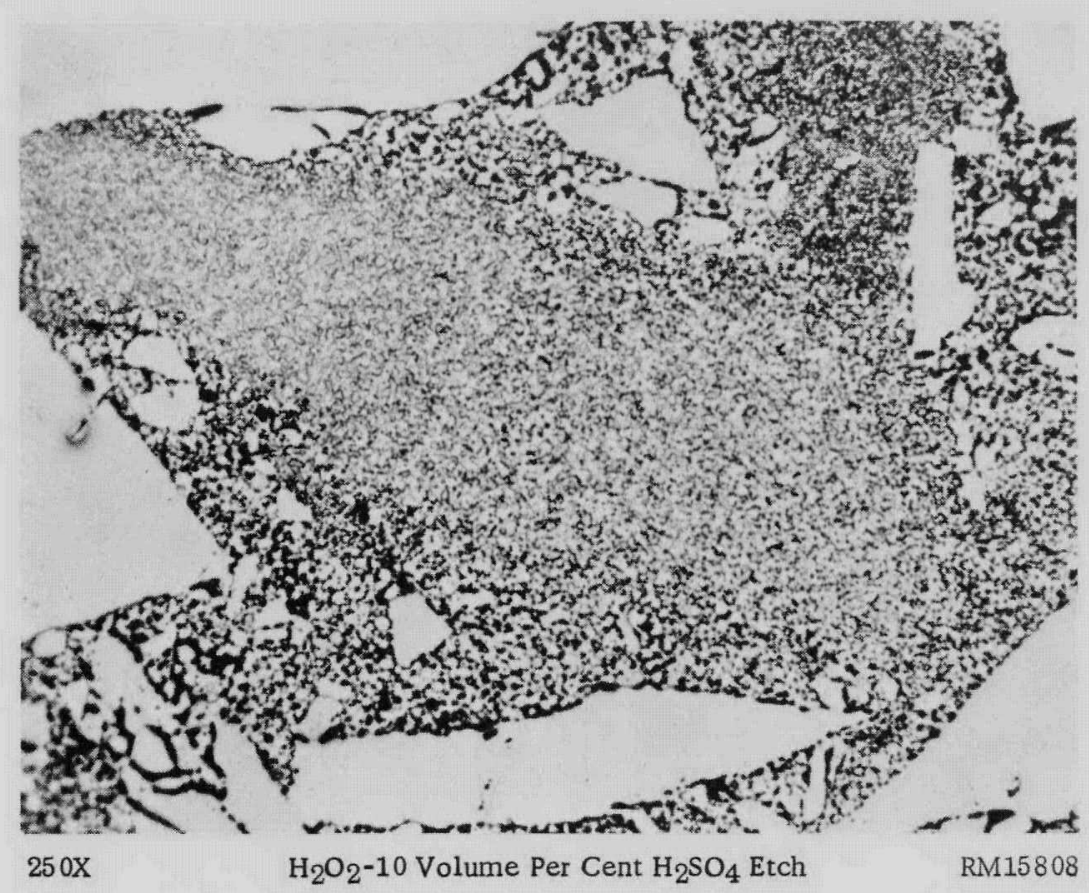

FIGURE 17. MICROSTRUCTURE OF A FUSED BASE UO 2 MIXTURE CORE GAS-PRESSURE BONDED AT 2100 F FOR 3 HR AT 10,000 PSI

Starting material was a mixture of $75 \mathrm{w} / \mathrm{o}$ fused (minus 20 mesh) and $25 \mathrm{w} / \mathrm{o}$ ceramic grade (minus 325 mesh) $\mathrm{UO}_{2}$ cold pressed to a density of 75.0 to

76.7 per cent of theoretical. Final density was 95.8 per cent of theoretical.

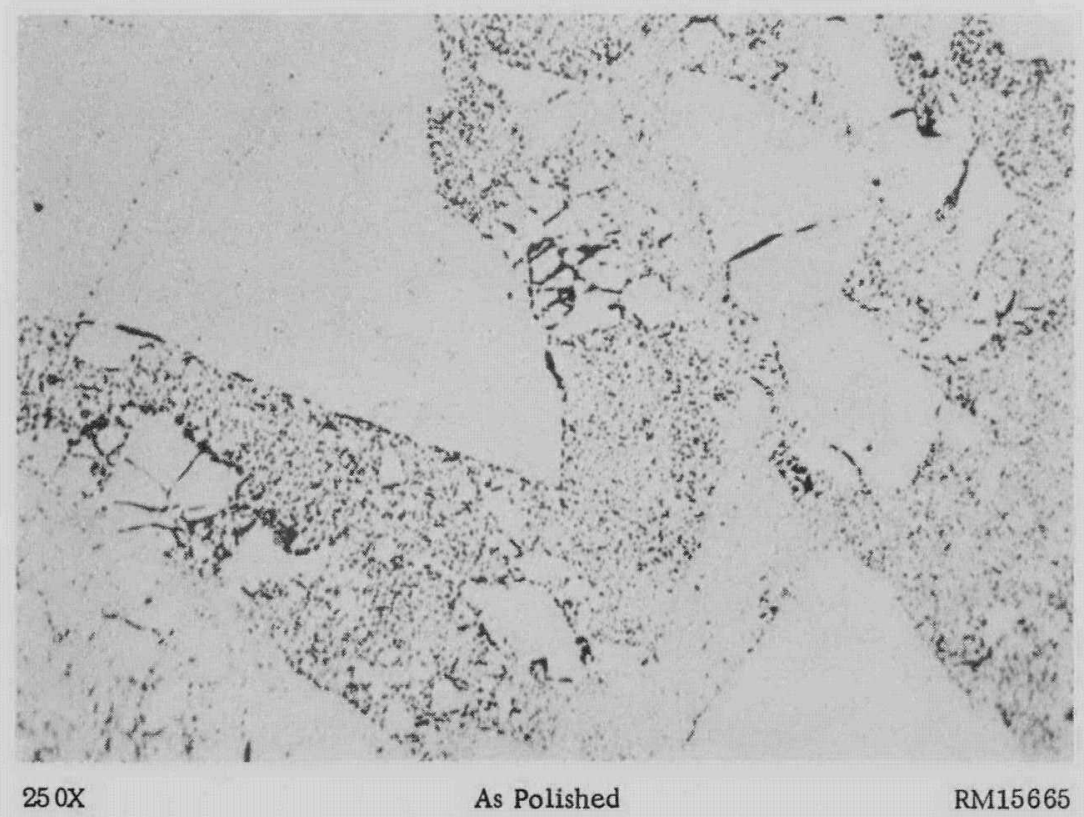

FIGURE 18. MICROSTRUCTURE OF A FUSED BASE UO 2 MIXTURE CORE GAS-PRESSURE BONDED AT 2300 F FOR 3 HR AT 10,000 PSI

Starting material was a mixture of $75 \mathrm{w} / \mathrm{o}$ fused (minus 20 mesh) and $25 \mathrm{w} / \mathrm{o}$ ceramic grade (minus 325 mesh) $\mathrm{UO}_{2}$ cold pressed to a density of 74.4 to 75.2 per cent of theoretical. Final density was 96.7 per cent of theoretical. 


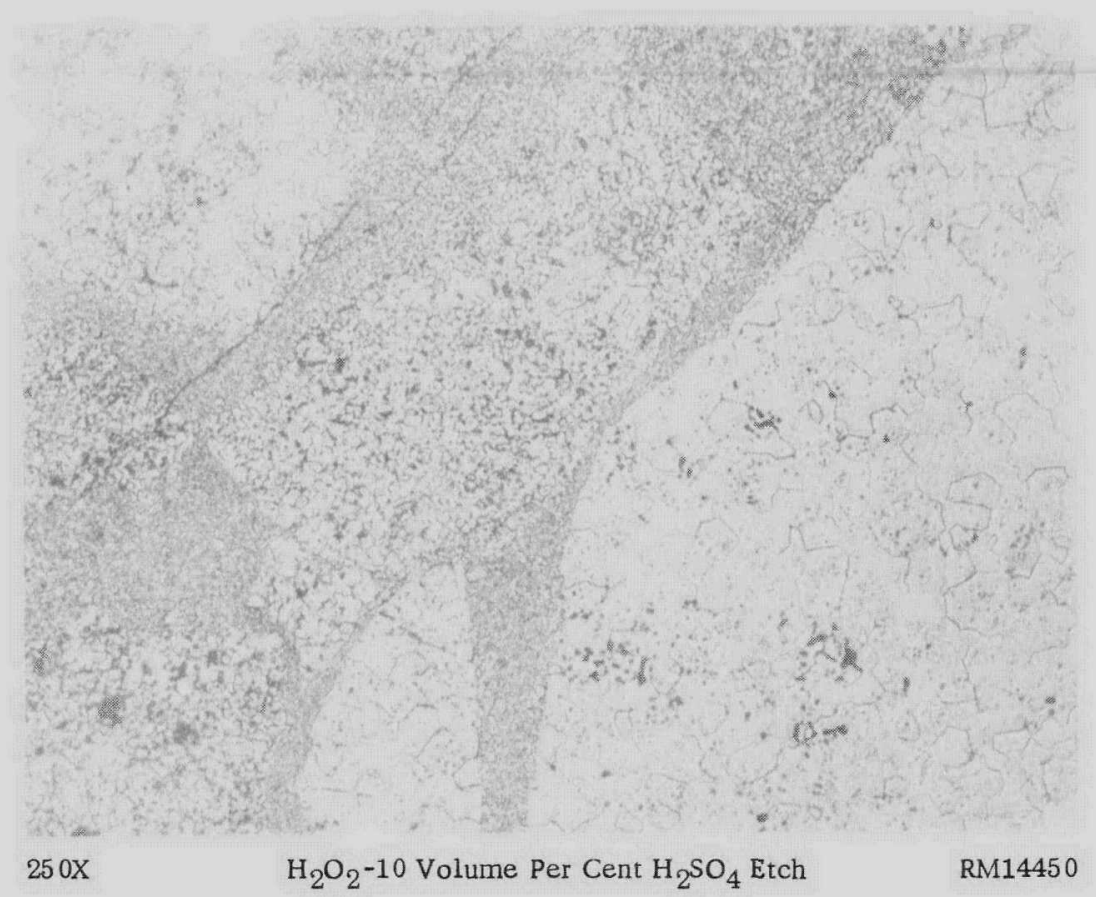

FIGURE 19. MICROSTRUCTURE OF A SPECIAL DENSE BASE UO 2 MIXTURE CORE GAS -PRESSURE BONDED AT 2100 F FOR 3 HR AT 10,000 PSI

Starting material was a mixture of $75 \mathrm{w} / \mathrm{o} \mathrm{MCW}$ special dense minus 20 plus 325 -mesh and $25 \mathrm{w} / \mathrm{o} \mathrm{MCW}$ ceramic grade minus 325 -mesh $\mathrm{UO}_{2}$ cold pressed to a starting density of 75.7 to 78.5 per cent of theoretical. Final density was 91.0 per cent of theoretical.

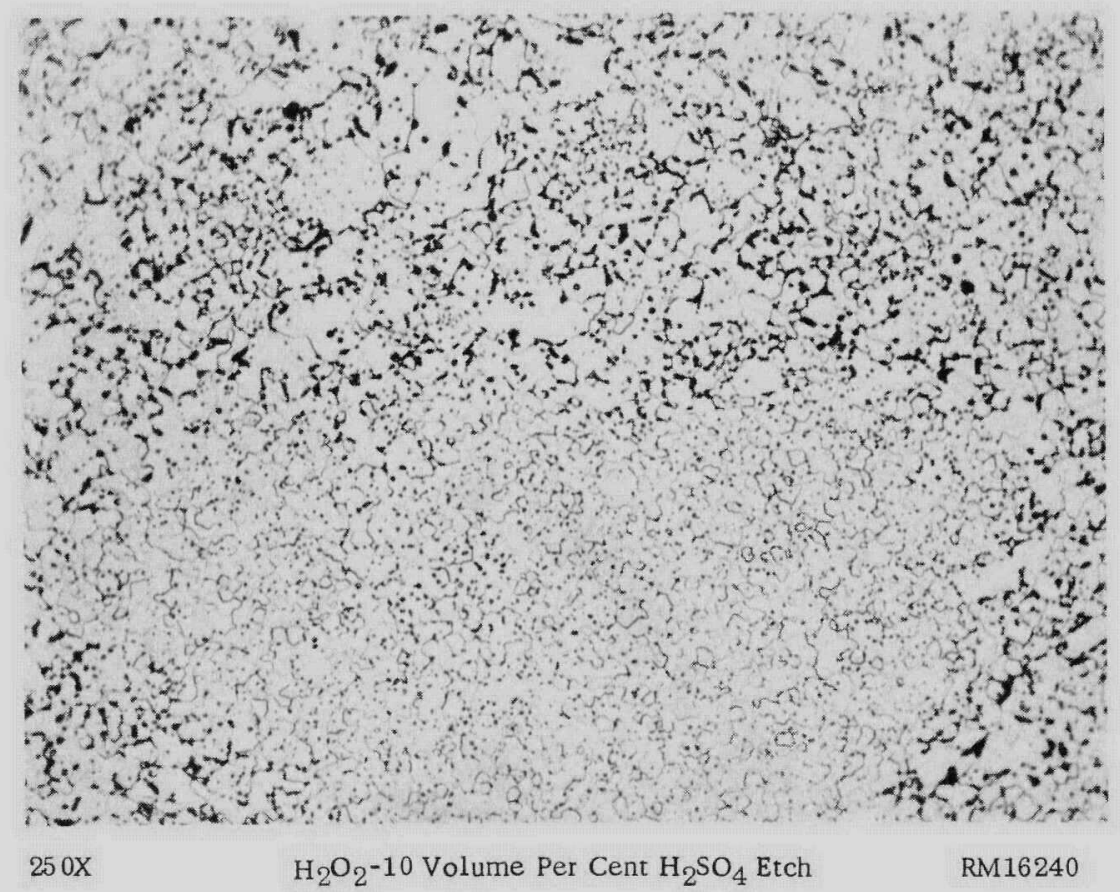

FIGURE 20. MICROSTRUCTURE OF A HIGH -FIRED BASE UO 2 MIXTURE CORE GAS -PRESSURE BONDED AT 2100 F FOR 3 HR AT 10,000 PSI AND RERUN AT 2300 F FOR 3 HR AT 10,000 PSI

Starting pellets were a mixture of $75 \mathrm{w} / \mathrm{o}$ Numec high-fired (minus 325 mesh) and $25 \mathrm{w} / \mathrm{o}$ ceramic grade (minus' 325 mesh) $\mathrm{UO}_{2}$ cold pressed to a starting density of 68.5 per cent of theoretical. Final density was 93.6 per cent of theoretical. 
Of the powders and powder mixtures investigated during this study, the most promising oxide for pressure bonding appears to be the mixture of fused and ceramic grade oxides where the ceramic grade oxide represents from 30 to $60 \mathrm{w} / \mathrm{o}$ of the total. Such an oxide material provides the required characteristics while also representing a low-cost fuel material. Should better means of obtaining high green densities with ceramic grade powder be found, it too would appear to hold promise in this application. With respect to these oxide materials, further studies of vibratory and ultrasonic compaction will be undertaken.

\section{Permeation of Helium at Room Temperature}

An investigation was made of the permeation of helium through several disks of pressure-bonded $\mathrm{UO}_{2}$ at room temperature. These disks were cut from stainless steelclad $\mathrm{UO}_{2}$ rod-type specimens. The results are shown in Table 11 . Also given in this table are the results obtained from two conventionally sintered platelets for comparison purposes.

Experimental procedure consisted of first polishing with 400 -grit silicon carbide paper in an attempt to remove surface cracks, and then sealing the disk into a glass permeation cell. Apiezon $W$ wax was used to seal the sample so that only the center portions of the faces of the disk were exposed to the helium. The permeation cell was sealed into the permeation apparatus and evacuated to less than $10^{-5} \mathrm{~mm}$ of mercury.

Permeation was initiated by admitting helium at the desired pressure (760 to 780 $\mathrm{mm}$ of mercury for most of the experiments) to the upstream side of the permeation cell. This pressure was continually maintained for the duration of the experiment. The downstream side of the cell was continually evacuated in the range 10-5 $\mathrm{mm}$ of mercury by a mercury diffusion pump into a calibrated volume. Thus, the gas permeating the disk, Q, was collected in this volume, and its pressure was periodically measured with a McLeod gage.

Permeation rates were determined on each disk and were found to be linear from the beginning of each experiment $(t=0)$. Permeability constants were then calculated from the relationship

$$
F=P\left(p_{1}-p_{2}\right) A / 1
$$

where

$$
\begin{aligned}
F= & \text { rates of permeation, } Q / \mathrm{t}, \mathrm{ml} \text { per } \mathrm{sec}, \mathrm{STP} \\
\mathrm{P}= & \text { permeability constant, } \mathrm{ml} / \mathrm{sec} \cdot \mathrm{cm} / \mathrm{cm}^{2} \cdot 1 / \mathrm{mm} \\
\mathrm{p}_{1} \mathrm{p}_{2}= & \text { respectively, the pressure on the upstream and downstream faces } \\
& \text { of the disk, } \mathrm{mm} \text { of mercury } \\
\mathrm{A}= & \text { average cross-sectional surface area of the path of permeation, } \mathrm{cm}^{2} \\
1= & \text { thickness of the disk, } \mathrm{cm} .
\end{aligned}
$$


TABLE 11. EXPERIMENTAL DATA AND PERMEABILITY CONSTANTS FOR PERMEATION OF HELIUM THROUGH UO 2 COMPACTS AT ROOM TEMPERAT URE

\begin{tabular}{|c|c|c|c|c|c|c|c|c|}
\hline \multirow[b]{2}{*}{ Sample } & \multirow[b]{2}{*}{ Composition of $\mathrm{UO}_{2}$} & \multirow{2}{*}{$\begin{array}{l}\text { Pressure-Bonding } \\
\text { Temperature }(\mathrm{a}) \\
\mathrm{F}\end{array}$} & \multicolumn{2}{|c|}{ Density } & \multirow[b]{2}{*}{$\begin{array}{c}\text { Thickness, } \\
\text { mm }\end{array}$} & \multirow[b]{2}{*}{$\begin{array}{c}\text { Pressure, } \\
\text { mm of mercury }\end{array}$} & \multirow[b]{2}{*}{$\begin{array}{c}\text { Permeation Rate, } \\
\text { ml per sec }\end{array}$} & \multirow[b]{2}{*}{$\begin{array}{l}\text { Permeability Constant, } \\
\mathrm{ml} / \mathrm{sec} \cdot \mathrm{cm} / \mathrm{cm}^{2} \cdot 1 / \mathrm{mm}\end{array}$} \\
\hline & & & $\mathrm{G}$ per $\mathrm{Cm}^{2}$ & $\begin{array}{l}\text { Per Cent of } \\
\text { Theoretical }\end{array}$ & & & & \\
\hline 1 & $\begin{array}{l}\text { Platelet prepared from MCW } \\
\text { ceramic grade ball milled } \\
\text { to } 10 \mu \text {, cold pressed at } \\
20,000 \text { psi, then sintered } \\
\text { in hydrogen at } 2800 \mathrm{~F} \\
\text { for } 1 \mathrm{hr}\end{array}$ & -- & 9.86 to 10.4 & 90 to 95 & 1.19 & 780 & 5.34 to $6.28 \times 10^{-6(b)}$ & 2.7 to $3.1 \times 10^{-9}$ \\
\hline 2 & PWR sintered platelet & -- & 10.4 & 95.0 & 2.525 & 768 & $6.13 \times 10^{-6}(\mathrm{~b})$ & $7.13 \times 10^{-9}$ \\
\hline 3 & $\begin{array}{l}75 \text { w/o Spencer fused ( }-20 \\
+325 \text { mesh) and } 25 \text { w/o } \\
\text { MCW ceramic grade } \\
\text { ( }-325 \text { mesh) }\end{array}$ & 2100 & 10.12 & 92.6 & 1.75 & 779 & $7.7 \times 10^{-4}$ & $5.5 \times 10^{-6}(\mathrm{c})$ \\
\hline 4 & $\begin{array}{l}75 \text { w/o special dense }(-20 \\
+325 \text { mesh) and } 25 \text { w/o } \\
\text { MCW ceramic grade } \\
\text { ( }-325 \text { mesh) }\end{array}$ & 2100 & 9.02 & 82.4 & 2.17 & 778 & $2.3 \times 10^{-3}$ & $1.6 \times 10^{-6}$ \\
\hline 5 & MCW high fired (-400 mesh) & 2300 & 10.5 & 95.8 & 2.58 & 763 & $1.7 \times 10^{-6^{(b)}}$ & $1.3 \times 10^{-9}$ \\
\hline 6 & $\begin{array}{l}\text { MCW ceramic grade }(-325 \\
\text { mesh) }\end{array}$ & 2100 & 10.8 & 98.5 & 2.75 & 772.5 & $1.06 \times 10^{-4}$ & $9.80 \times 10^{-8^{(c)}}$ \\
\hline 7 & $\begin{array}{l}25 \text { w/o Spencer fused ( }-20 \\
\text { mesh) and } 75 \text { w/o MCW } \\
\text { ceramic grade ( }-325 \text { mesh) }\end{array}$ & 2100 & 10.85 & 99.0 & 2.18 & 769.5 & $5.419 \times 10^{-6^{(b)}}$ & $3.33 \times 10^{-9}$ \\
\hline 8 & $\begin{array}{l}25 \text { w/o Spencer fused ( }-20 \\
\text { mesh) and } 75 \text { w/o MCW } \\
\text { ceramic grade ( }-325 \text { mesh) }\end{array}$ & 2100 & 10.9 & 99.5 & 1.99 & 768.5 & $5.83 \times 10^{-7}(\mathrm{~b})$ & $2.58 \times 10^{-10}$ \\
\hline
\end{tabular}

(a) All samples bonded $3 \mathrm{hr}$ at 10,000 psi.

(b) In range of blank rate for the apparatus.

(c) Disks had macroscopically visible surface crack, which may have traversed the sample thickness. Validity of the permeation constant is questioned. 
Since the pressure on the downstream face of the disk, $p_{2}$, was essentially zero, the equation for the permeability constant becomes

$$
\mathrm{P}=\frac{\mathrm{F} 1}{\mathrm{~A} \mathrm{p}_{1}}
$$

The experimentally determined permeation rates and permeability constants are given in Table 11. Prior to testing it was noted that Samples 3 and 6 had fine visible cracks in their surfaces, indicating that such cracks exist irregularly throughout the disks and result in apparently low permeabilities. No visible cracks were apparent in any of the other samples. The values of the permeability constants for Samples 1, 2, 5,7 , and 8 could not be accurately determined on the apparatus, since the rate of permeation was of the same order, or less than, the blank rate of the apparatus. However, judging from measured blank rates and a permeation experiment in which the permeating helium was collected in the permeation cell for a period of several days, the value of $P$ may be considered to be of the order of $1 \times 10^{-10} \mathrm{ml} /(\mathrm{sec})(\mathrm{cm})(\mathrm{mm})$.

The investigation indicated that the diffusion paths of the helium gas in $\mathrm{UO}_{2}$ above 95 per cent theoretical density, whether it be sintered or gas-pressure bonded for the conditions stated, are of microscopic dimensions. Typical photomicrographs of sections of Samples 2, 4, 5, and 8 are shown in Figure 21. It is interesting to note that the extremely high density sample shown in Figure 21 exhibits intimate contact between the ceramic and fused oxides with the small amount of contained porosity being random in the structure.

\section{Thermal Conductivity}

The thermal conductivity of pressure-bonded uranium dioxide specimens is being measured over the temperature range of 200 to $800 \mathrm{C}$ in order to provide a comparison with the more conventional pressed and sintered oxide. The four specimens selected for this comparison are described in Table 12. These samples were prepared from green-pressed cores of 72.1 to 74.2 per cent theoretical density with a $0.763-$ in. diameter, and were subsequently loaded into a stainless steel tube having a wall thickness of 30 mils. Five such pellets were placed into Specimen 2, while four pellets were contained in the other three specimens. The tubes were pressure bonded at $2100 \mathrm{~F}$ for $3 \mathrm{hr}$ at $10,000 \mathrm{psi}$, then rerun at $2300 \mathrm{~F}$ for $3 \mathrm{hr}$ at 10,000 psi to achieve the density reported in Table 12. After bonding, the cladding was removed from the cores by grinding, and the bulk $\mathrm{UO}_{2}$ was finish ground to a specimen $0.625 \mathrm{in}$. in diameter by 2. 242 in. long, as shown in Figure 22. The specimens were drilled for thermocouples and then electroplated on the ends with copper so that they could be soldered into the assembly required by the measuring apparatus. Figure 23 shows Specimen 4 assembled into the measuring apparatus. In this view the specimen is located in the lower section with the standard immediately above it.

In the pretinning operation, Specimen 3 cracked due to rough handling, and Specimen 2 similarly cracked during subsequent assembly into the measuring apparatus. Specimen 4, however, was prepared, assembled, and measured without incident, thus furnishing the most reliable test data of the series of experiments. Presently Specimen 5 is being measured. 


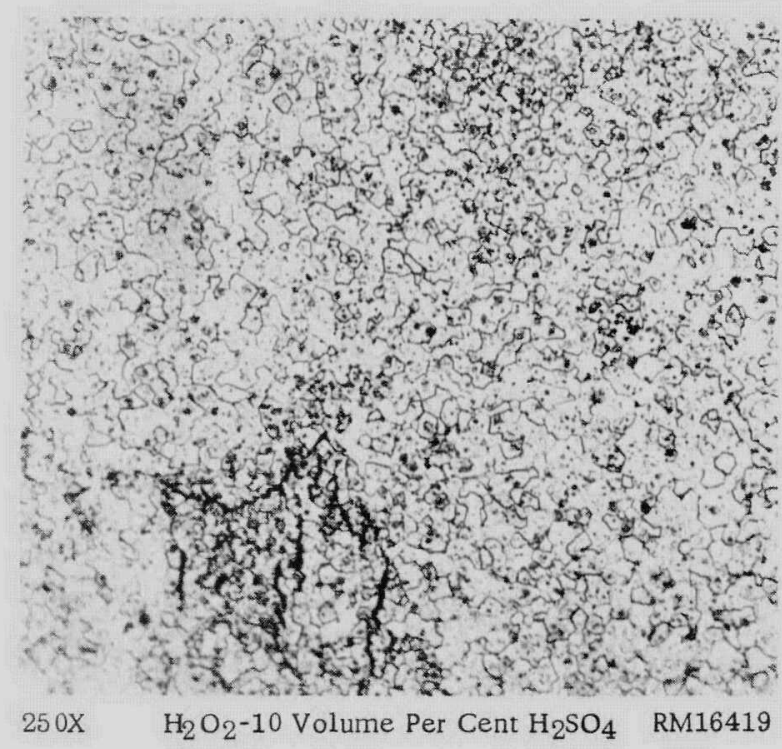

a. Sintered PWR Platelet (Sample 2)

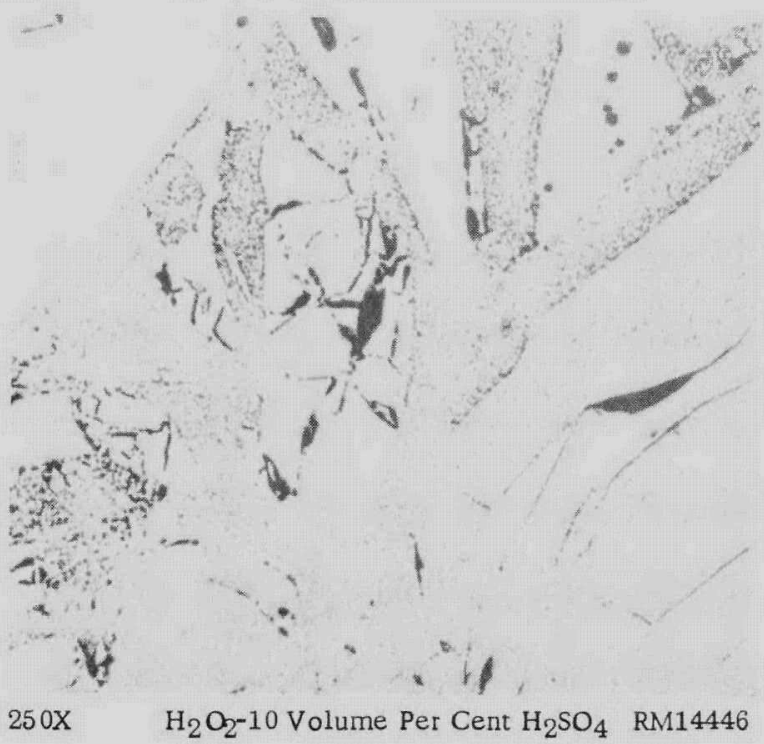

b. $75 \mathrm{w} / \mathrm{o}$ Special Dense-25 w/o MCW Ceramic Grade $\mathrm{UO}_{2}$ Gas-Pressure Bonded to a Density 82.4 Per Cent of Theoretical (Sample 4)

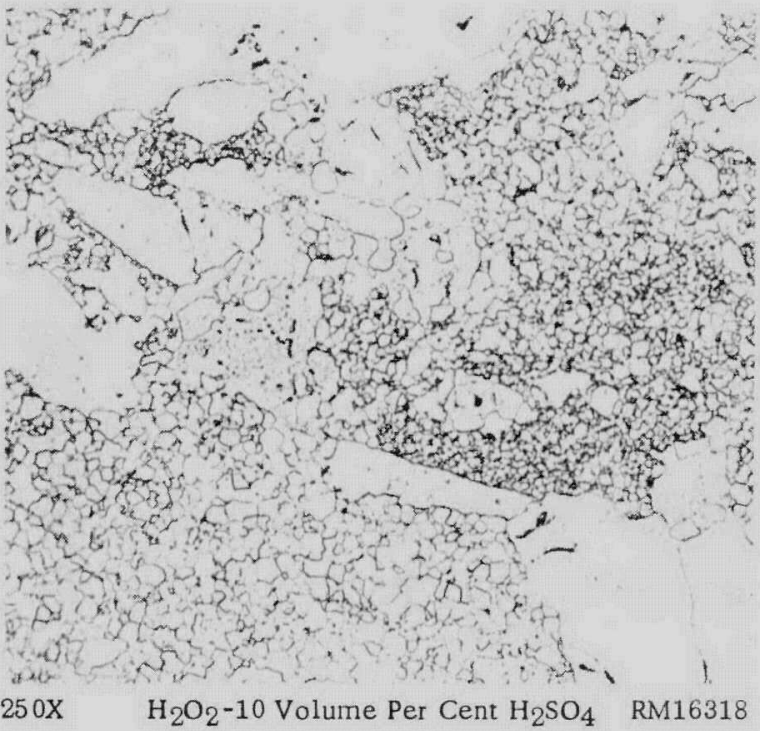

d. $25 \mathrm{w} / \mathrm{o}$ Spencer Fused-75 w/o MCW Ceramic Grade $\mathrm{UO}_{2}$ Gas-Pressure Bonded to a Density 99.5 Per Cent of Theoretical (Sample 8)

FIGURE 21. MICROSTRUCTURES OF SINTERED AND GAS-PRESSURE BONDED UO 2 SAMPLES USED FOR ROOMTEMPERATURE HELIUM-PERMEATION TESTS 
FIGURE 22. MASSIVE GAS-PRESSURE -BONDED UO 2 ROD SPECIMEN USED FOR THERMAL CONDUCTIVITY MEASUREMENTS

This specimen was bonded at $2100 \mathrm{~F}$ for $3 \mathrm{hr}$ at $10,000 \mathrm{psi}$ and rerun at $2300 \mathrm{~F}$ for $3 \mathrm{hr}$ at $10,000 \mathrm{psi}$. It was made from four green-pressed $75 \mathrm{w} / \mathrm{o}$ high-fired-25 w/o ceramic grade $\mathrm{UO}_{2}$ pellets sealed in a Type 304 stainless steel tube. The stainless steel tube was removed by grinding.

FIGURE 23 (Right). ASSEMBLY OF A GAS -PRESSUREBONDED UO 2 SAMPLE IN THE THERMAL-CONDUCTIVITY APPARATUS

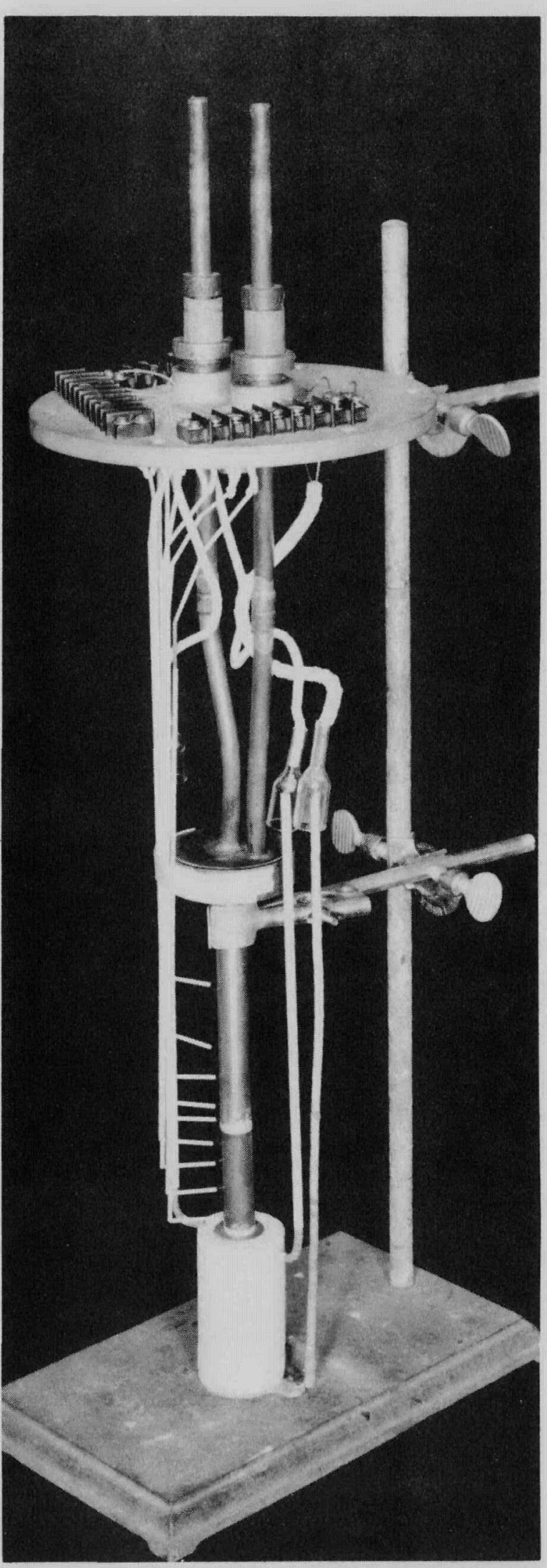

N68877 
TABLE 12. SPECIMEN DETAILS FOR THERMAL-CONDUCTIVITY MEASUREMENTS ON GAS-PRESSURE-BONDED UO ${ }_{2}^{(a)}$

\begin{tabular}{|c|c|c|c|c|c|}
\hline \multirow[b]{2}{*}{ Specimen } & \multirow[b]{2}{*}{ Type of $\mathrm{UO}_{2}$} & \multirow[b]{2}{*}{ Mass, g } & \multicolumn{2}{|c|}{ Density } & \multirow[b]{2}{*}{$\begin{array}{c}\text { Oxygen/Uranium } \\
\text { Ratio } \\
\end{array}$} \\
\hline & & & $\mathrm{G}$ per $\mathrm{Cm}^{3}$ & $\begin{array}{l}\text { Per Cent of } \\
\text { Theoretical } \\
\end{array}$ & \\
\hline 4 & MCW high fired ( -400 mesh) & 113.811 & 10.1 & 92 & 2.01 \\
\hline 2 & MCW high fired ( -400 mesh) & 115.258 & 10.23 & 93 & 2.01 \\
\hline 3 & $75 \mathrm{w} / 0$ special dense and $25 \mathrm{w} / \mathrm{o}$ ceramic grade & 117.388 & 10.41 & 95 & 2.02 \\
\hline 5 & $75 \mathrm{w} / \mathrm{o}$ special dense and $25 \mathrm{w} / \mathrm{o}$ ceramic grade & 117.738 & 10.43 & 95 & 2.02 \\
\hline
\end{tabular}

(a) Pressure bonded $3 \mathrm{hr}$ at $2100 \mathrm{~F}$ at 10,000 psi and then bonded again at $2300 \mathrm{~F}$ for $3 \mathrm{hr}$ at 10,000 psi.

Apparatus and Method

The apparatus and method used in making these thermal-conductivity measurements are essentially the same as the comparative, steady-heat-flow method described by Van Dusen and Shelton. (12) The method, in brief, consists of heating one end of a specimen, measuring the temperature gradient along the specimen, and determining the rate of heat flow through the specimen by means of a metal standard of known thermal conductivity attached to the cold end of the specimen. Radial heat flow into, or away from, the specimen is minimized by thermal radiation shielding and an encircling guard tube in which temperatures are balanced, as nearly as possible, to match those in the specimen and standard at corresponding levels. The thermal radiation shielding used was bubbled alumina, Norton E-163, poured into the annular spaces between the specimen assembly and the guard cylinder. The specimen is protected by a vacuum of approximately $2 \mathrm{x}$ $10^{-5} \mathrm{~mm}$ of mercury during the measurements.

The temperature gradient is measured by thermocouples of calibrated wire which are wedged in holes spaced along the specimen. Similar thermocouples are also placed in the standard to measure the heat flow. Depending upon the specimen length, this permits the calculation of several values of the thermal conductivity for each thermal equilibrium each at a different mean temperature.

Experience has established the relative error between different specimens run in this apparatus to not exceed \pm 2 per cent when the same standard is employed. The absolute error of the thermal-conductivity values is estimated to not exceed \pm 5 per cent, the chief uncertainty being the absolute thermal conductivity of the Type 347 stainless steel, used as the comparative standard.

Results

The observed thermal-conductivity values for Specimen 4 are given in Table 13, while the interpolated values at selected temperatures, read from a smooth curve drawn through the data, are given in Table 14. Values from the literature, adjusted to 100 per cent of theoretical density, are also given for comparison with the observed data. For the adjustment, the conductivity is assumed to be directly proportional to the bulk density. In the repeated measurements at lower temperatures there was no indication of any change in the measuring process. 
TABLE 13. OBSERVED THERMAL CONDUCTIVITY OF UO ${ }_{2}$ SPECIMEN 4

\begin{tabular}{ccc}
\hline $\begin{array}{c}\text { Temperature, } \\
C\end{array}$ & $\begin{array}{c}\text { Thermal Conductivity, } \\
\text { W/(cm)(C) }\end{array}$ & Equilibrium \\
\hline 184 & 0.054 & 1 \\
240 & 0.052 & 1 \\
249 & 0.049 & 3 \\
284 & 0.044 & 6 \\
316 & 0.044 & 2 \\
337 & 0.045 & 3 \\
390 & 0.040 & 6 \\
440 & 0.040 & 2 \\
464 & 0.039 & 4 \\
542 & 0.036 & 5 \\
664 & 0.036 & 4 \\
785 & 0.033 & 5 \\
\hline \hline
\end{tabular}

TABLE 14. THERMAL CONDUCTIVITY OF GAS-PRESSURE-BONDED UO 2

Thermal Conductivity, $w /(\mathrm{cm})(\mathrm{C})$

\begin{tabular}{|c|c|c|c|c|c|c|}
\hline \multirow{3}{*}{$\begin{array}{c}\text { Temperature, } \\
\mathrm{C} \\
\end{array}$} & \multicolumn{6}{|c|}{ Thermal Conductivity, $w /(\mathrm{cm})(\mathrm{C})$} \\
\hline & \multicolumn{2}{|c|}{ Interpolated for Specimen 4} & \multicolumn{4}{|c|}{$\begin{array}{c}\text { Literature Values for } \mathrm{UO}_{2} \text { With a Density } \\
100 \text { Per Cent of Theoretical }\end{array}$} \\
\hline & 92 Per Cent Dense & 100 Per Cent Dense(a) & $\mathrm{BMI}(\mathrm{b})$ & $\mathrm{BMI}(\mathrm{c})$ & Armour(c) & Kingery(d) \\
\hline 100 & 0.066 & 0.072 & 0.077 & 0.084 & - & 0.098 \\
\hline 200 & 0.054 & 0.059 & 0.063 & 0.070 & 0.054 & 0.080 \\
\hline 300 & 0.046 & 0.050 & 0.053 & 0.059 & 0.047 & -- \\
\hline 400 & 0.041 & 0.045 & 0.046 & 0.052 & 0.041 & 0.058 \\
\hline 500 & 0.037 & 0.040 & 0.041 & 0.046 & 0.037 & -- \\
\hline 600 & 0.035 & 0.038 & 0.036 & 0.041 & 0.033 & 0.044 \\
\hline 700 & 0.034 & 0.037 & 0.033 & -- & 0.030 & -- \\
\hline 800 & 0.033 & 0.036 & 0.030 & - & 0.028 & 0.037 \\
\hline
\end{tabular}

(a) Values adjusted linearly to 100 per cent theoretical density.

(b) Reference (13).

(c) Reference (14).

(d) Reference (15). 
The data agree reasonably well with the literature values, as shown in Table 14 . At lower temperature, below $400 \mathrm{C}$, the observed data are in good agreement with other Battelle measurements, determined in another apparatus; however, above $400 \mathrm{C}$ the values appear somewhat high. They cross the other Battelle values and the slope of the curve is higher than reported in the literature. Difficulty was experienced in balancing the corresponding specimen and guard temperatures at the higher temperatures. Below $400 \mathrm{C}$ the usual over-all error of \pm 5 per cent holds, but above $400 \mathrm{C}$ the error is estimated to increase to about \pm 10 per cent. Consequently, the highest observed values are not considered as reliable as at the lower points. The differences could, of course, be real and have resulted from the materials or method of fabrication. Further tests will be performed to help evaluate these results.

\section{EVALUATION OF PRESSURE-BONDED CERMETS}

Uranium dioxide-stainless steel cermets considered in this investigation included compositions with from 60 to 90 volume per cent oxide. Of these materials, it was found that the 80 volume per cent oxide cermet permitted the achievement of high pressurebonded densities in addition to representing a high oxide loading. Densities of greater than 90 per cent of theoretical were generally attained with bonding cycles of $3 \mathrm{hr}$ at $2200 \mathrm{~F}$ and $10,000 \mathrm{psi}$; however, to insure high final densities, the cermets were pressure bonded for $3 \mathrm{hr}$ at $2300 \mathrm{~F}$ and $10,000 \mathrm{psi}$. These bonding conditions represented the optimum combination of parameters studied in the present work.

The examination of structures resulting from the pressure-bonding operation showed that densities of up to 96.5 per cent of theoretical were achieved. Initial experiments with cermets containing Mallinckrodt high-fired oxide produced considerable bonding of the oxide particles, resulting in structures in which the oxide phase was continuous. A typical structure with high-fired oxide is shown in Figure 24. In contrast, the use of spherical oxide yielded desirable structures such as shown in Figure 25. In this case, the stainless steel is present as the continuous phase, thus providing a considerable improvement in the potential thermal conductivity of the composite material.

Bend tests on 74 volume per cent uranium dioxide-stainless steel cermets were performed to establish typical values for modulus of rupture. All tests were accomplished on a 1000-1b Amsler testing machine with the load applied in simple bending through a 1/8-in.-radius steel contact. The results of room-temperature tests with a loading rate of $100 \mathrm{lb}$ per min showed a general increase of modulus with cermet density. Modulus-of-rupture values ranged from 8,770 to 16,700 psi at respective densities of 82. 6 to 92.4 per cent of theoretical. The relationship appeared to be linear with an appreciable scatter of experimental values.

The thermal conductivity of several 80 volume per cent $\mathrm{UO}_{2}$-stainless steel cermets was measured at various temperatures up to approximately $900 \mathrm{C}$. The apparatus and procedure used in these experiments were similar to that described previously for thermal conductivity tests on pressure-bonded uranium dioxide. The experimental results from the cermet tests are listed in Table 15, where it can be seen that there were no significant differences between values for the two types of specimens. Interpolated values for the cermet material are compared with corresponding values for stainless steel and uranium dioxide in Table 16. In this comparison an improvement of thermal conductivit y over that of the oxide is noted at all temperatures, with the difference 


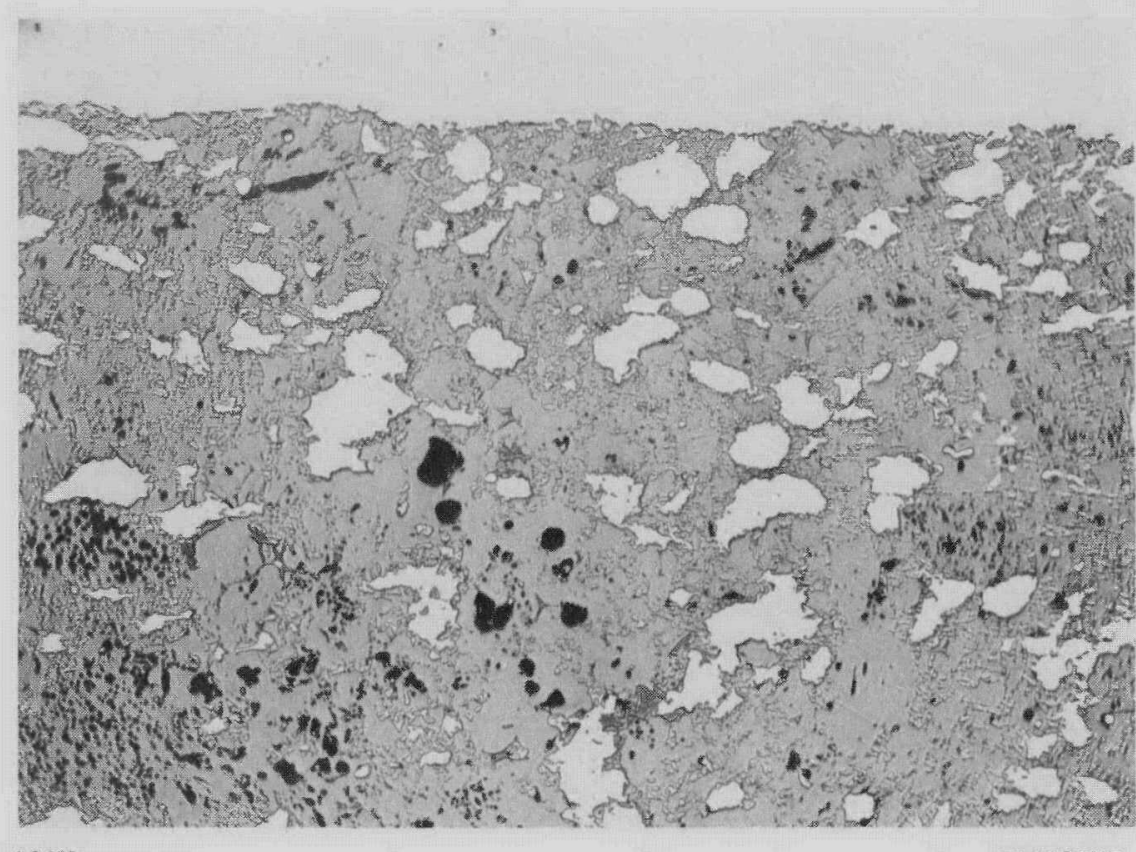

$100 \mathrm{X}$

RM12077

FIGURE 24. 80 VOLUME PER CENT URANIUM DIOXIDE -ST AINLESS STEEL CERMET PRESSURE BONDED FOR 3 HR AT $2300 \mathrm{~F}$ AND 10,000 PSI

Note the bonding of high-fired oxide particles and isolation of stainless steel phase. Final density was 95.5 per cent of theoretical. Oxide particle size was minus 100 plus 140 mesh.

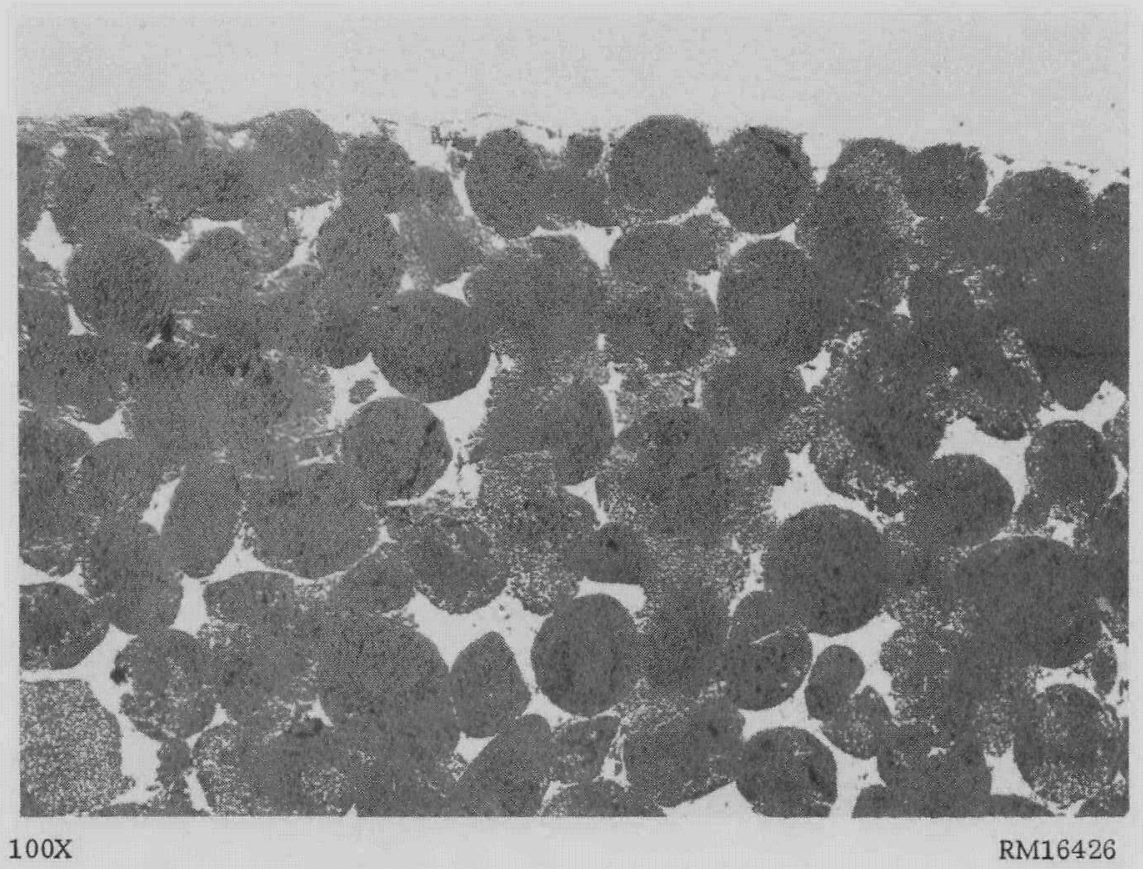

FIGURE 25. 80 VOLUME PER CENT SPHERICAL URANIUM DIOXIDE-ST AINLESS STEEL CERMET PRESSURE BONDED FOR 3 HR AT 2300 F AND 10,000 PSI

Note the continuity of the stainless steel phase. Oxide particle-size range was minus 140 plus 200 mesh. Final density was 96.5 per cent of theoretical. 
TABLE 15. THERMAL-CONDUCTIVITY MEASUREMENTS OF TWO 80 VOLUME PER CENT UO 2 -STAINLESS STEEL CERMETS

\begin{tabular}{|c|c|c|c|c|c|}
\hline \multicolumn{3}{|c|}{ Sample TC -102} & \multicolumn{3}{|c|}{ Sample TC-103 } \\
\hline $\begin{array}{c}\text { Temperature, } \\
\text { C }\end{array}$ & $\begin{array}{c}\text { Thermal } \\
\text { Conductivity, } \\
w /(\mathrm{cm})(\mathrm{C})\end{array}$ & Equilibrium & $\begin{array}{c}\text { Temperature, } \\
\text { C }\end{array}$ & $\begin{array}{c}\text { Thermal } \\
\text { Conductivity, } \\
w /(\mathrm{cm})(\mathrm{C})\end{array}$ & Equilibrium \\
\hline 215 & 0.073 & 1 & 331 & 0.070 & 1 \\
\hline 160 & 0.072 & 1 & 291 & 0.075 & 1 \\
\hline 122 & 0.077 & 1 & 245 & 0.066 & 1 \\
\hline 383 & 0.079 & 2 & 531 & 0.084 & 2 \\
\hline 302 & 0.073 & 2 & 472 & 0.085 & 2 \\
\hline 211 & 0.076 & 2 & 401 & 0.072 & 2 \\
\hline 571 & 0.080 & 3 & 774 & 0.102 & 3 \\
\hline 454 & 0.071 & 3 & 697 & 0.102 & 3 \\
\hline 317 & 0.070 & 3 & 600 & 0.081 & 3 \\
\hline 811 & 0.106 & 4 & 896 & 0.133 & 4 \\
\hline 670 & 0.096 & 4 & 815 & 0.119 & 4 \\
\hline 492 & 0.081 & 4 & 705 & 0.091 & 4 \\
\hline 940 & 0.127 & 5 & 197 & 0.095 & 5 \\
\hline 797 & 0.116 & 5 & 169 & 0.067 & 5 \\
\hline 611 & 0.094 & 5 & -- & -. & -- \\
\hline 259 & 0.067 & 6 & -. & -- & -. \\
\hline 203 & 0.071 & 6 & -. & -. & -. \\
\hline 145 & 0.073 & 6 & -. & - & - \\
\hline
\end{tabular}


increasing with temperature. As expected, the conductivity of the stainless steel is greater than that of the cermet at all temperatures by an approximate factor of 2 . In general, there appears to be little change in this difference factor with increasing temperature. These conductivity comparisons demonstrate the effectiveness of cermets in achieving high thermal conductivity with high uranium loadings.

TABLE 16. THERMAL-CONDUCTIVITY VALUES FOR STAINLESS STEEL, UO ${ }_{2}$, AND UO $_{2}$-STAINLESS CERMETS

\begin{tabular}{|c|c|c|c|}
\hline \multirow[b]{2}{*}{$\begin{array}{c}\text { Temperature, } \\
\text { C }\end{array}$} & \multicolumn{3}{|c|}{ Thermal Conductivity, $w /(\mathrm{cm})(\mathrm{C})$} \\
\hline & Stainless Steel & $\begin{array}{l}80 \text { Volume Per Cent } \\
\text { UO }_{2} \text {-Stainless }(\mathrm{a})\end{array}$ & $\mathrm{UO}_{2}{ }^{(b)}$ \\
\hline 100 & 0.133 & 0.079 & 0.077 \\
\hline 200 & 0.151 & 0.071 & 0.063 \\
\hline 300 & 0.170 & 0.071 & 0.053 \\
\hline 400 & 0.185 & 0.074 & 0.046 \\
\hline 500 & 0.204 & 0.081 & 0.041 \\
\hline 600 & 0.223 & 0.090 & 0.036 \\
\hline 700 & 0.240 & 0.100 & 0.033 \\
\hline 800 & 0.258 & 0.112 & 0.030 \\
\hline 900 & 0.275 & 0.124 & -- \\
\hline 1000 & -. & -. & -. \\
\hline
\end{tabular}

(a) Interpolated values.

(b) Reference (13).

\section{GAS-PRESSURE-BONDED FUEL-ELEMENT DESIGNS}

During Phase II of this program, fabrication of several basic fuel-element geometries, incorporating $\mathrm{UO}_{2}$ ceramic fuel with a Type 304 stainless steel cladding, were undertaken. In general, no specific reactor conceptual design was considered for these fuel-element shapes. The designs were defined first by their application to the gaspressure-bonding process and then by the general considerations of anticipated hydraulic behavior, surface-to-volume ratio, thermal stability, structural stability, and fabricability of the required components. An effort was made to keep the designs flexible, while endeavoring to reduce manufacturing costs and maintain or improve the quality of the final elements.

Fuel-element geometries investigated have consisted of various rod designs, tube designs, a compartmented flat-plate design, and a compartmented flat-plate-assembly design. In many instances modifications of the basic designs have produced unique elements which cannot be fabricated readily by other means. 
$\underline{\text { Rod-Type Elements }}$

The rod-type nuclear fuel elements have received wide interest to date, particularly with respect to the civilian reactors. This basic design, containing uranium dioxide as the fuel material, has demonstrated good reactor performance, as evidenced by the successful operation of Core I of the Pressurized Water Reactor. Such fuel rods represent a mechanically stable configuration which offers wide flexibility as to general reactor design and core geometry. With this type of element it is also possible to contain the greatest amount of uranium dioxide in a given volume, a feature which is particularly advantageous when considering natural oxide as the fuel material. Continued interest in $\mathrm{UO}_{2}$ rod elements is indicated in presently designed and future reactors, where the uranium dioxide fuel is required because of its high-temperature properties and burnup capability.

It appeared that, by the application of the gas-pressure-bonding process, highquality ceramic rod-type elements could be fabricated with possible reductions in manufacturing costs. By the simultaneous densification and cladding of the ceramic fuel by pressure bonding, the cost of preparing high-temperature-sintered and ground pellets would be eliminated.

With respect to cost, the rod-type element produced by pressure bonding is also desirable, in that commercial-tolerance tubing can be used in place of tubing prepared to narrow tolerances. Rod-type designs have been utilized in the major portion of the present study to define the pressure-bonding behavior of various types and mixtures of oxides. The cylindrical rod offered a simple experimental design which readily demonstrated the differences in oxide behavior. In addition to representing an acceptable reactor fuel-element configuration, the rod shape also served to define problem areas characteristic of the simultaneous densification and cladding of uranium dioxide during pressure bonding. In an effort to circumvent processing difficulties associated with the use of low-green-density oxides, a corrugated-rod design was also considered in this investigation. In addition a further refinement of the basic rod element was studied that consisted of a compartment fuel rod. This design demonstrated the unique flexibility of the pressure-bonding process and presents unique capabilities as to reactor-operation performance.

\section{Cylindrical-Rod Design}

The cylindrical-rod design was selected to demonstrate the effects of gas-pressure bonding upon the different oxides, as well as representing an acceptable reactor fuelelement configuration. It was the first design considered in which simultaneous densification and cladding of both green-pressed cores and tamp-packed powders with stainless steel was attempted. Because of its simplicity, this design was therefore used extensively throughout the present program.

Specimens for the densification studies and the initial studies of the rod design consisted of sealed stainless steel tubes with a 20-mil wall, containing several 0.540-in. diameter by $1 / 2$-in. -long $\mathrm{UO}_{2}$ cold-pressed pellets and the necessary stainless steel end plugs, as illustrated in Figure 26. The evaluation of pressure-bonded $\mathrm{UO}_{2}$ was given primarily in this report while this section will concern the evaluation of the design itself. 
In order to prevent excessive cladding deformation during the pressure-bonding operation, a minimum cold-pressed density of 70 per cent of theoretical was arbitrarily selected. However, cores in these first specimens had various green densities, ranging from 55 to 86 per cent of theoretical. These cores were difficult to handle, were friable, and, as a result, many had broken edges. With these specimens, however, many of the problems involved in the simultaneous densification and cladding of ceramic fuels with stainless steel were defined. Immediately encountered were problems of cladding deformation such as indentations, wrinkling or pleating, warpage, cladding-bond contamination, core cracking, cladding thickening, and poor dimensional control.

Problems Associated With Gas-Pressure Bonding. The problems associated with the simultaneous densification and cladding of ceramic fuels by gas-pressure bonding have been defined. During the course of this investigation, parallel studies concerned with the source of the various problem areas and means for their elimination were undertaken. A brief description of their effects and their respective sources are presented as follows.

Indentation Defects. Indentation defects were the direct effect of either cores with fragmented edges or loosely loaded tubes. Figure 27 illustrates this type of defect in a sample in which the edges of the Spencer fused $\mathrm{UO}_{2}$ green-pressed pellets were chipped and the cladding subsequently flowed in to fill these voids. This defect has been overcome for the most part with the preparation of better green-pressed $\mathrm{UO}_{2}$ cores, particularly with more well-defined edges, and with careful loading of the cores into the tubes. Slight indentations up to 1 to 2 mils are common even with the se precautions.

Wrinkling or Pleating. When green-pressed cores are used, the cross section of the rod specimens is initially symmetrical; however, wrinkling or pleating defects have occurred in the resulting pressure-bonded assemblies. This type of defect has been attributed to low-density or unevenly-cold-compacted cores. It results from a mechanical instability during deformation, and appears as a ridge down the side of the specimen, forming somewhat of a tear-drop cross section. Out of the large number of rod-type specimens bonded using cold-pressed cores, only four or five have shown this fault.

Warpage. Warpage of the rod-type specimens has generally been caused by cores with nonparallel ends and by loosely loaded tubes. This defect can also be caused by an uneven heat zone down the length of the specimen or poor loading in the autoclave. By the preparation of better green-pressed cores, careful loading of the autoclaves, and installation of newly designed heaters, rod specimens up to $12 \mathrm{in}$. long have been produced with minimum warpage.

Cladding Thickening. Due to the configuration of the rod-type specimen, measurable increases in the stainless steel tube-wall thickness were obtained during pressure bonding on those specimens that retained their symmetry. Figure 28 illustrates this thickening difference between two specimens. This effect is not evident, however, in those specimens that wrinkle during bonding. Figure 29 shows the change in wall thickness with the change in diameter and density of some representative specimens. These specimens were uniform within 3 mils on the diameter down their length. It will be necessary to consider this effect in the formulation of process specifications for 


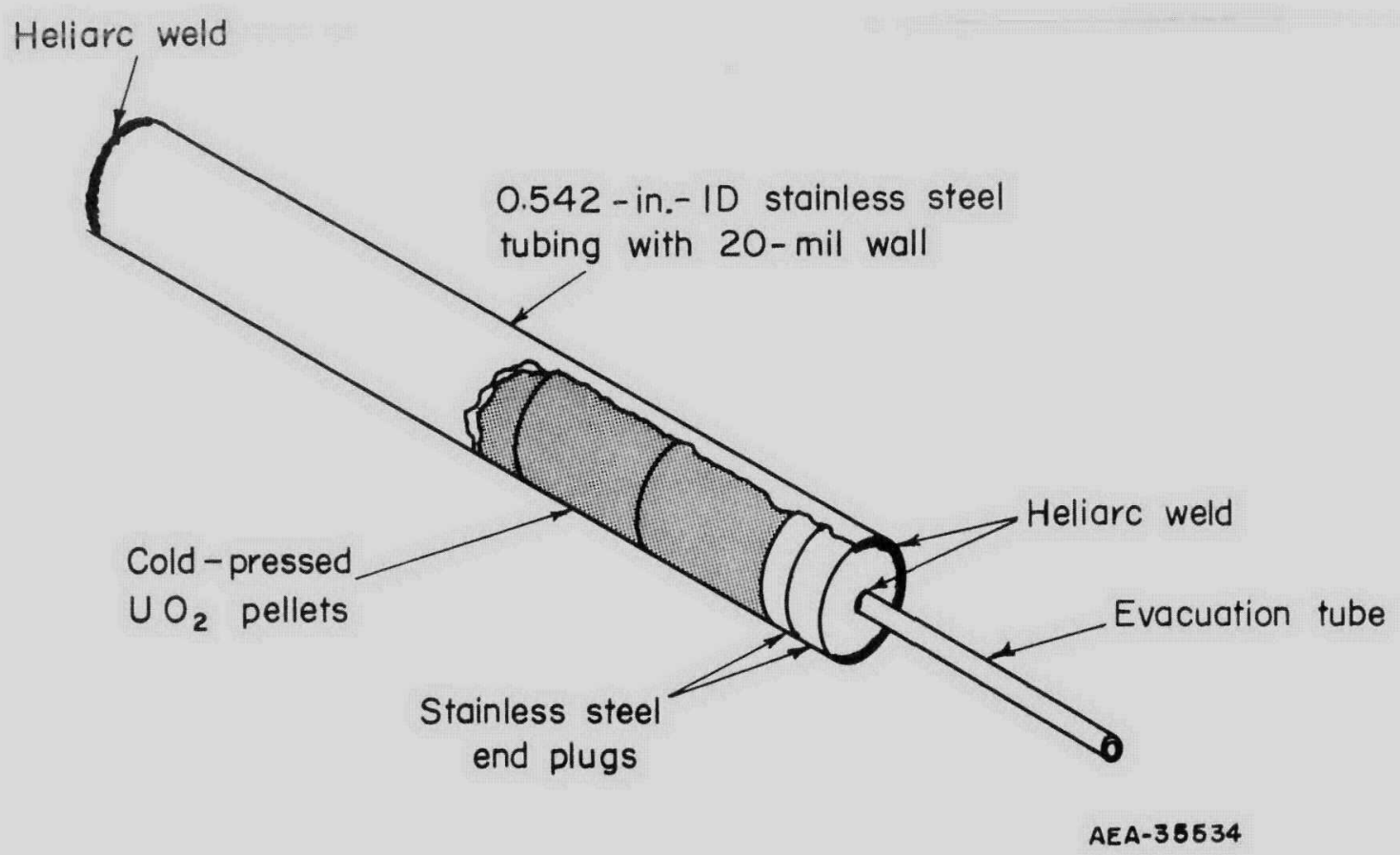

FIGURE 26. DRAWING OF THE ASSEMBLY OF COMPONENTS FOR A CYLINDRICAL-ROD SPECIMEN This type of specimen was used to demonstrate the effects of gas-pressure bonding upon different oxides.

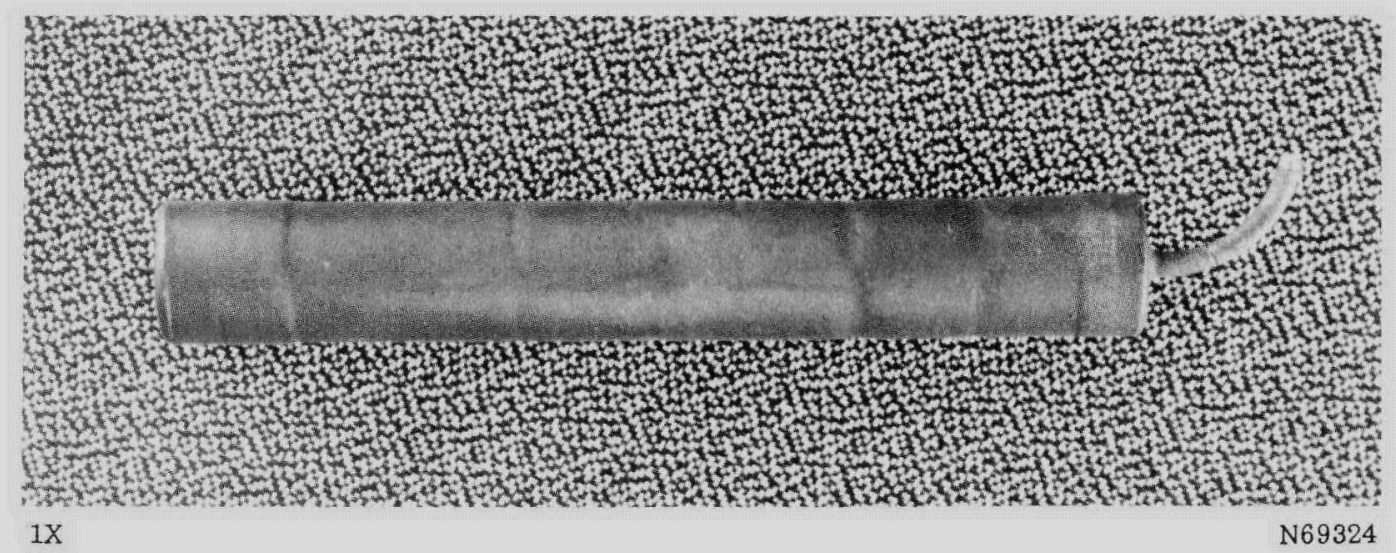

FIGURE 27. GAS -PRESSURE-BONDED CYLINDRICAL-ROD SPECIMEN SHOWING THE INDENTATION DEFECT The tube contained Spencer fused $\mathrm{UO}_{2}$ cold-pressed pellets and was bonded at $2100 \mathrm{~F}$ for $3 \mathrm{hr}$ at 10,000 psi. 


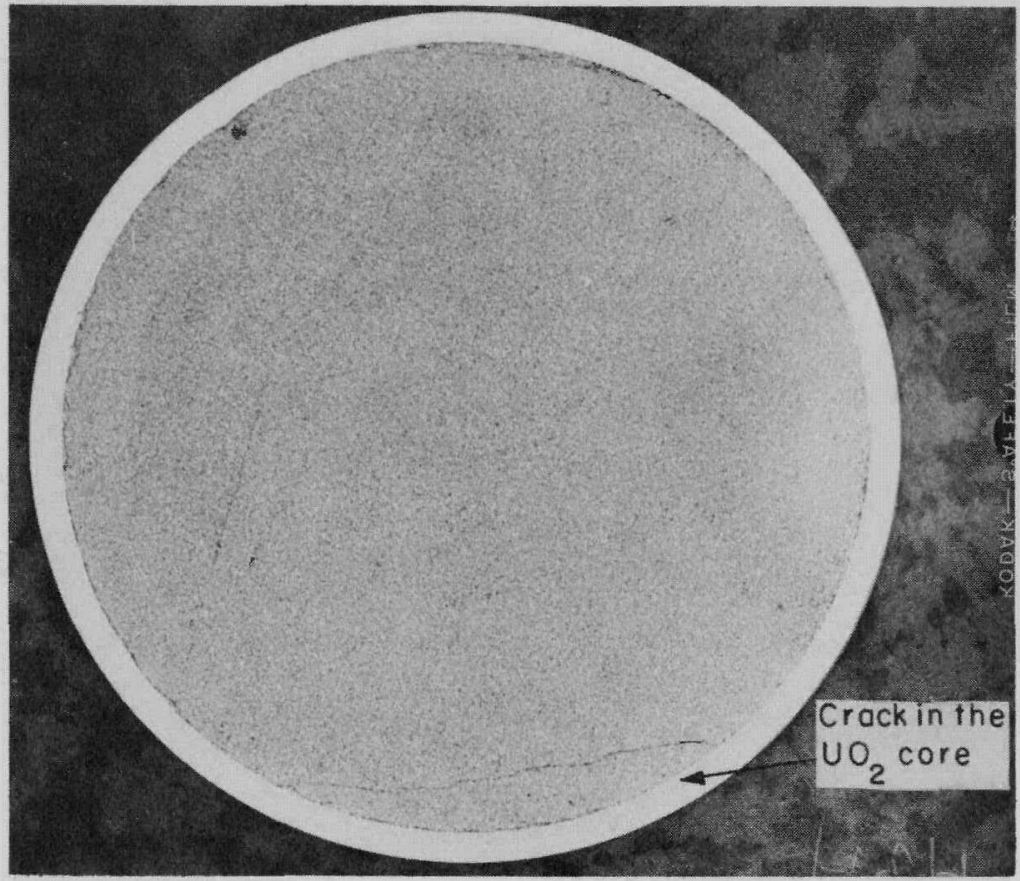

$6 \mathrm{X}$

RM16562

a. Fused Minus $325-\mathrm{Mesh} \mathrm{UO}_{2}$ Core Clad With Type 304 Stainless Steel

The specimen was bonded at $2100 \mathrm{~F}$ for $3 \mathrm{hr}$ at 10,000 psi to a density of 92.2 per cent of theoretical. The wall thickness is 0.0206 to 0.0219 in.

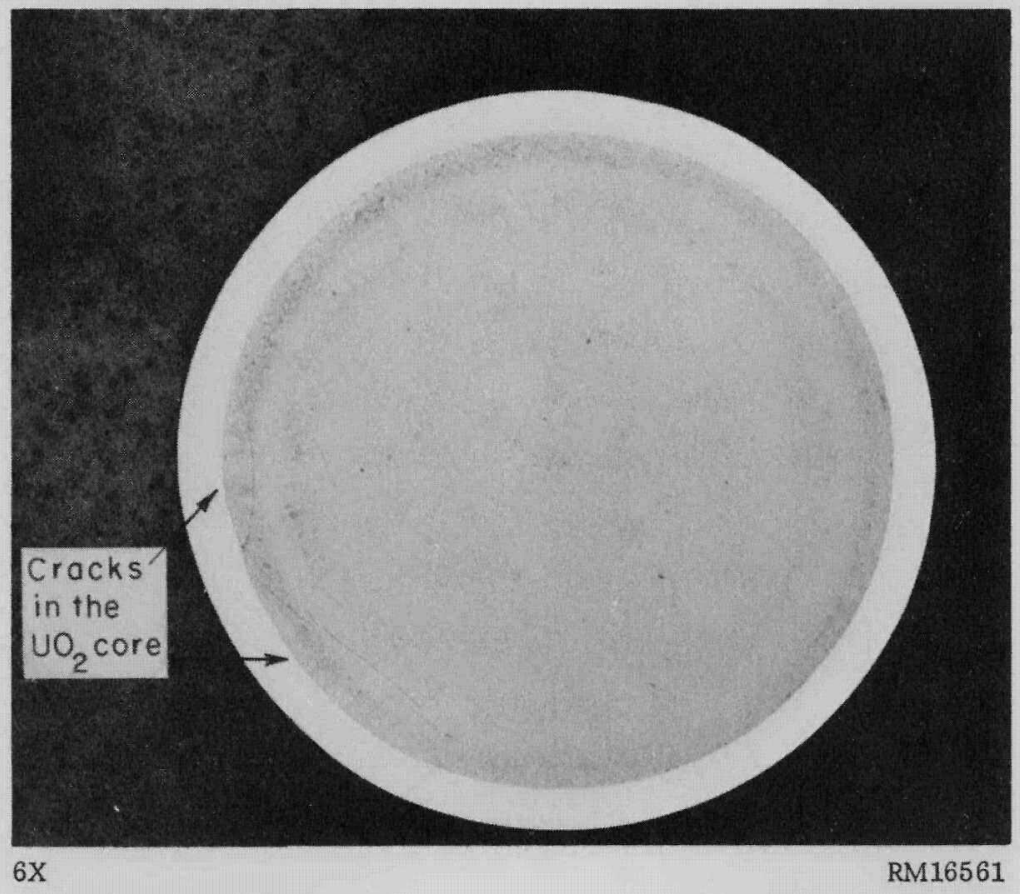

b. As-Received Ceramic UO 2 Core Clad With Type 304 Stainless Steel

The specimen was bonded at $2100 \mathrm{~F}$ for $3 \mathrm{hr}$ at $10,000 \mathrm{psi}$ to a density of 98.5 per cent of theoretical. The wall thickness is 0.0275 to 0.0279 in.

FIGURE 28. CROSS-SECTIONAL VIEWS OF GAS-PRESSURE-BONDED CYLINDRICAL-ROD ELEMENTS REVEALING THE DIFFERENCE IN WALL THICKENING

The cracks shown in these cores are not uncommon in this type of element. 
Wall Thickness, in

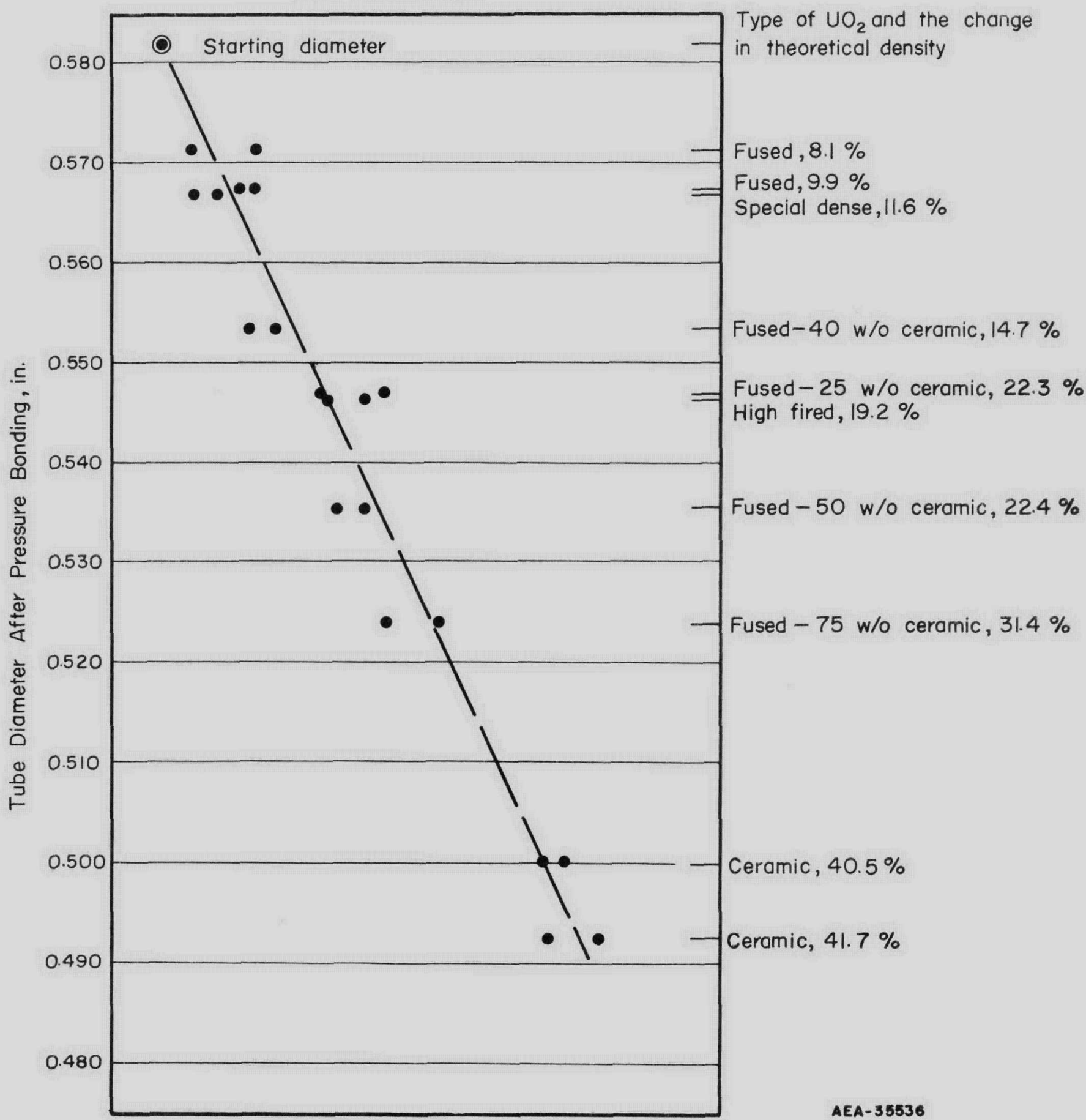

FIGURE 29. WALL-THICKNESS MEASUREMENTS MADE ON TYPE 304 STAINLESS STEEL TUBING AFTER PRESSURE BONDING 
rod-type elements in order that the required cladding thickness will be achieved in the final bonded elements.

Bond Contamination. It was observed during metallographic examination of these specimens that contamination of the stainless steel bond interfaces occurred when the cores were dewaxed by the standard procedure. During heating, while the binder is being volatilized and the system is under vacuum, the powder fines tend to locate in the bond interfaces of the stainless steel end plugs and cladding. The use of different binders, methods of their removal, and the use of cores dewaxed prior to cladding are still being investigated.

Core Cracking. Metallographic examination of the cross section of these rod specimens revealed some cracking of the pressure-bonded cores. Generally these cores are sound, as shown in Figure 30; however, cracking, as illustrated in Figure 28, is not uncommon. With the green-pressed cores there is a good mechanical bonding of the cladding to the high-density core, and with the differences in thermal expansion some minor cracking is expected. Generally these cracks appear through the core next to the cladding, extending from one-fourth to one-half the circumference of the core material. Cracking as it appears in Figure 31 has been observed in a few specimens. These have always been very-high-density cores containing better than $50 \mathrm{w} / 0$ ceramic grade $\mathrm{UO}_{2}$ and generally have been cores that were rebonded or bonded at temperatures above $2100 \mathrm{~F}$. It should be pointed out that during pressure bonding the green-pressed cores in most cases bond to each other, forming a solid core from the pellets.

Dimensional Control. Meeting set dimensional tolerances down the length of the rod-type specimen utilizing green-pressed cores has been a major problem. This has been mainly due to the nonuniformity of the cores produced to date. Several control sets of specimens, in which cores were produced from the same powder mixtures under the same conditions, have been bonded at the same time with good results as to the duplication of their final diameter. Where sintered high-density cores were employed, excellent dimensional tolerances were achieved during the pressure-bonding operation. This was also true when $\mathrm{UO}_{2}$ cores, as pressed and dewaxed with a theoretical density of 78.0 per cent and produced by Mallinckrodt Nuclear Corporation, were pressure bonded in tubes having an inside diameter of $0.318 \mathrm{in}$. with a wall thickness of $10 \mathrm{mils}$. The four tubes were pressure bonded to densities of between 95.0 and 97.2 per cent of theoretical. They remained symmetrical within $0.5 \mathrm{mil}$, and the diameters measured down each tube did not vary more than $0.5 \mathrm{mil}$. One of these specimens is shown in Figure 32.

Preparation of more uniform duplicate pellets will for the most part overcome this problem, as has been observed with specimens recently pressure bonded. To help improve dimensional control and minimize other problem areas, the minimum greenpressed density of the starting ceramic pellets was raised to a more realistic value of 75 per cent of theoretical. 


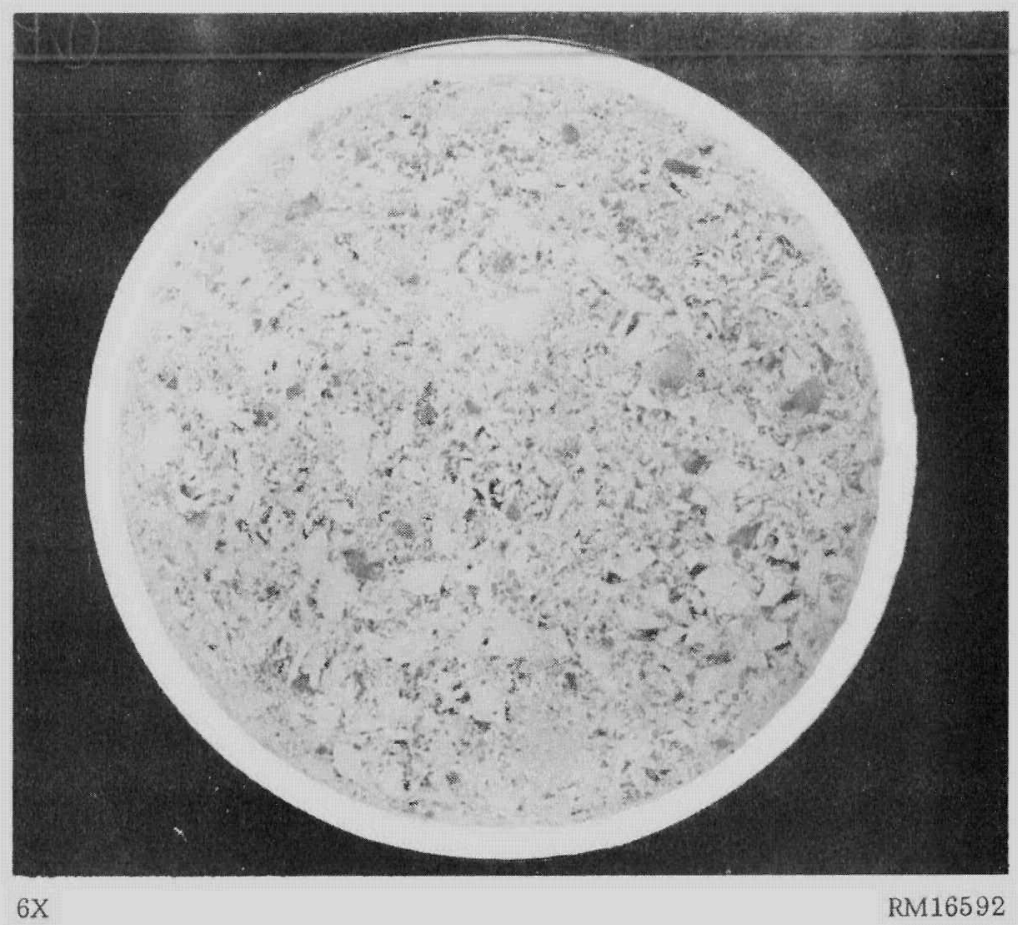

a. A Mixture of $70 \mathrm{w} / 0$ Fused (Minus $20 \mathrm{Mesh}$ ) and $30 \mathrm{~W} / \mathrm{o}$ Ceramic (Minus $325 \mathrm{Mesh}$ ) UO 2 Clad With Type 304 Stainless Steel

This specimen was bonded at $2100 \mathrm{~F}$ for $3 \mathrm{hr}$ at $10,000 \mathrm{psi}$ to a density of 97.8 per cent of theoretical.

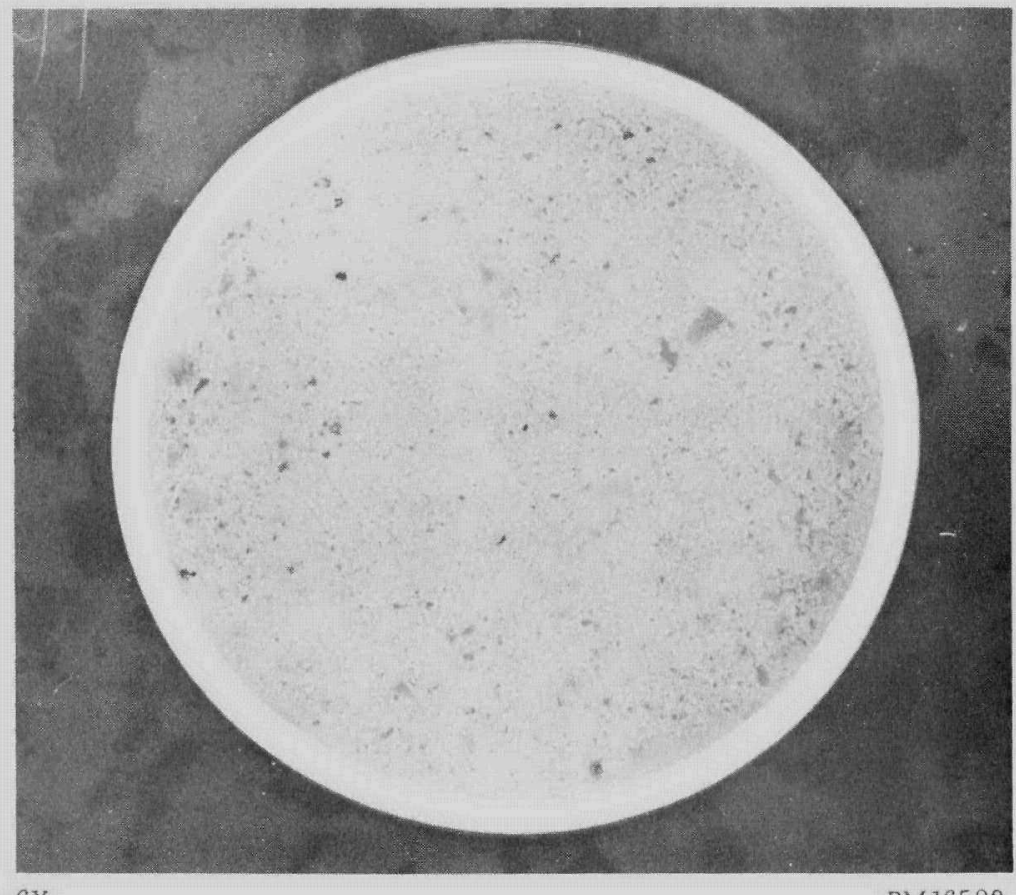

b. A Mixture of $50 \mathrm{w} / \mathrm{o}$ Fused (Minus 200 Mesh) and $50 \mathrm{w} / \mathrm{o}$ Ceramic (Minus 325 Mesh) $\mathrm{UO}_{2}$ Clad With Type 304 Stainless Steel This specimen was bonded at $2100 \mathrm{~F}$ for $3 \mathrm{hr}$ at $10,000 \mathrm{psi}$ to a density of 95.0 per cent of theoretical.

FIGURE 30. CROSS-SECTIONAL VIEWS OF GAS-PRESSURE-BONDED CY LINDRICAL-ROD ELEMENTS REVEALING THE SOUND $\mathrm{UO}_{2}$ CORES WITH ST AINLESS STEEL CLADDING 


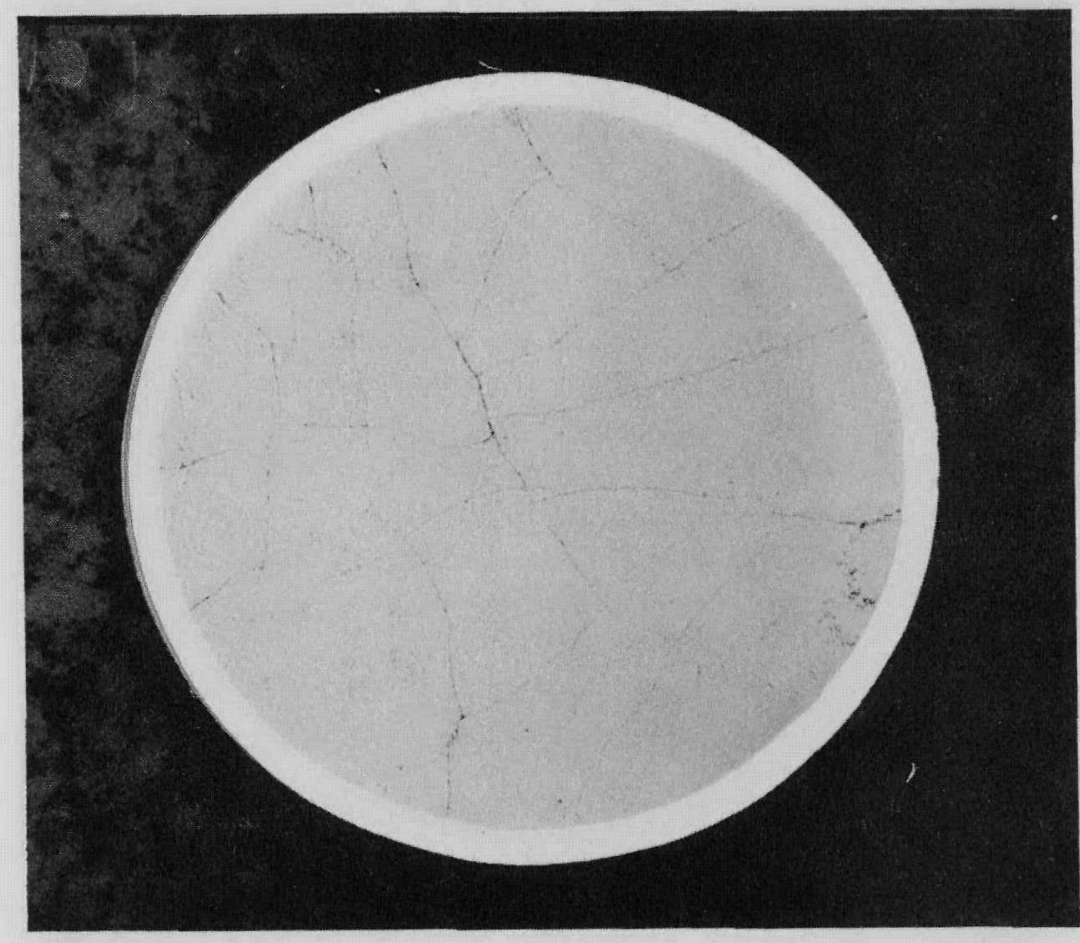

$6 \mathrm{X}$

RM16565

FIGURE 31. CROSS-SECTIONAL VIEW OF A GAS-PRESSURE-BONDED CYLINDRICAL-ROD ELEMENT REVEALING THE MOST SEVERE CRACKING OF THE UO ${ }_{2}$ CORE OBSERVED IN THIS STUDY

The $\mathrm{UO}_{2}$ core contains a mixture of $50 \mathrm{w} / \mathrm{o}$ fused (minus 20 mesh) and $50 \mathrm{w} / \mathrm{o}$ ceramic (minus 325 mesh) $\mathrm{UO}_{2}$ pressure bonded at a temperature of $2300 \mathrm{~F}$ for $3 \mathrm{hr}$ at $10,000 \mathrm{psi}$ to a density of 99.5 per cent of theoretical. 
Effect of Compaction Method on Element Uniformity. In general it appears feasible to produce cylindrical-rod-type fuel elements incorporating green-pressed ceramic pellets by the gas-pressure-bonding process. Such rods attain a high core density, from 95 to 99.5 per cent of theoretical, retain their symmetry, and have fairly good dimensional tolerance. The pellets bond together during the cycle, and good mechanical bonds are obtained with the cladding. In an effort to reduce the costs of producing the gaspressure-bonded cylindrical-rod element and eliminate the use of binders, a method of tamp packing the powders directly into the stainless steel tubes, as described previously, was investigated. Densities of approximately 70 per cent of theoretical and greater were achieved with only fused and special dense oxides. The initial specimens of this type were 0.490 -in. -ID tubes with a 10-mil wall thickness filled with a $\mathrm{UO}_{2}$ powder mixture of $75 \mathrm{w} / 0 \mathrm{MCW}$ special dense (minus $325 \mathrm{mesh}$ ) and $25 \mathrm{w} / \mathrm{o} \mathrm{MCW} \mathrm{ceramic} \mathrm{grade} \mathrm{(minus}$ 325 mesh) tamp-packed to a density ranging between 64 to 70 per cent of theoretical. The rods were pressure bonded at $2100 \mathrm{~F}$ for $3 \mathrm{hr}$ at $10,000 \mathrm{psi}$, and in each case warpage and wrinkling or pleating of the stainless steel cladding occurred, as illustrated in Figure 33. An interesting observation was made of the cross section of the tamp-packed rod specimens used in the study of oxide-stoichiometry changes during gas-pressure bonding. All powders were tamp packed in 0.540-in. -ID stainless steel tubes 4 in. long with 20-mil-thick walls. As shown in Figure 34, all the specimens wrinkled or pleated to an extent depending upon the amount of densification change that occurred during the pressure-bonding operation. The interesting part of this study from the elementconfiguration standpoint is the duplication of cross sections for each type of oxide used.

Wrinkling or pleating of the cylindrical-rod-type element using tamp-packed oxide was of particular concern since this loading technique offered a significant cost advantage. To endeavor to overcome this problem it appeared feasible that a heavy-walled cylinder containing the rod specimen during pressure bonding, but being plastic enough at bonding temperature to allow densification, would restrain nonuniform deformation of the stainless steel tube and thus maintain symmetry. Figure 35 illustrates the design of the specimens used in this investigation. Ti-Namel, an enameling grade of mild steel, was selected as the outer cylinder material. Two specimens of this type were pressure bonded at $2100 \mathrm{~F}$ for $3 \mathrm{hr}$ at $10,000 \mathrm{psi}$. One tube, PB-66, contained a mixture of $50 \mathrm{w} / 0$ fused (minus $325 \mathrm{mesh}$ ) and $50 \mathrm{w} / 0$ ceramic (as received) $\mathrm{UO}_{2}$ tamp packed to a density of 35.0 per cent of theoretical while the other, PB-67, contained 100 per cent fused (as received) tamp packed to a density of 68.7 per cent of theoretical. The stainless steel tubes were inserted into the Ti-Namel cylinders, which were then welded, evacuated, and sealed. After pressure bonding, the Ti-Namel was removed by pickling in a 50-50 aqueous nitric acid solution. The rods, as shown in Figure 36, retained their symmetry better than any previously bonded rod-type specimen containing tamp-packed powders; however, the surfaces were rough, and PB-66 was somewhat elliptical in shape, measuring an average of $0.380 \mathrm{in}$. across the minor diameter and $0.420 \mathrm{in}$. across the major diameter. The final densities for PB-66 and PB-67 were 95.0 and 92,4 per cent of theoretical, respectively. The results with these and the other cylindrical-rod specimens containing tamp-packed powders did not prove encouraging enough for further study. It was felt that only by special designs could tamp-packed powders be used in rod-type configurations. In this respect, present efforts concern the investigation of vibratory and ultrasonic packing techniques, which, it is anticipated, will provide a more uniform density and, subsequently, a more uniform deformation on pressure bonding. 


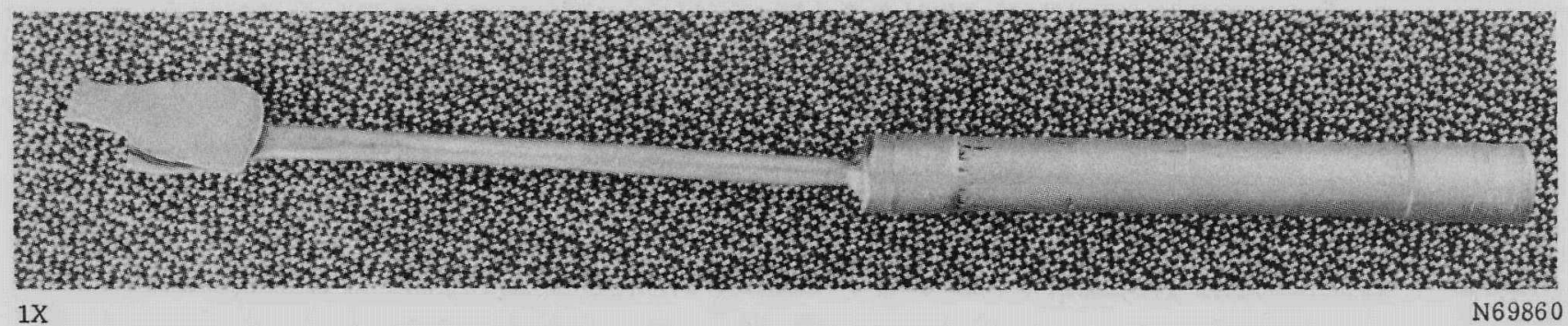

FIGURE 32. GAS-PRESSURE -BONDED CYLINDRICAL-ROD FUEL ELEMENT EMPLOYING CERAMIC UO 2 CORES THAT WERE PRESSED AND DEW AXED BY A PARTIAL SINTER

This stainless-clad specimen was bonded at $2100 \mathrm{~F}$ for $3 \mathrm{hr}$ at $10,000 \mathrm{psi}$ to a core density of 97.2 per cent of theoretical.

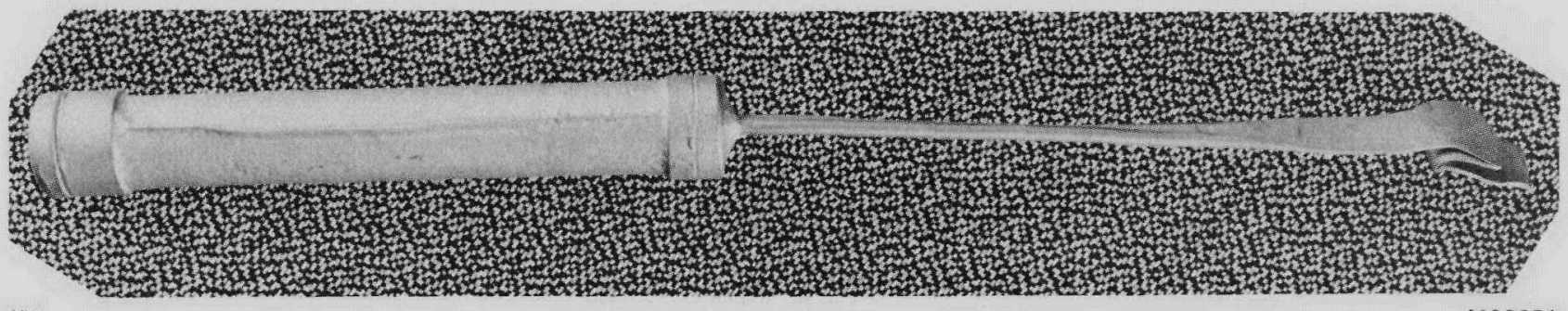

FIGURE 33. CYLINDRICAL-ROD SPECIMEN UTILIZING A TAMP-PACKED UO 2 CORE

This specimen was pressure bonded at $2100 \mathrm{~F}$ for $3 \mathrm{hr}$ at $10,000 \mathrm{psi}$. It displays the wrinkling or pleating effect that occurred with all specimens specimens of this type. 


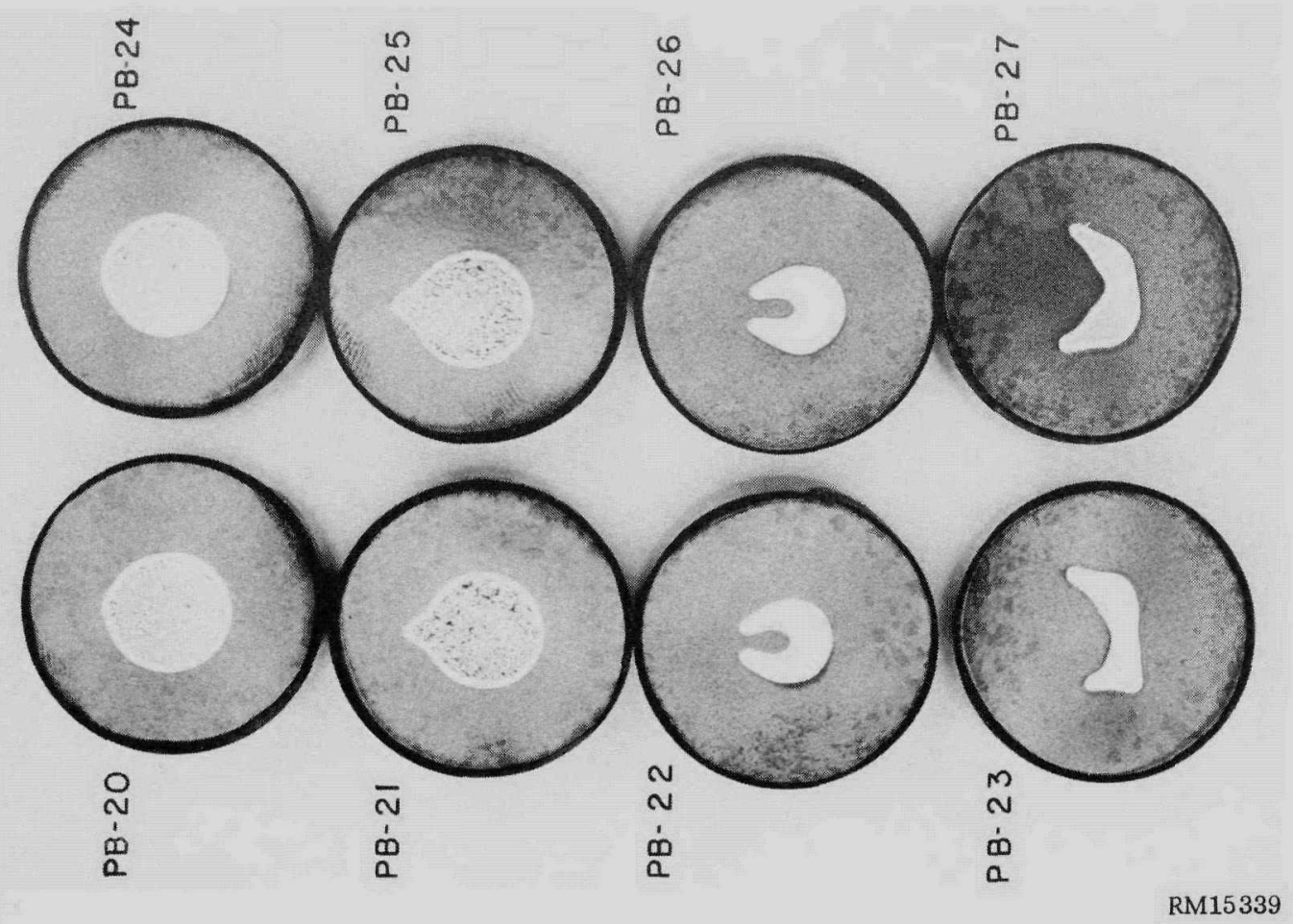

FIGURE 34. CROSS SECTIONS OF ROD-TY PE SPECIMENS UTILIZING TAMP-PACKED UO ${ }_{2}$ CORES EMPLOYED FOR A STUDY OF STOICHIOMETRY CHANGE DURING PRESSURE BONDING

\begin{tabular}{|c|c|c|}
\hline Tube & Type of $\mathrm{UO}_{2}$ Powder (a) & $\begin{array}{c}\text { Approximate Density As Tamp Packed, } \\
\text { per cent of theoretical }\end{array}$ \\
\hline PB -20 & MCW special dense & 78.0 \\
\hline $\mathrm{PB}-21$ & Spencer fused & 70.0 \\
\hline PB -22 & MCW ceramic & 19.6 \\
\hline $\mathrm{PB}-23$ & MCW ceramic & 19.6 \\
\hline PB -24 & MCW special dense & 78.0 \\
\hline PB -25 & Spencer fused & 70.0 \\
\hline PB -26 & MCW ceramic & 19.6 \\
\hline PB -27 & MCW ceramic & 19.6 \\
\hline
\end{tabular}

$\frac{\frac{\text { Bonding Conditions }(\mathrm{b})}{\text { Time, hr }}}{4} \frac{\text { Temp, F }}{2100} \quad \frac{\begin{array}{l}\text { Pressure Bonded Density, } \\ \text { per cent of theoretical }\end{array}}{87.0}$

$\begin{array}{ll}4 & 2100 \\ 4 & 2100 \\ 3 & 2200 \\ 4 & 2100 \\ 4 & 2100 \\ 4 & 2100 \\ 3 & 2200\end{array}$

87.0
98.5
98.5
85.7
89.0
93.1
99.4

(a) Carbowax 6000-MEOH binder employed in all specimens.

(b) All specimens bonded at 10,000 psi. 


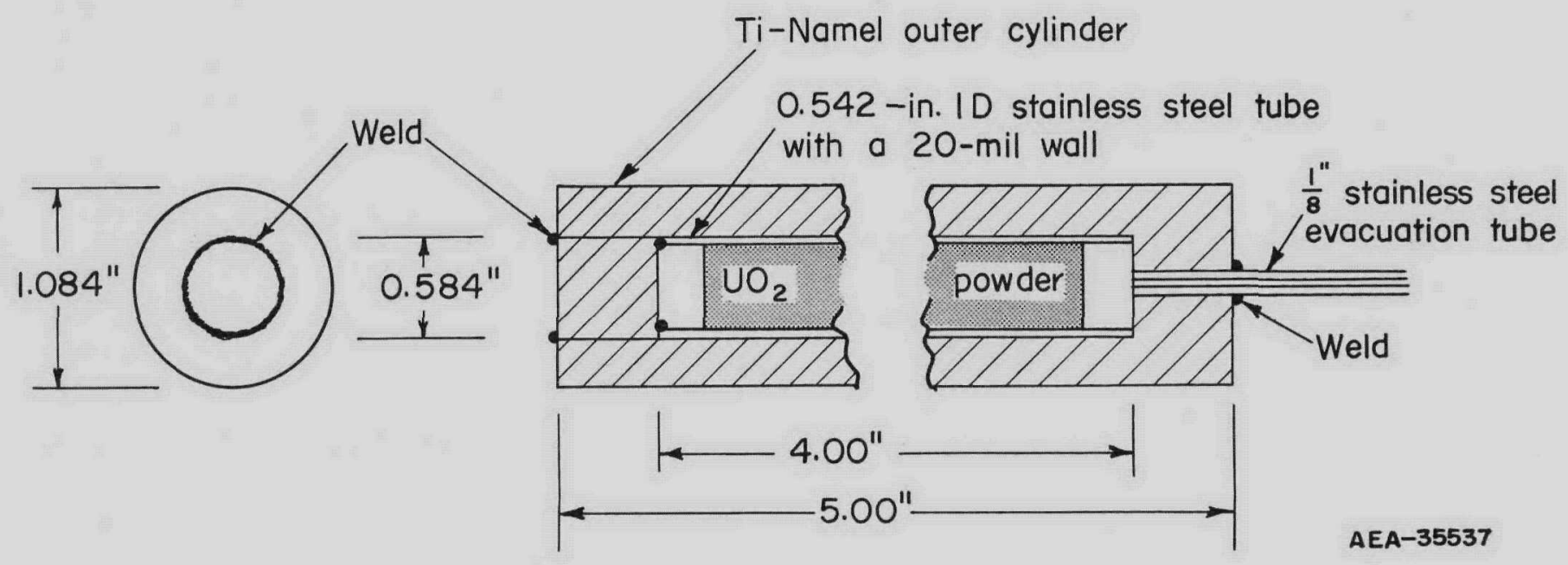

FIGURE 35. DRAWING OF THE ASSEMBLY OF COMPONENTS FOR A CYLINDRICAL-ROD SPECIMEN WITH A RESTRAINING CYLINDER OF MILD STEEL 
Design Modifications. Due to the deformation of the core and cladding in rod elements, it became evident that the solid end plugs would necessitate the use of pressed stainless steel powder plugs if uniform rods were to be produced. With this technique it should then be possible to section the final rod through the densified stainless steel powder ends, yielding rods uniform down their entire length. Three exploratory tubes measuring $0.542 \mathrm{in}$. in ID with $20 \mathrm{mil}$ walls and containing Type $304 \mathrm{~L}$ stainless steel powdered cores were pressure bonded at $2100 \mathrm{~F}$ for $3 \mathrm{hr}$ at $10,000 \mathrm{psi}$. The stainless steel cores were prepared by cold pressing at $50 \mathrm{tsi}$ and sintering in hydrogen for $2 \mathrm{hr}$ at 1800,2000 , and $2200 \mathrm{~F}$, giving densities of 78,82 , and 88 per cent of theoretical, respectively. The densities of these cores after pressure bonding were $97.4,97.6$, and 97.6 per cent of theoretical, respectively, with Figure 37 showing a typical section of the stainless steel cladding and core. These results indicated that the use of pressed stainless steel powdered cores as end plugs in the rod-type element was feasible. Further studies are being conducted to match the final movement and deformation of these end spacers to that of green-pressed $\mathrm{UO}_{2}$ cores to achieve uniform rod diameters.

Preliminary Requirements for a Stable Cylindrical-Rod Configuration. The gaspressure bonding of the cylindrical-rod element containing ceramic cores appears to be a feasible method of fabrication with the proper selection of oxide and compaction methods.

The preliminary requirements for making a stable rod of this configuration appear to be as follows:

(1) Green-pressed pellets or uniformly packed oxide having a uniform minimum theoretical density of 75 per cent would be required.

(2) The pellets must be of a fairly uniform size, having close diametral tolerances.

(3) The ends of the pellets must be parallel and have well-defined edges.

(4) Stainless steel powdered cores of a density selected to produce the required deformation must be used as end spacers.

(5) The pellets must be dewaxed or contain a binder that can be subsequently removed without contaminating the stainless steel interfaces.

These elements have been prepared using a mixture of low-cost ceramic grade $\mathrm{UO}_{2}$ and fused as-received $\mathrm{UO}_{2}$ to densities of between 95 to 99.5 per cent of theoretical. The pellets have good bonds between each other and good mechanical bonds to the stainless steel cladding. Further work is needed to overcome some of the problems referred to in this section before final specifications can be established for fabricating this type of element.

\section{Corrugated-Rod Design}

The results obtained when tamp-packed $\mathrm{UO}_{2}$ powders were employed in the cylindrical-rod elements measuring approximately 6 in. long indicated that a different rod configuration would be required to minimize densification effects. The corrugated-rod 


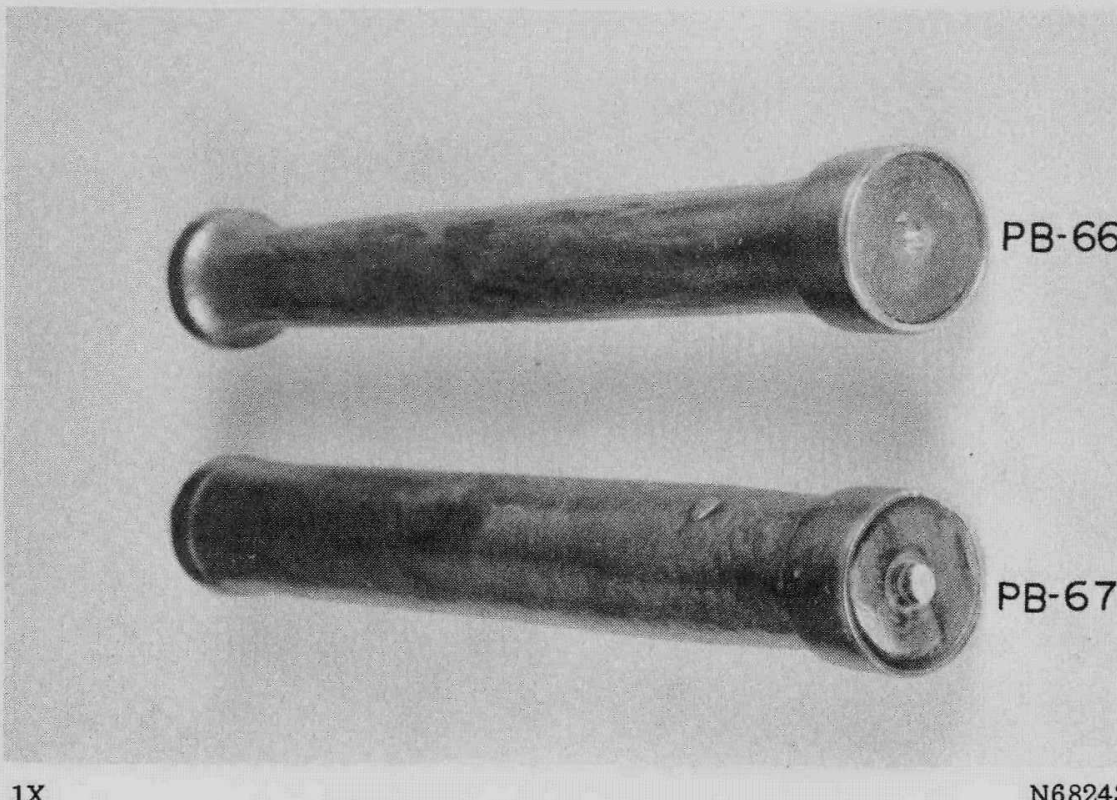

FIGURE 36. GAS-PRESSURE-BONDED ROD-TY PE SPECIMENS UTILIZING T AMP-PACKED $\mathrm{UO}_{2}$ POWDERS AND TI-NAMEL RESTRAINING JACKETS

These specimens were pressure bonded at $2100 \mathrm{~F}$ for $3 \mathrm{hr}$ at $10,000 \mathrm{psi}$. The Ti-Namel jackets were pickled away in a 50-50 aqueous nitric acid solution. Specimen PB -66 is a mixture of $50 \mathrm{w} / \mathrm{o}$ fused (minus $325 \mathrm{mesh}$ ) and $50 \mathrm{w} / \mathrm{o}$ ceramic (minus 325 mesh) $\mathrm{UO}_{2}$. The final density was 95.0 per cent of theoretical. Specimen PB -67 is $100 \mathrm{w} / \mathrm{o}$ fused (minus 20 mesh) $\mathrm{UO}_{2}$. The final density was 92.4 per cent of theoretical.

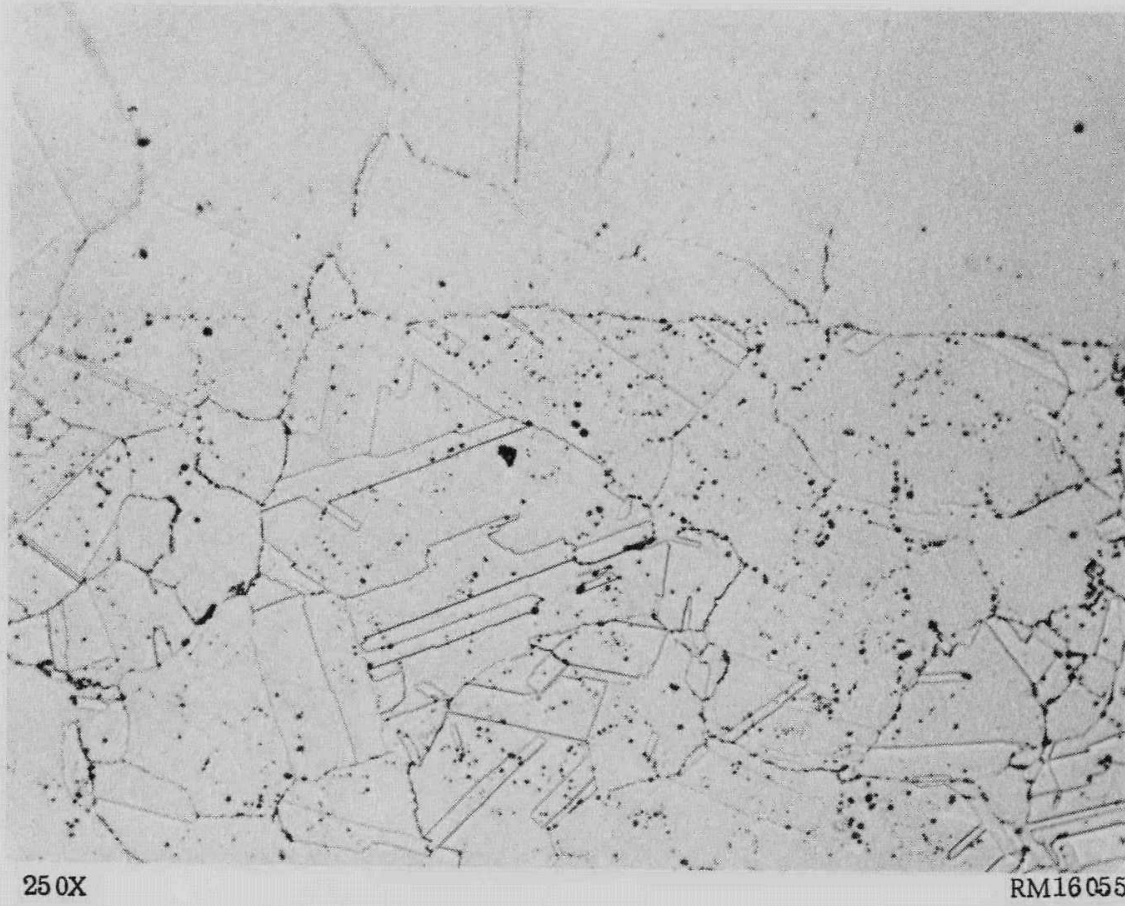

Type 304 stainless steel cladding

Type 304 stainless steel powdered spacer

FIGURE 37. A TYPICAL SECTION OF A ST AINLESS STEEL-CLAD ST AINLESS STEEL POWDERED SPACER PRESSURE BONDED AT 2100 F FOR' 3 HR AT 10,000 PSI TO A DENSITY OF 97.4 PER CENT OF THEORETICAL 
design appeared to be the most promising type for utilization of the direct loading of powders into the stainless steel tube which would serve as the cladding after pressure bonding. Also this design would tend to locate "pleats" such as experienced with the densification of cylindrical rods.

The tamp-packing technique which has been previously described was employed in loading all of these specimens. The first specimens of this type were produced by tamp packing the $\mathrm{UO}_{2}$ into a 10 -mil-wall stainless steel tube having a $0.510-\mathrm{in}$. OD and welding the 1/2-in. -thick end plugs into place, as in the cylindrical rods. The rod was then placed in a die consisting of two halves having, when closed, an opening just large enough for the tube. One of these die halves had a 1/8-in. raised radius running longitudinally on the back side of its groove. When the rod was clamped into the die, a $1 / 8-$ in. - radius indentation was formed on one side. Four indentations were placed in each rod. It was difficult to place these indentations at equal intervals and to keep from crimping the tube. However, upon densification during pressure bonding, the tubes took the shape of the indentations and did not appear to wrinkle or pleat at any other point along the rod. The results from these rod specimens appeared encouraging; therefore, further investigation of the corrugated-rod design is continuing.

A cursory study of a rod design employing stainless steel ribs placed inside the tube to give a corrugated shape after pressure bonding was also undertaken. It was believed that the tube would deform evenly in between the ribs and that in the bonded element the ribs would transmit heat from the center of the core to the cladding when in reactor operation. Tubes of both $10-$ and 20- mil wall thickness and ribs of $10-$ and 20mil thickness were utilized. The ribs were cut to size, bent on a 90-deg angle, tack welded into a cruciform shape, and placed into the tube as illustrated in Figure 38a. These tubes were then tamp packed with $\mathrm{UO}_{2}$. This was a difficult operation since it was required to pack the oxide in areas of restricted access. During pressure bonding, these tubes deformed very unevenly, as shown in Figure $38 \mathrm{~b}$. This effect, which was not initially expected, was attributed to both the uneven loading and the deformation at the ends of the specimens, which caused the ribs to buckle. Further development on this type of element was discontinued in light of these results.

To further study the corrugated-rod design, a corrugated stainless steel tubing was formed from 0.490-in. -ID tubing having a 10-mil wall upon a mandrel as shown in Figure 39a. Two methods were used in forming this type of tubing. One consisted of using a die as previously discussed in conjunction with the mandrel; the other consisted of hydrostatic forming, in which the mandrel was sealed in the tubing and a gas pressure of 10,000 psi was applied to the outside. The tubing, as illustrated in Figure 39b, could be easily produced by conventional commercial methods where large quantities would be required.

After forming the corrugated tubing, end plugs were cut from the mandrel stock and welded into place. The tubes were loaded by tamp packing with various $\mathrm{UO}_{2}$ powders and mixtures, the end plugs welded in place, and the tubes were evacuated and sealed. The specimens were then pressure bonded at $2100 \mathrm{~F}$ for $3 \mathrm{hr}$ at 10,000 psi. Cross-sectional views of two of these rods, PB-29 and PB-54, are shown in Figure 40. Specimen PB-29 shows the effect of too low a tamp-packed density. It was loaded with a mixture of $50 \mathrm{w} / \mathrm{o}$ fused and $50 \mathrm{w} / \mathrm{o}$ ceramic grade as-received $\mathrm{UO}_{2}$ to a density of approximately 36 per cent of theoretical. After bonding, it achieved a density of 89.4 per cent of theoretical. The deformation was not uniform due to the large amount of densification that had taken place. Specimen PB-54 shows the more even deformation 

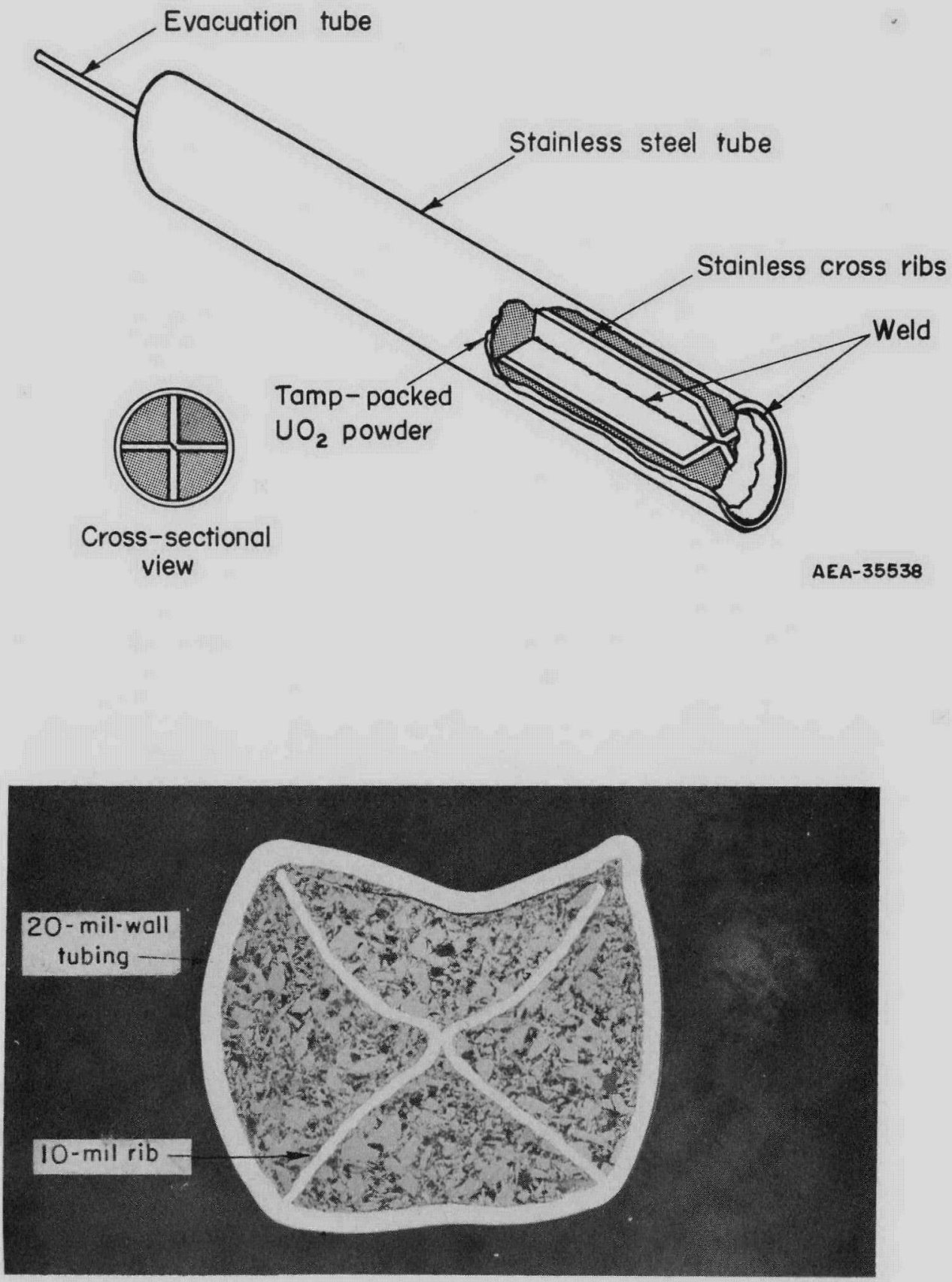

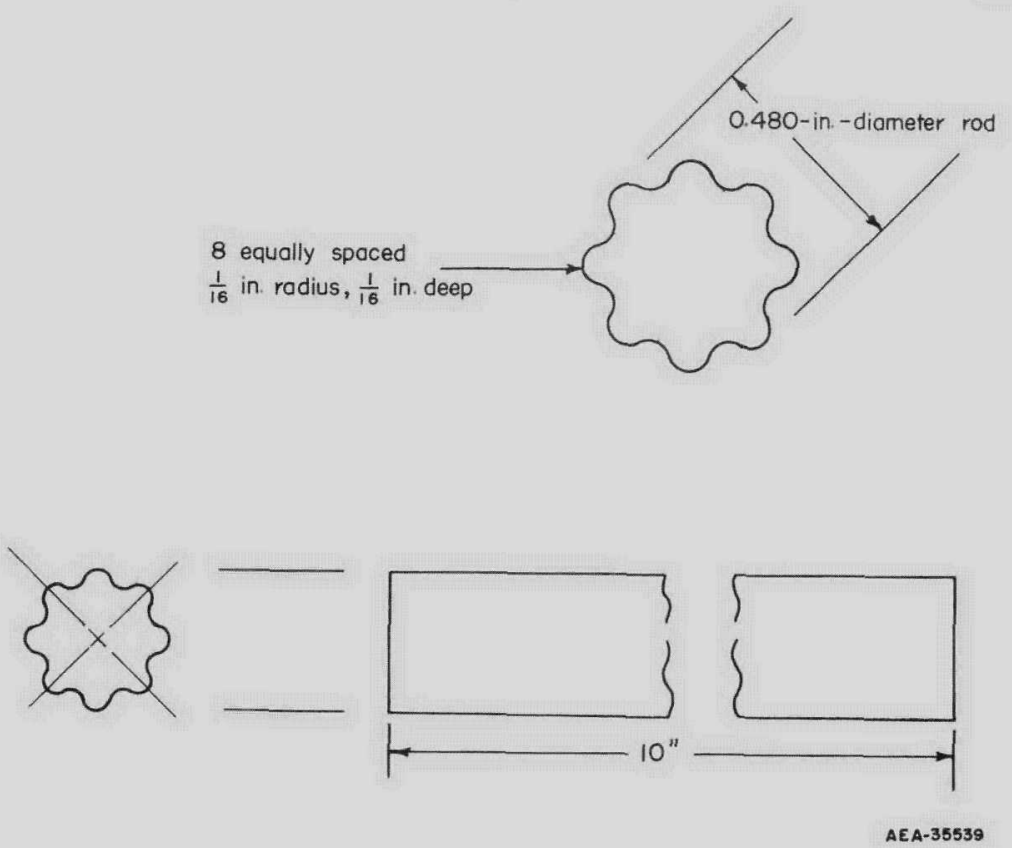

a. Type 304 Stainless Steel Mandrel Used for Forming Corrugated Tubing

b. Cross Section of the Corrugated Tubing Formed from Type 304 Stainless Steel Tubing $0.490 \mathrm{In}$. in ID with a $10-\mathrm{Mil}$ Wall

FIGURE 39. CORRUGATED TUBING USED IN PRESSURE -BONDING STUDIES 


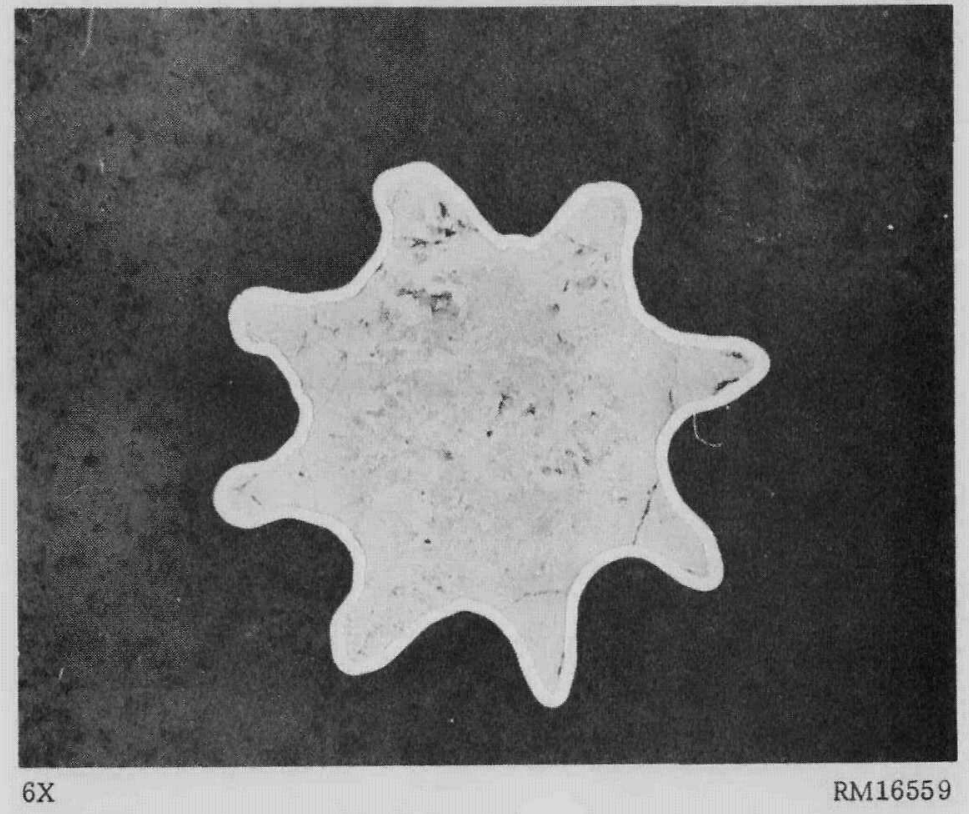

a. Specimen PB-29 With a Core of 50 w/o Fused and 50 w/o Ceramic Grade (Minus $325 \mathrm{Mesh}$ ) $\mathrm{UO}_{2}$

Starting and final density were 36 and 89.4 per cent of theoretical, respectively.

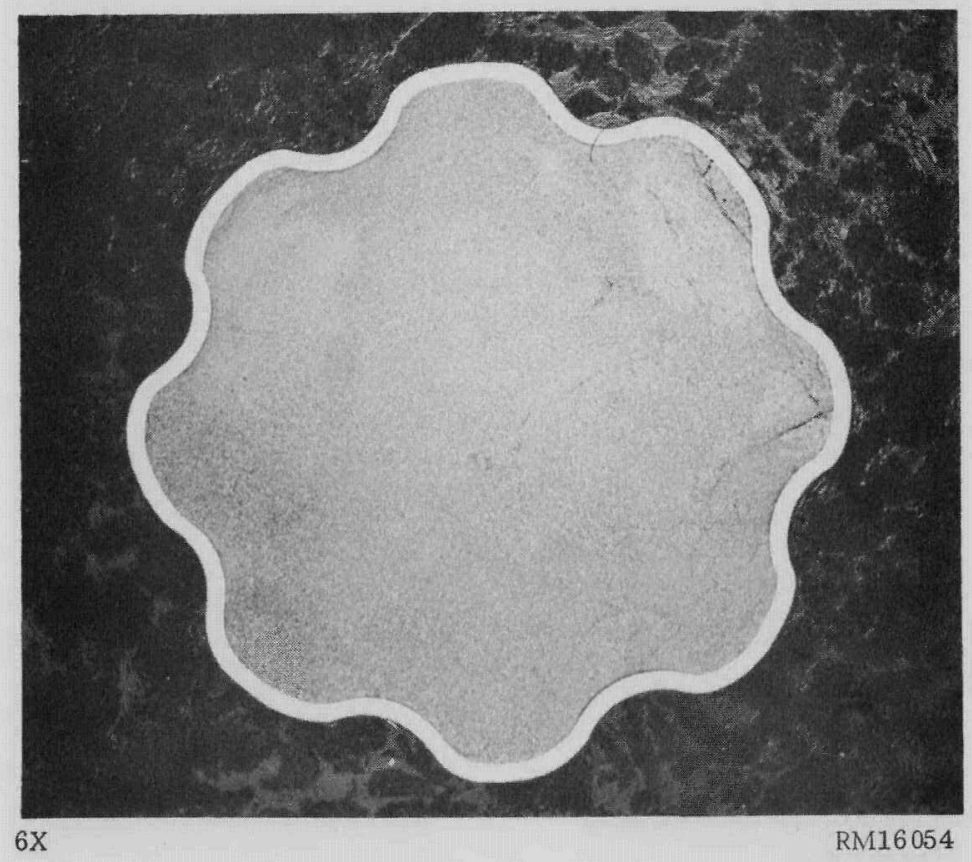

b. Specimen PB-54 with a Core of High-Fired $\mathrm{UO}_{2}$

Starting and final density were 54.7 and 92.4 per cent of theoretical, respectively.

FIGURE 40. CROSS SECTION OF TWO CORRUGATED -ROD -TY PE ELEMENTS AFTER PRESSURE BONDING AT 2100 F FOR 3 HR AT 10, 000 PSI 
that is normally achieved with the corrugated rod. This specimen was tamp-packed to a density of 54.7 per cent of theoretical with high-fired (minus 325-mesh) UO2 powder. A density of 92.4 per cent of theoretical was reached during pressure bonding.

The corrugated rod appears to be of a reasonable configuration for a reactor fuel element; however, there are many problems associated with the design. These include proper end closures, improving and duplicating powder-loading methods, bond contamination, and the strength of the clad element.

End closures have included solid end plugs of the corrugated configuration and tamp-packed stainless steel powders. Difficulties have been encountered in welding of the corrugated-type end plugs, leading to several failures during bonding. Several steps have been taken to improve this welding, and the methods now being used appear satisfactory. This solid end plug, however, as in the cylindrical-rod element, is not satisfactory to yield a completely uniform element. Tamp-packed stainless steel powders were investigated, being loaded into the tube at either end of the $\mathrm{UO}_{2}$ powder. This, as expected, was unsuccessful due to the low tamp-packed density achieved with the stainless steel powder. The deformation over the stainless steel powders was greater than that over the $\mathrm{UO}_{2}$ powders. The possible use of pressed and sintered end plugs is being presently investigated. Methods of direct loading the powders into the tubes to achieve better and more uniform loading are also being investigated. These include investigations into ultrasonic- and vibration-loading techniques.

During the tamp packing of the tubes, ceramic powders sift down around the bottom end plugs, causing contamination of the bond interfaces between the end plugs and the tubing. Further work will be required to eliminate this problem as no satisfactory method has been found to date. It is anticipated, however, that the loose-powder end spacers which are pressed in place or vibratory compacted may offer the solution.

The utility of the corrugated element appears to be somewhat in question when considering the fission-gas-retention capacity of this design. Pressure tests show that this type of tubing, having a 10-mil wall thickness, retains its shape under internal pressures of 300 psi of helium gas. At higher pressures, there is a tendency of the shape to revert to the initial round and eventually fail as a cylinder. This feature would seem to limit this design to low-power use only, unless dispersions of stainless steel or stainless steel pressed and sintered spacers were used to give the tubing added strength. Since the design offers an increased surface area for heat removal, this configuration may tend to minimize over-all fission-gas release and increase its utility. Limited investigation of this corrugated design will be continued.

\section{Compartmented-Rod. Design}

Both the interest shown in the compartmented flat-plate design and the results obtained from the use of cold-pressed and sintered stainless steel end plugs in the cylindrical-rod element brought about an investigation of pressure-bonded compartmented rods. As in the compartmented flat plate, use of individual compartments would tend to minimize reactor operational difficulties in the event of cladding rupture, would also strengthen the element internally, and would provide thermal paths for conducting the heat from the center of the rod during reactor operation. 
In the first compartmentalized rod specimens, an attempt was made to match the final movement and deformation of the stainless steel powdered spacers with that of a green-pressed UO2 core. Three exploratory 0.542-in.-ID tubes with a 20-mil wall thickness and $4 \mathrm{in}$. long were each loaded with pellets of a different $\mathrm{UO}_{2}$ mixture. Stainless steel powdered pellets which had been cold pressed and sintered to a density of 82 per cent of theoretical were used as spacers. The method of assembly of these specimens is shown in Figure 41. The stainless steel powdered cores were 0.529 in, in diameter. The green-pressed $\mathrm{UO}_{2}$ pellets contained the following mixtures and greenpressed densities:

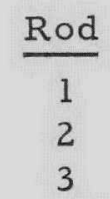

Type of $\mathrm{UO}_{2}$ Powders in Pellets

$75 \mathrm{w} / 0$ fused ( $-325 \mathrm{mesh}$ ) and $25 \mathrm{w} / 0$ ceramic (as received) $65 \mathrm{w} / \mathrm{o}$ fused ( $-325 \mathrm{mesh}$ ) and $35 \mathrm{w} / \mathrm{o}$ ceramic (as received) $50 \mathrm{w} / 0$ fused ( $-325 \mathrm{mesh}$ ) and $50 \mathrm{w} / 0$ ceramic (as received)
Density, per cent of theoretical

74

73

68

The three tubes were pressure bonded at $2100 \mathrm{~F}$ for $3 \mathrm{hr}$ at 10,000 psi. Examination of the rods after bonding revealed that the tubes retained their symmetry, with the variation of the diameters of the $\mathrm{UO}_{2}$ cores and the stainless steel spacers in each of the tubes within 2 mils. The differences between the $\mathrm{UO}_{2}$ core and the stainless steel spacer diameters, measured over the cladding, and their respective densities were as follows:

\begin{tabular}{|c|c|c|c|c|}
\hline \multirow[b]{2}{*}{ Rod } & \multicolumn{2}{|c|}{$\mathrm{UO}_{2}$ Core } & \multicolumn{2}{|c|}{ Stainless Steel Spacer } \\
\hline & $\begin{array}{c}\text { Diameter, } \\
\text { in. }\end{array}$ & $\begin{array}{l}\text { Density, } \\
\text { per cent of } \\
\text { theoretical }\end{array}$ & $\begin{array}{c}\text { Diameter, } \\
\text { in. }\end{array}$ & $\begin{array}{l}\text { Density, } \\
\text { per cent of } \\
\text { theoretical }\end{array}$ \\
\hline 1 & $0.553-0.554$ & 96.6 & $0.541-0.543$ & 97.6 \\
\hline 2 & $0.551-0.552$ & 93.0 & $0.540-0.541$ & 98.0 \\
\hline 3 & $0.5360-0.537$ & 98.2 & $0.539-0.540$ & 98.0 \\
\hline
\end{tabular}

The diameter measurements down the 4-in. length of Rod 3 demonstrated a close match of deformation and final densities in the oxide and stainless steel. The stainless-tostainless powder bonds in all cases were similar to that shown previously in Figure 37.

Two 8-1/16-in. -long tubes with a 0.375-in. ID and a 10-mil wall were then loaded with $\mathrm{UO}_{2}$ cores and stainless steel spacers of the same properties as those used in Rod 3, the only difference being that both the $\mathrm{UO}_{2}$ pellets and the stainless steel spacers had the same diameter of $0.374 \mathrm{in}$. These two tubes were also pressure bonded under the same conditions as Rod 3. Examination of the specimens after pressure bonding revealed that they remained very straight, and their symmetry was within 2 mils. One of these rods with a ground flat to show the internal structure is shown in Figure 42 . The diameter of the cladding over the $\mathrm{UO}_{2}$ cores measured 0.371 to $0.375 \mathrm{in}$. while over the stainless steel spacers it measured 0.376 to 0.378 in.

Another rod, shown in Figure 43, was assembled and pressure bonded at $2100 \mathrm{~F}$ for $3 \mathrm{hr}$ at 10,000 psi, using cores prepared from a mixture of $75 \mathrm{w} / \mathrm{o}$ fused, $15.7 \mathrm{w} / 0$ ceramic, and $9.3 \mathrm{w} / 0$ high-fired $\mathrm{UO}_{2}$ with a green-pressed density of 76 per cent of theoretical. The stainless steel powdered cores having a density of 84.5 per cent of theoretical were used as spacers. This rod, 0.542 in. in ID with a 20-mil wall, was loaded with two $\mathrm{UO}_{2}$ cores for every stainless steel spacer down the length of the stainless tube. The tube over its $11-1 / 2$ in. was very straight, and symmetry was again 


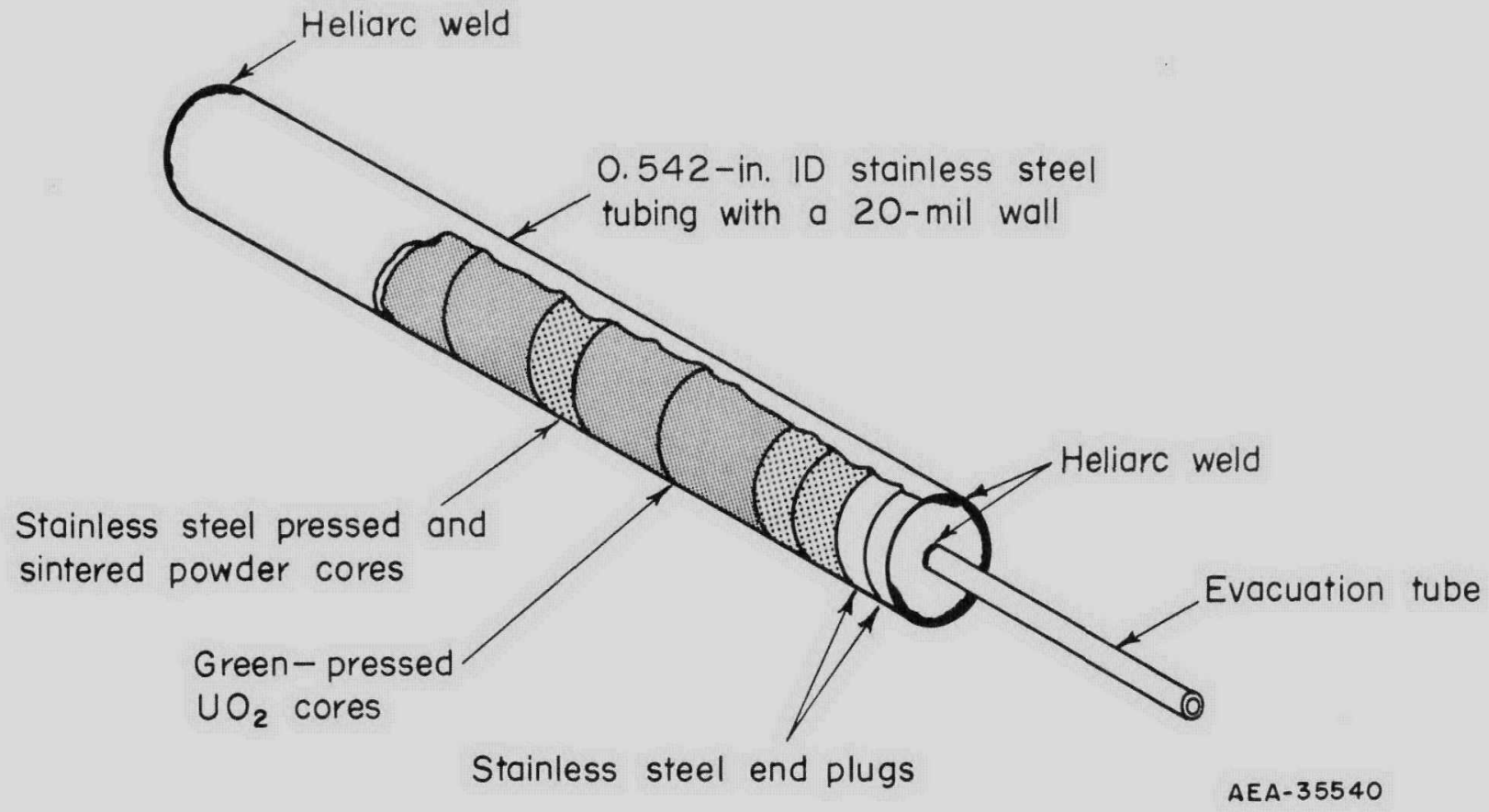

FIGURE 41. DRAWING OF THE ASSEMBLY OF COMPONENTS FOR A COMPARTMENTALIZED ROD 


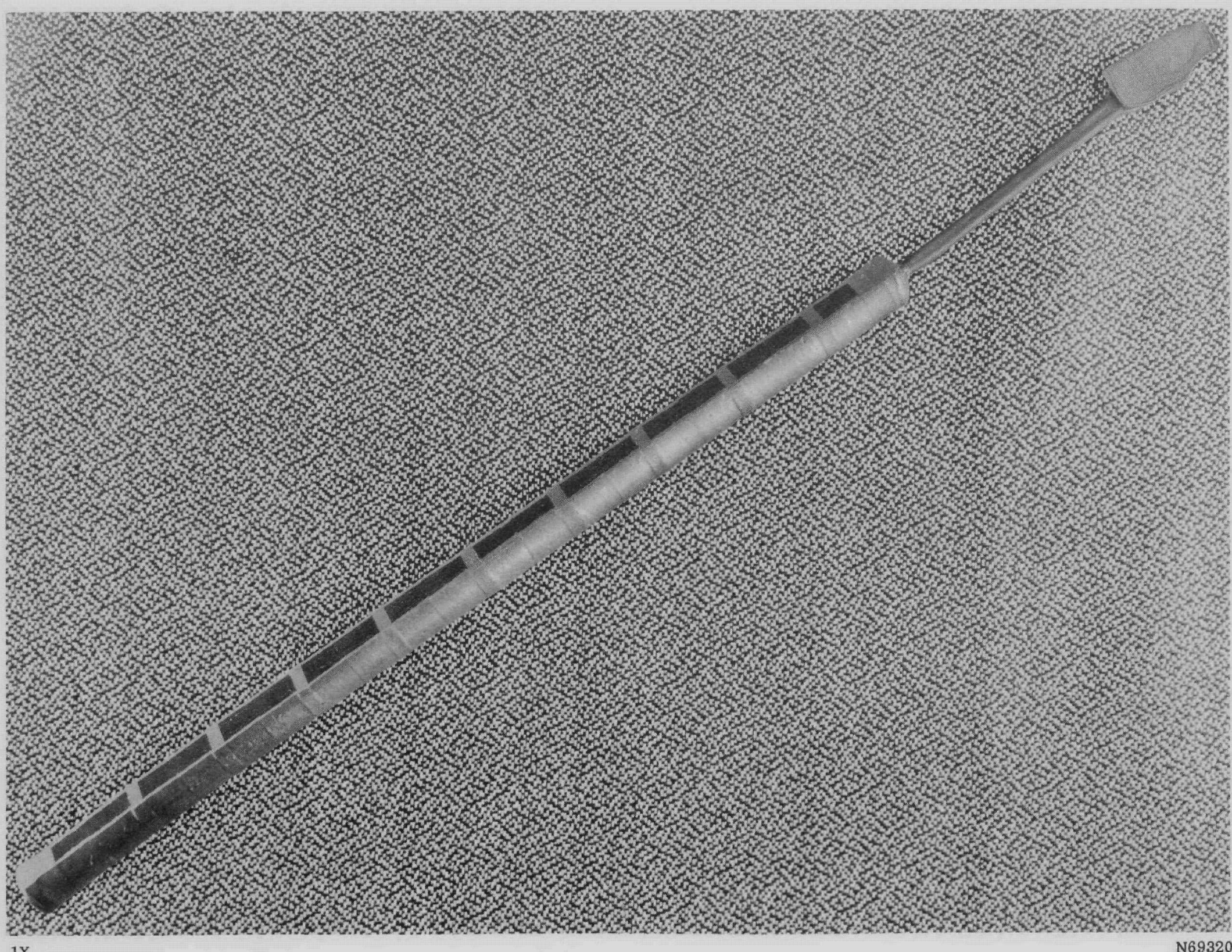

$1 \mathrm{X}$

FIGURE 42. A GAS-PRESSURE -BONDED COMPARTMENT ALIZED ROD FUEL ELEMENT EMPLOY ING GREEN-PRESSED UO 2 PELLETS AND COLD-PRESSED AND SINTERED ST AINLESS STEEL POWDER SPACERS

One side of the element was ground to explore the location of the cores and the spacers. 


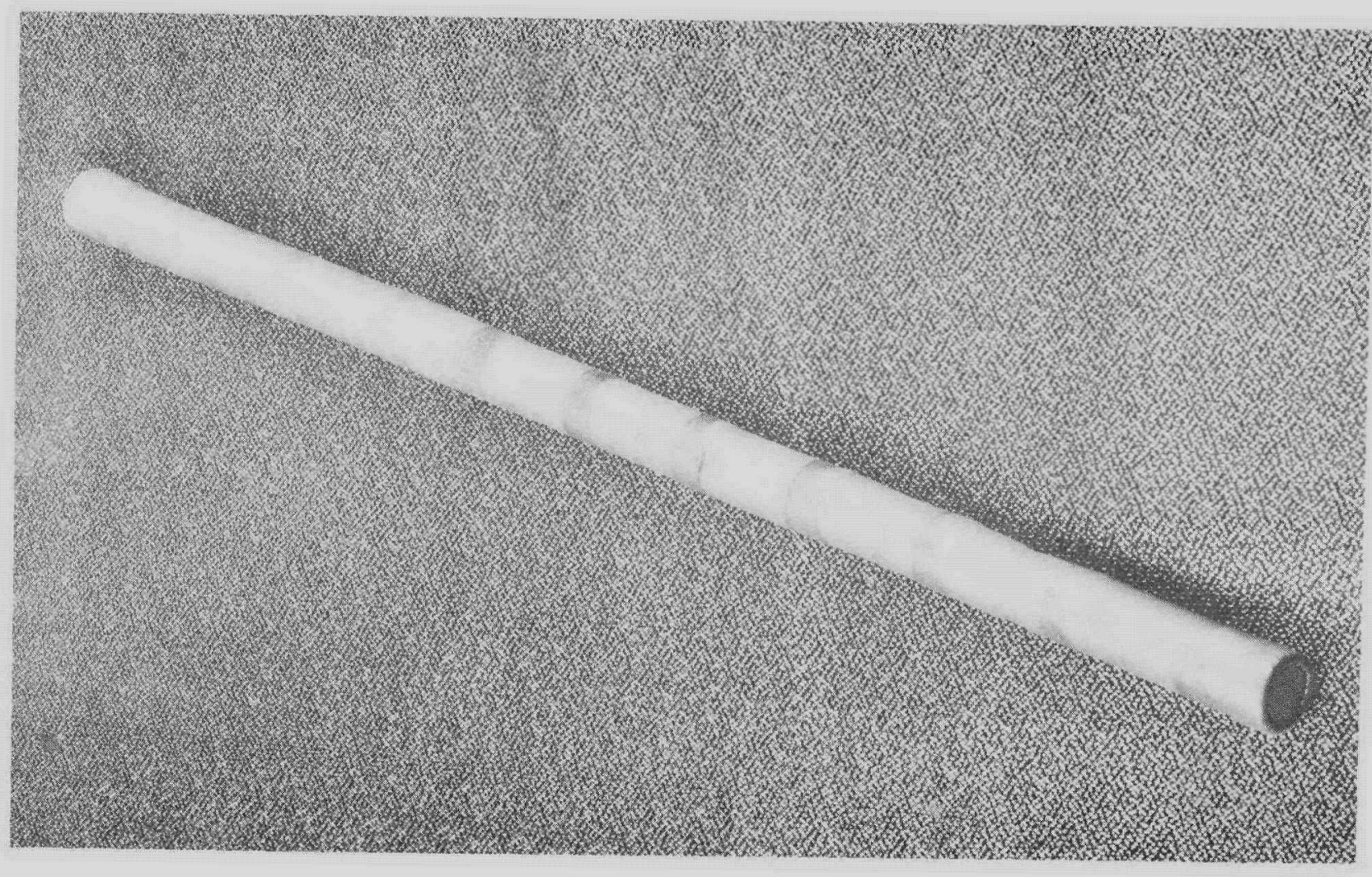

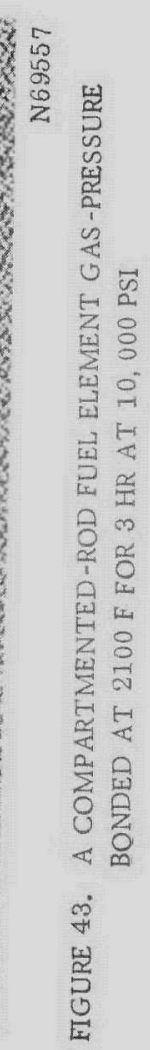


achieved within 2 mils. The difference between the diameter of the cladding over the $\mathrm{UO}_{2}$ cores and over the stainless steel spacers was only 2 mils along the greater part of the elements, with only several depressions measuring 3 mils below this difference.

The results have shown that with the proper matching of the stainless steel powder spacers and the $\mathrm{UO}_{2}$ pellets, uniform movement and deformation can be achieved during pressure bonding. Further work will be required on the selection of the optimum properties of such pellet components and their mode of preparation before fully satisfactory compartmented rods can be fabricated.

\section{Tubular Elements}

The tubular-type element appears to offer some advantages in certain reactor applications over conventional rod and plate assemblies. Perhaps the most distinct advantage is the increased surface area, which offers the potential of more efficient use of coolants. Stainless steel tubular fuel elements containing highly enriched $\mathrm{UO}_{2}$ dispersed in stainless steel have been long considered for power applications. Past investigations have proved the feasibility of gas-pressure bonding tubular fuel elements with metal cores; however, to produce high-density $\mathrm{UO}_{2}$ pellets for this type element by sintering appears unattractive from a cost standpoint. Techniques have been developed for pressing such oxide shapes, but even the green cores would represent a high processing cost. (16) Studies on the present program involving the rod designs indicated that the possibility of producing low-cost tubular elements utilizing tamp-packed oxide powders might be feasible. Consequently, a brief study was undertaken to establish the feasibility of this element.

The first specimens produced of the tubular design consisted of two concentric commercial stainless steel tubes 1.090 and $0.372 \mathrm{in}$. in OD with a wall thickness of 30 and $10 \mathrm{mils}$, respectively, with welded $1 / 2$-in.-thick end caps and filled with tamppacked $\mathrm{MCW}$ special dense $\mathrm{UO}_{2}$ powder as illustrated in Figure $44 \mathrm{a}$. Because of the larger surface area, it was anticipated that the outer tube would tend to deform before the inside tube. To try to overcome this effect, the heavier tubing was placed on the outside of the assembly. This precaution, however, did not prove adequate. The inside tube did not deform at all during pressure bonding at $2100 \mathrm{~F}$ for $3 \mathrm{hr}$ at $10,000 \mathrm{psi}$. Of the several 6-in. specimens pressure bonded, similar results were encountered, with the outer tube deforming between 60 to 80 mils on the diameter. In all cases, final densities were somewhat low for the special dense oxide, being in a range of 80 to 85 per cent of theoretical. However, initial densities were also low due to the methods of loading the assemblies.

The next approach, which is still being investigated, entailed the use of corrugated tubing at the interior of the element to obtain deformation from both the inside and outer tubes, as shown in Figure 44b. The specimens pressure bonded using this design show promise. Deformation has been obtained from both sides of the tubular element, and higher densities have been achieved. The outer tube in this group of specimens has deformed between 25 to $30 \mathrm{mils}$ on the diameter, maintaining uniformity and straightness. Figure 45 shows end views of two tubular elements after pressure bonding. The design of these elements is being further studied to endeavor to produce a simpler element and one which will produce a denser, crack-free core. 


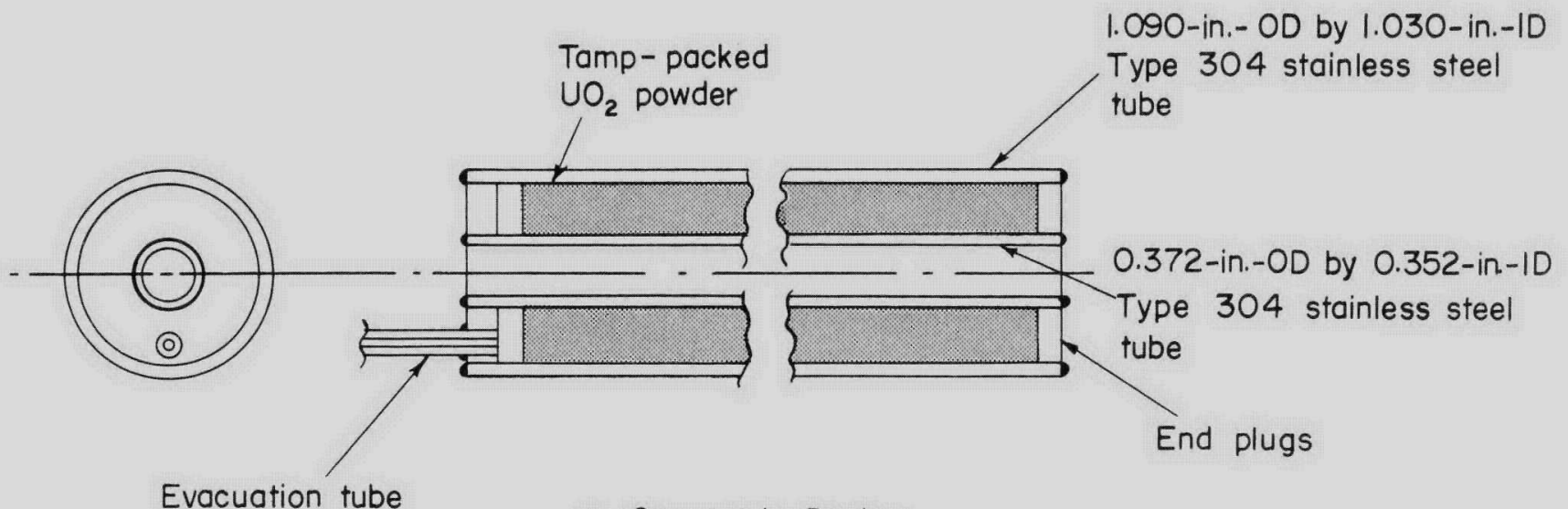

a. Concentric Design

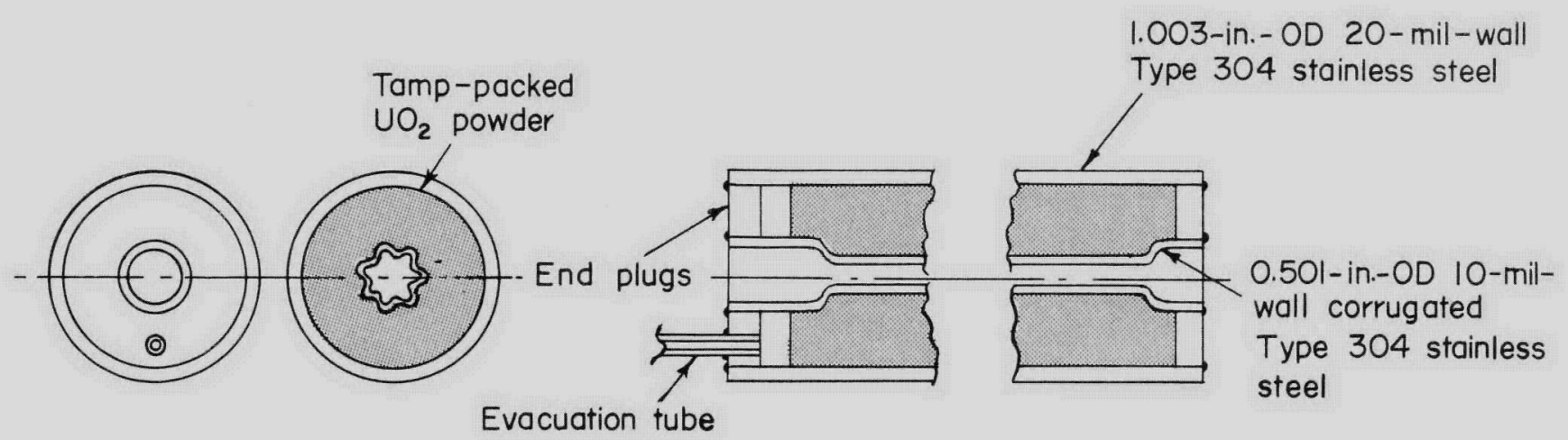

b. Corrugated Center-Tube Design

AEA-35541

FIGURE 44. DRAWINGS OF TUBULAR FUEL-ELEMENT DESIGNS FOR THE GAS-PRESSURE-BONDING APPLICATION 


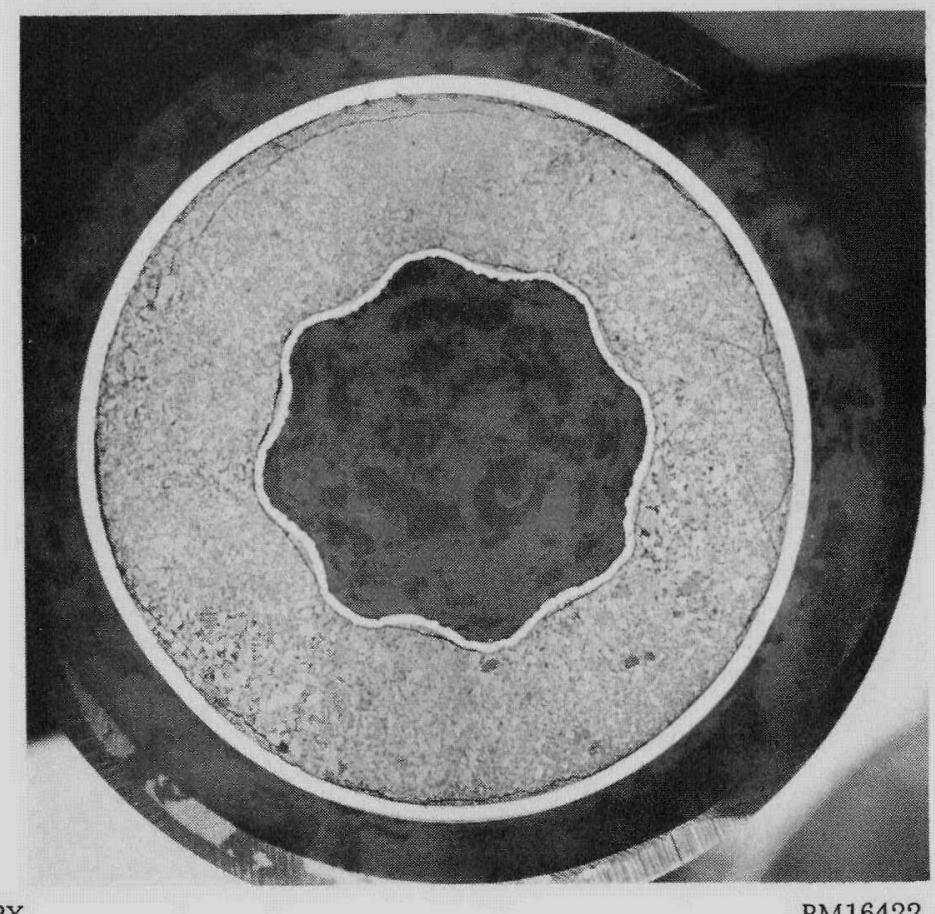

a. Core is Made Up of a Mixture Containing 75 w/o Spencer Fused (Minus 325 Mesh) and 25 w/o MCW High-Fired (Minus $400 \mathrm{Mesh}$ ) $\mathrm{UO}_{2}$

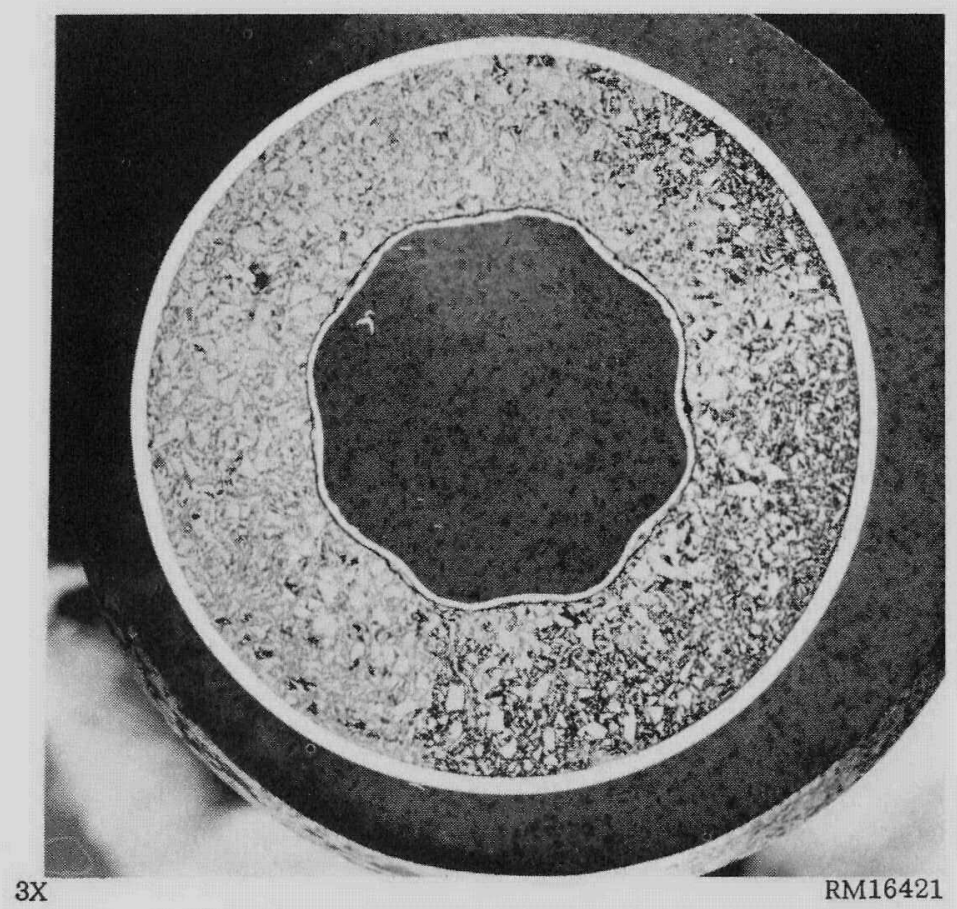

b. Core is Made Up of MCW Special Dense (Minus 40 Mesh) $\mathrm{UO}_{2}$

FIGURE 45. PRESSURE -BONDED TUBULAR-TYPE FUEL ELEMENTS

Both specimens contained tamp-packed $\mathrm{UO}_{2}$ powder cores and both were bonded $3 \mathrm{hr}$ at $2100 \mathrm{~F}$ and 10,000 psi. 
Flat-Plate Elements

Flat-plate reactor fuel elements are of particular interest because of their better thermal performance as compared with other simple fuel-element designs. Flat elements utilizing a ceramic fuel such as $\mathrm{UO}_{2}$ would permit significantly higher burnups than similar elements containing metallic fuels. Compartmented flat plates containing small $\mathrm{UO}_{2}$ cores would represent a mechanically rigid as sembly which would tend to minimize reactor operational difficulties in the event of cladding rupture. Also, the individual compartments would function as separate pressure chambers, and, in cases where they are designed sufficiently small, a high capacity for containing fission gases would be realized. In view of the advantages of such an element, the compartmented design was included as one of the basic fuel-element geometries to be investigated in Phase II of the present study. Previous efforts at Battelle have demonstrated the feasibility of utilizing the gas-pressure-bonding technique in fabricating Zircaloy- 2 clad elements of a similar design, although in this case only sintered high-density $\mathrm{UO}_{2}$ cores were used in the initial assembly. $(9,17)$

In the present study, techniques employing $\mathrm{UO}_{2}$ in the initial form of tamped powders, green-pressed compacts, and sintered compacts have been investigated. The general approach to using such core materials in a stainless steel-clad compartmented flat-plate element has consisted of a series of preliminary studies designed to establish material behavior followed by a more detailed investigation of a large flat-plate design. Cursory studies of corrugated and honeycomb plates representing modified flat-plate designs were also included in this area of work. In general, the nature of the compartmented flat-plate design resulted in severe cladding-component deformation when lowdensity $\mathrm{UO}_{2}$ cores were used in the initial assembly, although high final $\mathrm{UO}_{2}$ densities were achieved. To date only those assemblies utilizing high-density $\mathrm{UO}_{2}$ cores prior to pressure bonding appear entirely feasible. The success experienced with powder spacers in compartmented-rod elements has prompted the more recent initiation of studies of flat-plate composites containing both low-density $\mathrm{UO}_{2}$ cores and low-density stainless steel powder components.

$\underline{\text { Preliminary Studies }}$

The first design studied consisted of a single core in a container of the flanged design with stainless steel spacers placed around the edge of the core to form a frame as shown in Figure 46. Initial specimens of this type were assembled by loading the container through the end; however, it was found that assembly was facilitated by loading from the top of the container. The cores for these experiments measured 0.125 and 0.250 by 1.0 by $1.0 \mathrm{in}$. and represented a density of between 60 and 71 per cent of theoretical. These specimens were pressure bonded at $2100 \mathrm{~F}$ and $10,000 \mathrm{psi}$ for periods of 2 and $3 \mathrm{hr}$. All assemblies deformed readily from the flat sides, but in all cases the edges of the container and frame bowed in more than $1 / 8 \mathrm{in.}$ as shown in Figure 47. The flat faces of the specimens were generally smooth and purallel with each other within 10 to 15 mils. The cores achieved a high density, in excess of 95 per cent of theoretical, but were generally badly cracked. Three additional specimens of this general type, consisting of four cores placed end to end, were bonded with similar results. 


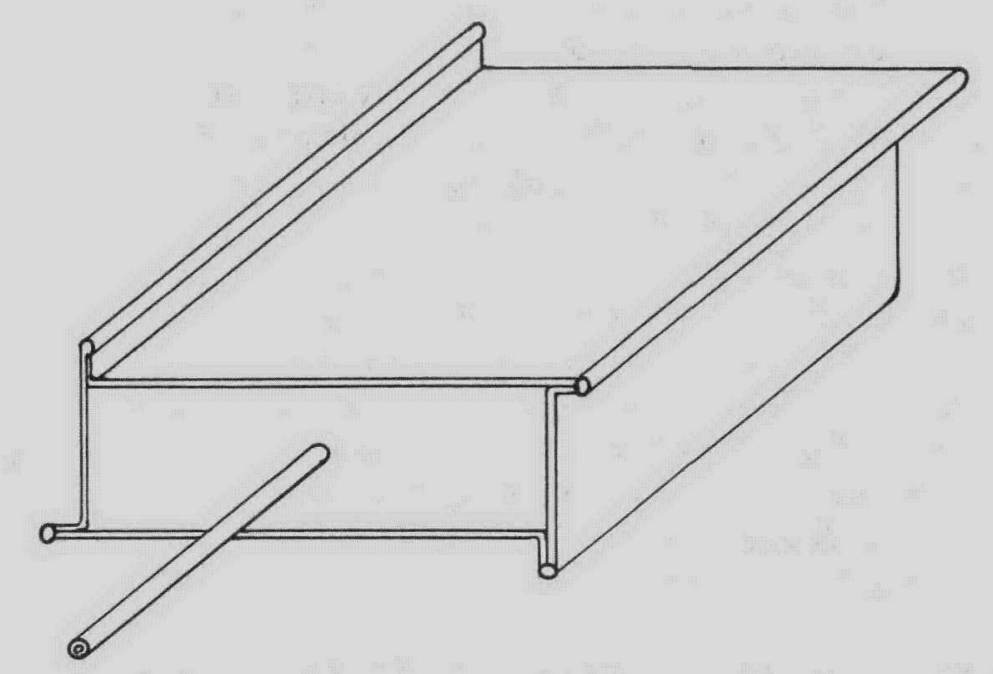

Flanged (swastika configuration) container

0.080 -in. stainless

steel end plates

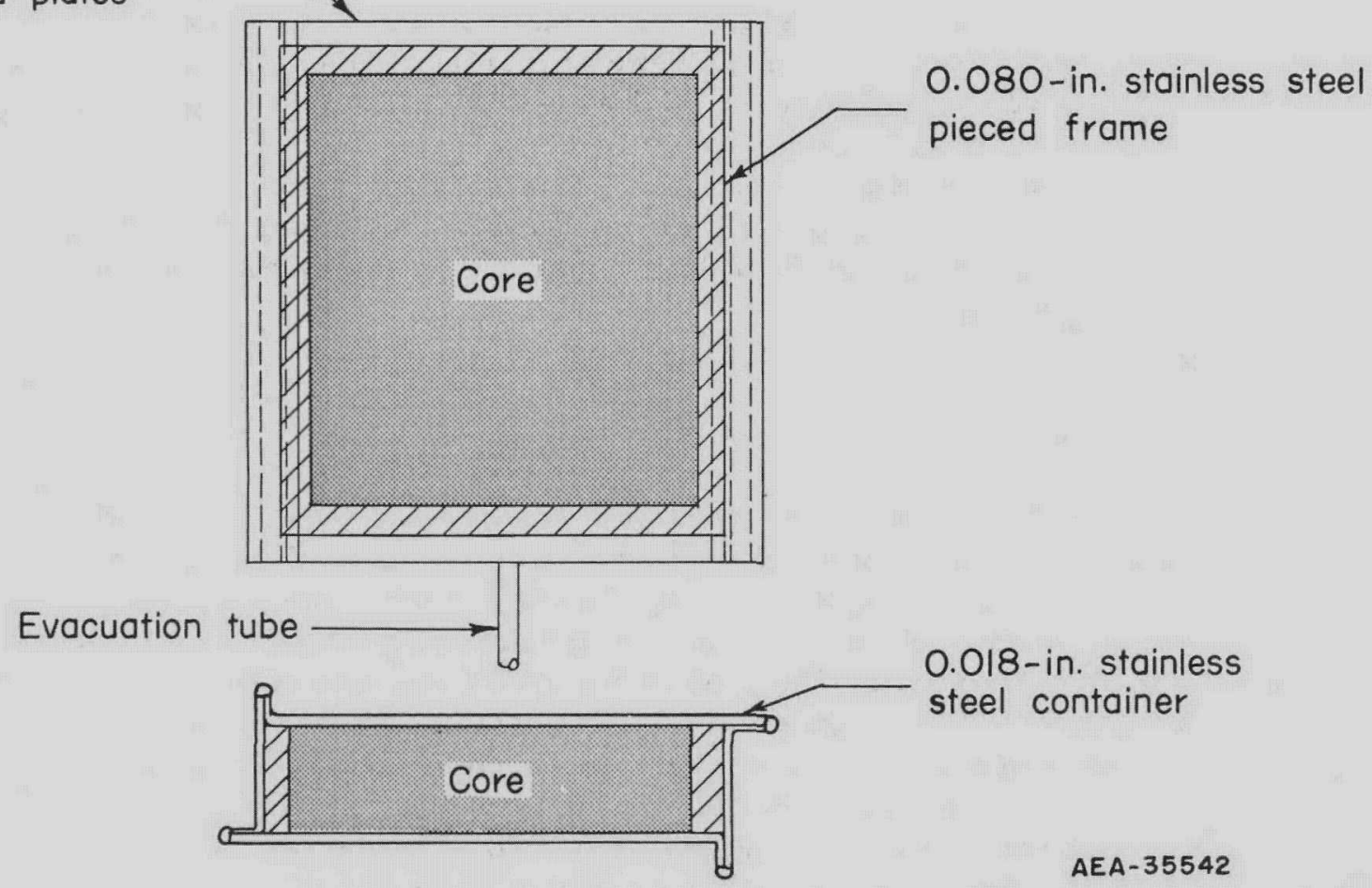

FIGURE 46. ASSEMBLY OF GREEN-PRESSED $\mathrm{UO}_{2}$ CORE FOR PRESSURE BONDING 


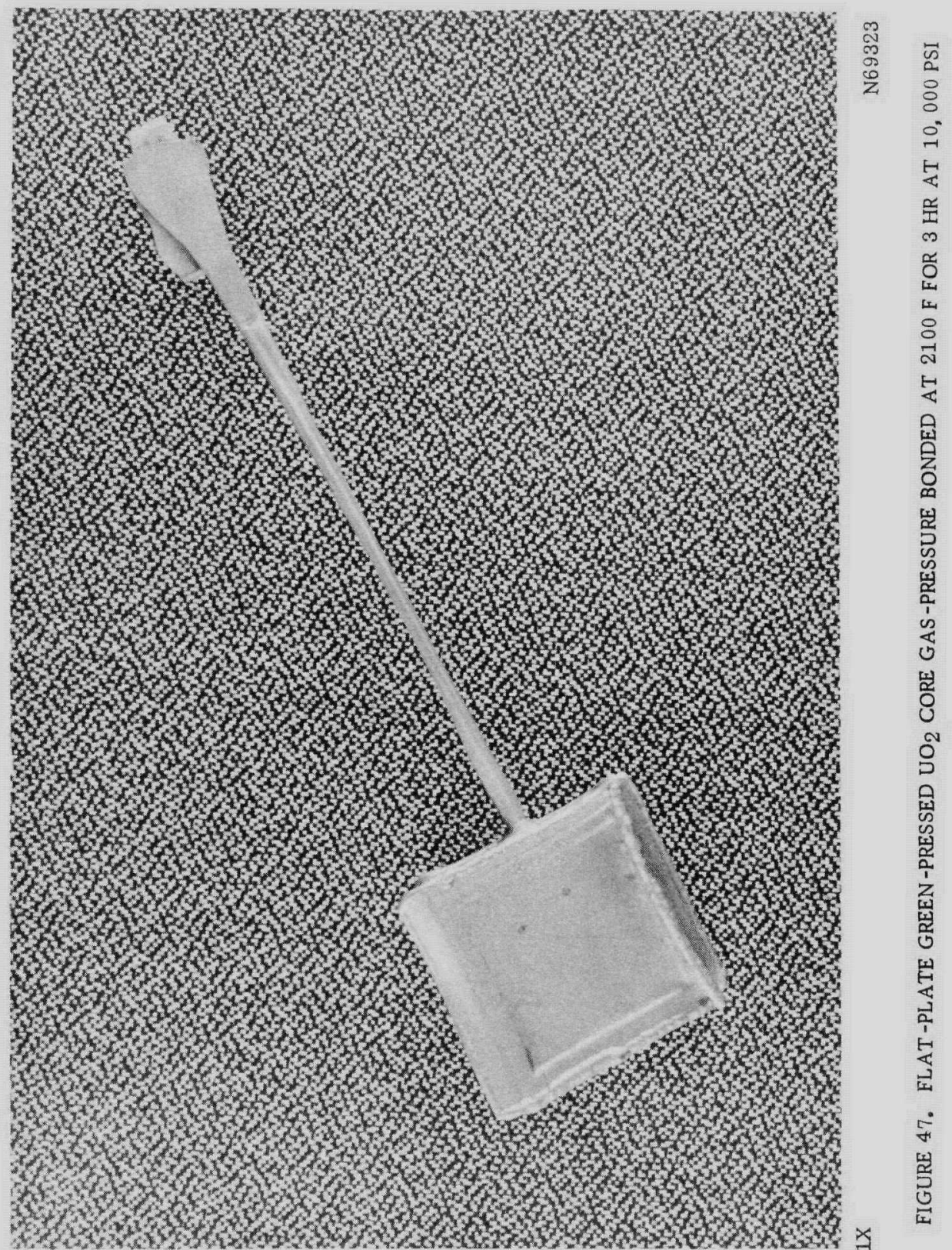


The loading of green-pressed cores and tamp-packed powders directly into the flanged type container without the addition of the pieced frames was also investigated. It was believed that the flanges of the container would deform to allow a more even deformation of the core material. In general this was verified, and, consequently, a more uniform plate was achieved; however, the surface of the densified tamp-packed powders and the stainless steel surface were rough. There appeared to be little cracking of the final cores, which also exhibited densities in excess of 95 per cent of theoretical. By the use of stainless steel powder frame strips, it appears that plates of uniform thickness could be produced in this manner.

Edge-Welded Flat Plates

The preliminary investigations to demonstrate the feasibility of pressure bonding an edge-welded stainless steel-clad $\mathrm{UO}_{2}$ compartmented flat plate was conducted on plates measuring 0.120 by 1.875 by 5.500 in. These plates contained nine high-density cores, each being compartmented individually. The pieced frame and cladding components were machined from 10- and 100-mil Type 304 stainless as-rolled sheet. Tolerances on all machined parts were held to $\pm 0.001 \mathrm{in.}$, readily attainable by established commercial practices. The stainless steel components were treated with the standard wash cycle, assembled, and clamped between two copper weld blocks. The edges of the covers and frames were fusion welded in a helium atmosphere to form a gastight asser bly. After peripheral welding, the plates were evacuated through a groove in the stem and sealed by resistance-upset welding. The plates were then pressure bonded at $2100 \mathrm{~F}$ for $3 \mathrm{hr}$ at 10,000 psi. Examination of the plates revealed that this type of element can be prepared with excellent dimensional control. Some cracking of the $\mathrm{UO}_{2}$ cores was apparent in these plates; however, this effect was attributed to the assembly procedures and was corrected on subsequent large plates. Metallographic examination of all stainless steel interfaces revealed excellent bonds with 90 to 100 per cent grain growth across the original interface as illustrated in Figure 48. Bond integrity and strength were determined by mechanical bend tests and peel tests. No failures occurred. The relative strength and ductility of the cladding and the strength of the bonds between compartments was established by internally pressurizing intentionally defected compartments. In this test, compartments of an element are subjected to increasing internal pressures until rupture of the cladding occurs. Pressures of 5400 to 5600 psi were required to produce rupture of the 10-mil cladding, as shown in Figure 49. Deflections of 0.074 to 0.085 in. were recorded before rupture occurred. Examination of the specimens after burst testing revealed no bond failures between any of the components during this test. A large edge-welded stainless steel-clad $\mathrm{UO}_{2}$ compartmented flat plate was also pressure bonded to demonstrate size feasibility. The plate measured 0.120 by $3-5 / 32$ by $13-15 / 16-$ in. and contained 48 cores, as illustrated in Figure 50. Examination of the bonded specimen indicated good dimensional control. In view of these results, the gas-pressurebonding process appears to be a feasibile method for fabricating high-density $\mathrm{UO}_{2}$ platelets into stainless steel-clad $\mathrm{UO}_{2}$ compartmented flat plates.

\section{Flat-Plate Fuel Assemblies}

A further step in the development of flat-plate elements utilizing a ceramic fuel involves the gas-pressure bonding of fabricated components directly into flat-plate fuel assemblies. Successful application of the one-step bonding technique to full assembly fabrication would offer the equal performance of the flat-plate design at a lower 


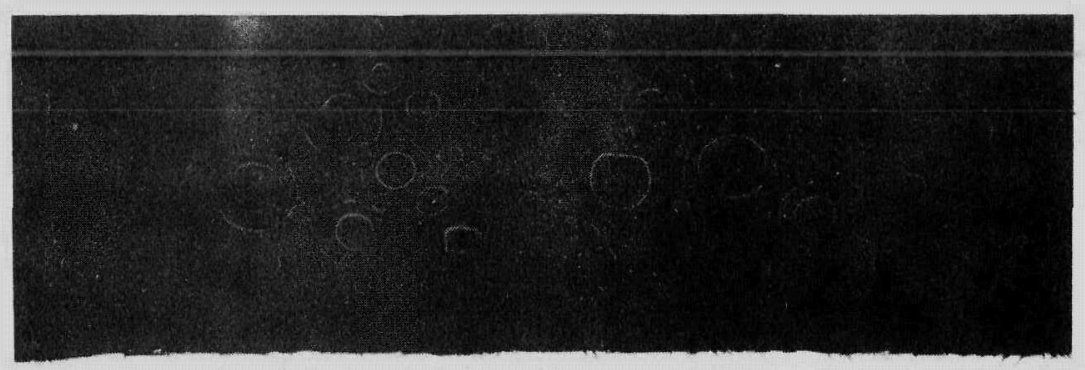

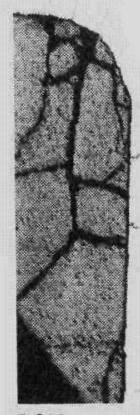

$50 \mathrm{x}$

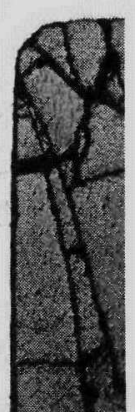

RM15174

a. Transverse Section Showing the Bonds Achieved Between the 10-Mil Cladding and a Longitudinal Rib Intimate contact was achieved between the core and cladding. Evidence of core cracking can be seen.

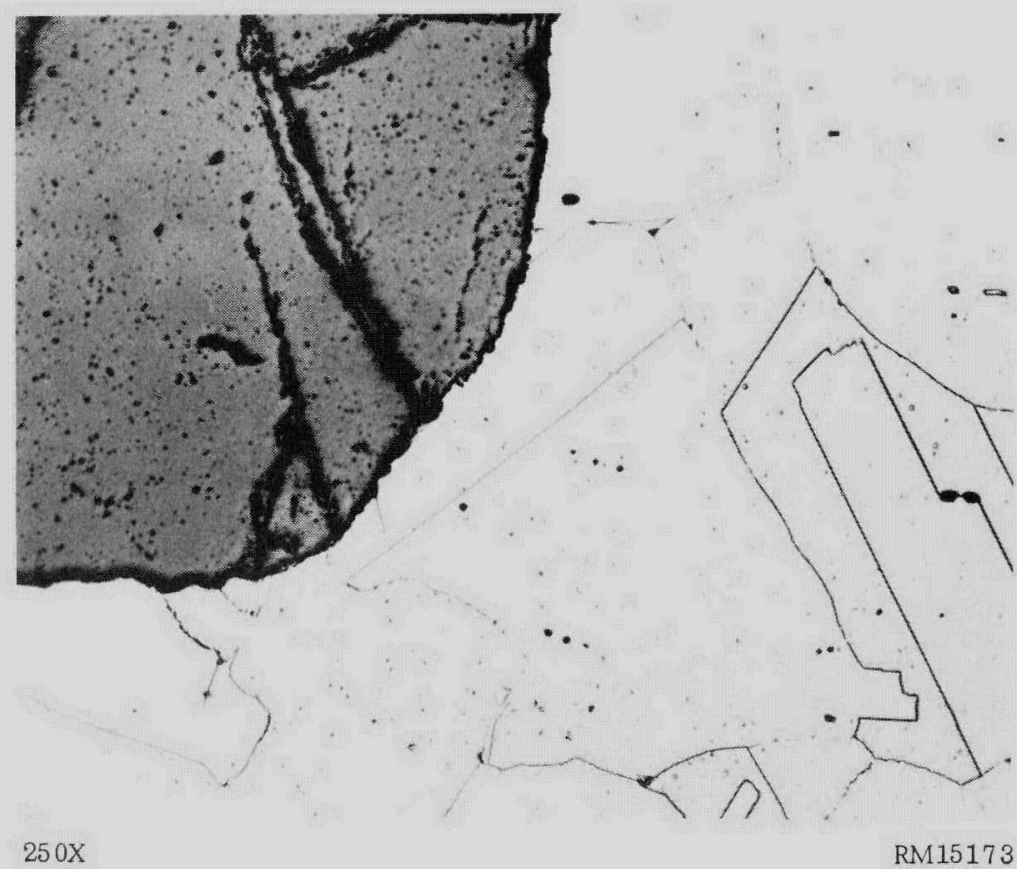

b. Longitudinal Section Showing the Stainless-to-Stainless Interface Between the 10-Mil Cladding and the Transverse Rib

FIGURE 48. TYPICAL SECTIONS OF A PRESSURE-BONDED ST AINLESS STEEL-CLAD UO 2 COMPARTMENTED FLAT-PLATE SPECIMEN GAS-PRESSURE BONDED AT $2100 \mathrm{~F}$ FOR 3 HR AT 10,000 PSI 


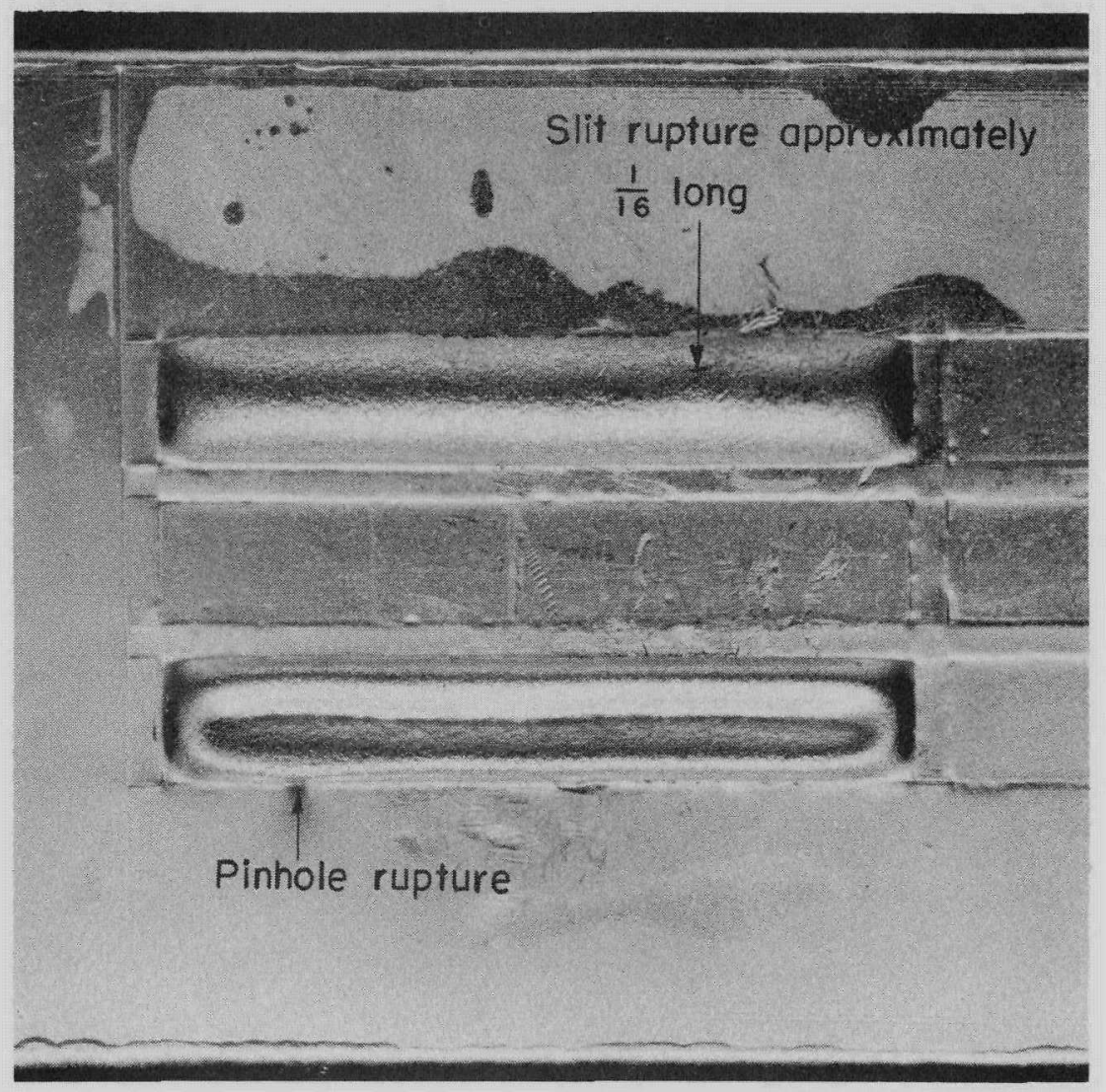

N65396

FIGURE 49. PRESSURE-BONDED STAINLESS STEEL-CLAD UO 2 COMPARTMENTED FLAT -PLATE SPECIMEN WHICH WAS BURST TESTED

This specimen illustrates the failure of the cladding in a normal manner during burst testing. This specimen was prepared utilizing the edge-welding technique and a piece-component frame and was gas-pressure bonded at $2100 \mathrm{~F}$ for $3 \mathrm{hr}$ at $10,000 \mathrm{psi}$. The pressure was applied through an intentional defect in each of the compartments. The compartment in the lower half of the frame was deformed by the fixture while testing the other compartment. 


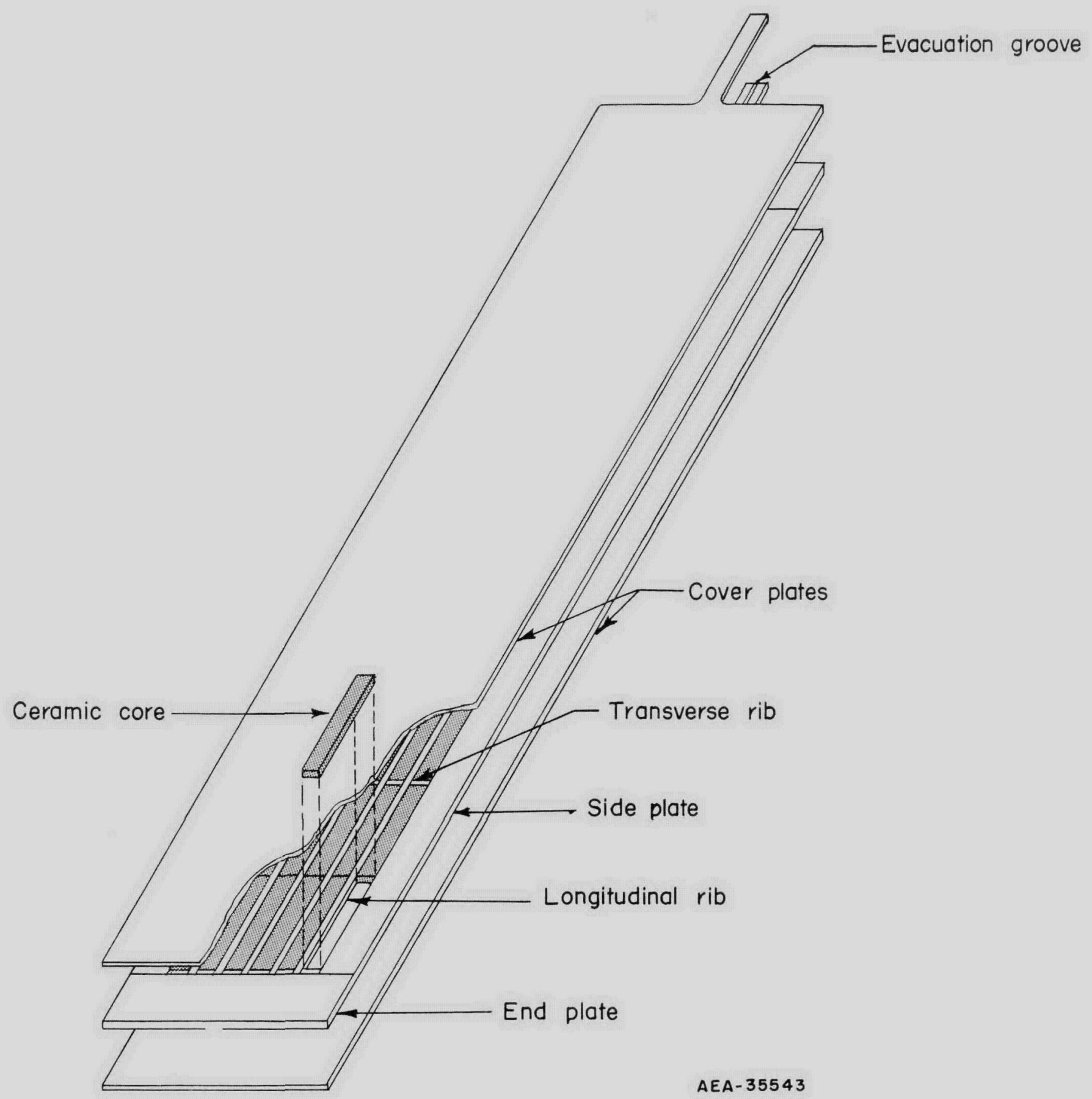

FIGURE 50. DIAGRAM OF PIECE-COMPONENT FLAT-PLATE ELEMENT 
manufacturing cost per assembly. The feasibility of fabricating Zircaloy-2-clad uranium-zirconium flat-plate assemblies by the gas-pressure-bonding technique was previously demonstrated at Battelle. $(10,11)$ Also, a cursory investigation in Phase I of the present study indicated that with further development the gas-pressure-bonding process could be utilized for the fabrication of stainless steel-clad $\mathrm{UO}_{2}$ flat-plate assemblies in a one-step operation.

In the initial studies, assemblies containing five fuel plates with over-all dimensions of 0.600 by 2.411 by $4.572 \mathrm{in}$. were bonded for evaluation as illustrated in Figure 51. The components for these assemblies were fabricated from 0.010-, 0.040-, and 0.075-in. -thick Type 304 stainless steel as-rolled sheet, with 0.075-in.-thick TiNamel sheet being used as channel inserts. Each plate contained four compartments and eight $\mathrm{UO}_{2}$ platelets possessing a high initial density and measuring 0.040 by 0.8305 by $0.8305 \mathrm{in}$.

The components were assembled into either a Ti-Namel or stainless steel pressure container of the swastika or flanged design, after being put through the standard wash cycle. The container was evacuated, sealed, and pressure bonded at $2100 \mathrm{~F}$ for $3 \mathrm{hr}$ at 10,000 psi. After bonding, the ends of the container were machined away and the TiNamel was dissolved by an aqueous acid solution, leaving the clad assembly with five fuel plates and four channels.

The stainless steel container proved to give the best results, an effect also noted in previous studies. This container appeared to retain sufficient rigidity, during heating and pressurizing, to keep the components aligned and restrict container-metal flow between the components. Such flow if permitted would result in restricting subsequent movement of the components and prevent achieving intimate component-surface contact. At pressures and temperatures involved in these experiments the stainless steel container allowed uniform pressure to be transmitted to the entire assembly. Ti-Namel pressure plates were placed at the top and bottom of the assembly to prevent distortion of the assembly at the corners of the container.

Examination of these assemblies revealed good dimensional stability. The metallographic sections from the assemblies revealed that very good stainless steel-tostainless steel bonds were obtained; however, some intergranular attack was observed along the edges of the specimen where the stainless steel was in contact with Ti-Namel. Further examination disclosed that a carbide precipitation at grain boundaries was being formed along this surface. An anneal at $1850 \mathrm{~F}$ for $1 / 2 \mathrm{hr}$ before decanning removed this intergranular weakness. Further study will be given to coatings for the Ti-Namel inserts and the possibility of employing a stabilized stainless steel such as Type 321 and Type 347.

No difficulties were encountered in scaling up to an assembly measuring 1.698 by 2.000 by 6.875 in., as illustrated in Figure 52 . The assembly contains nine fuel plates and eight 75-mil coolant channels. Each fuel plate is 0.120 in. thick and contains 20 high-density $\mathrm{UO}_{2}$ cores, each individually compartmented. The assembly is shown in Figure 53. With only minor refinements the gas-pressure-bonding process can be utilized for the bonding of stainless steel-clad $\mathrm{UO}_{2}$ flat-plate assemblies of full scale. 


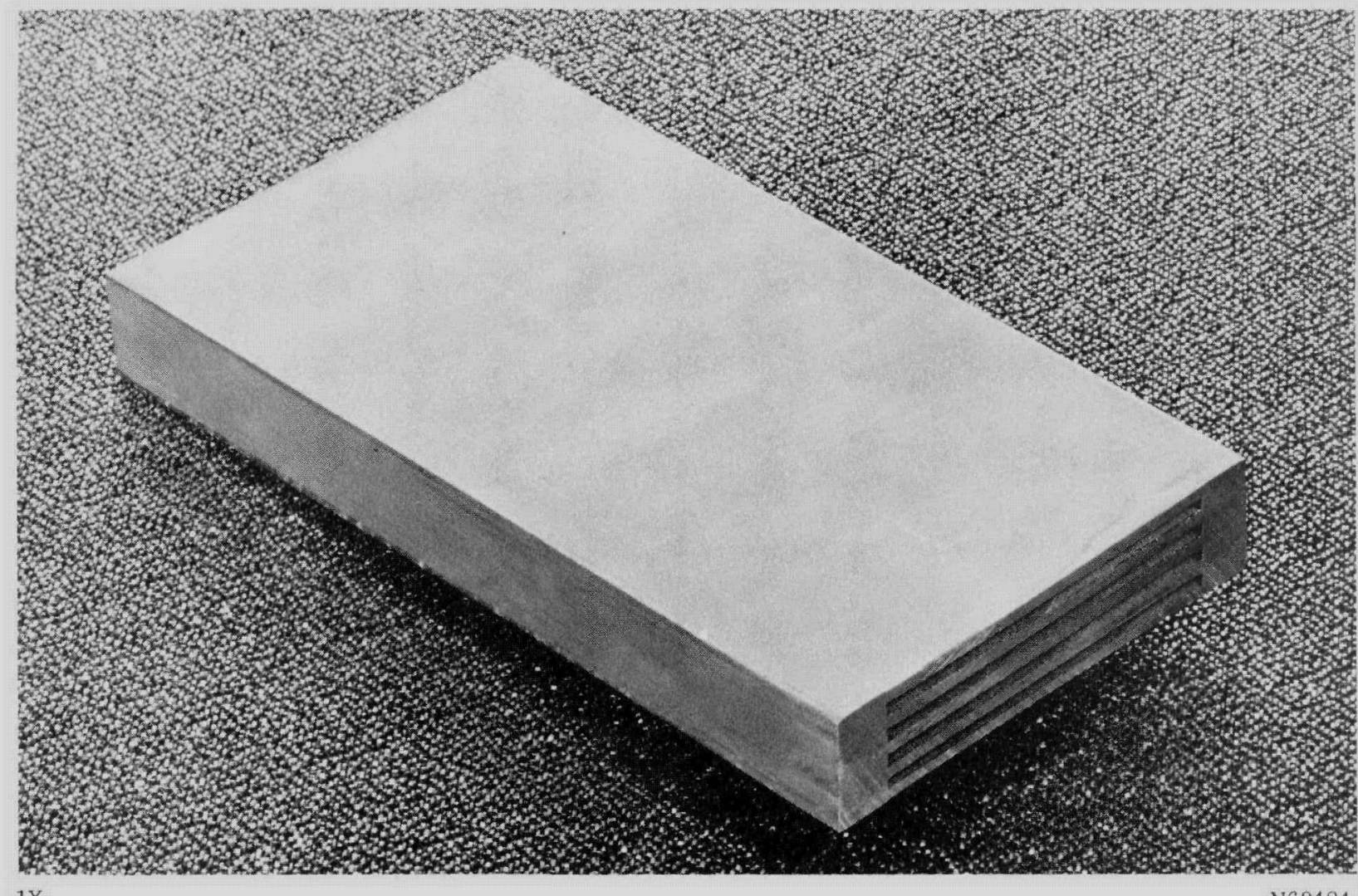

1X

N69424

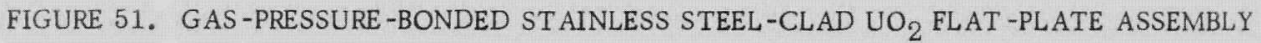

Assembly consisted of 101 pieced components pressure bonded in a one-step operation at $2100 \mathrm{~F}$ for $3 \mathrm{hr}$ at $10,000 \mathrm{psi}$. 


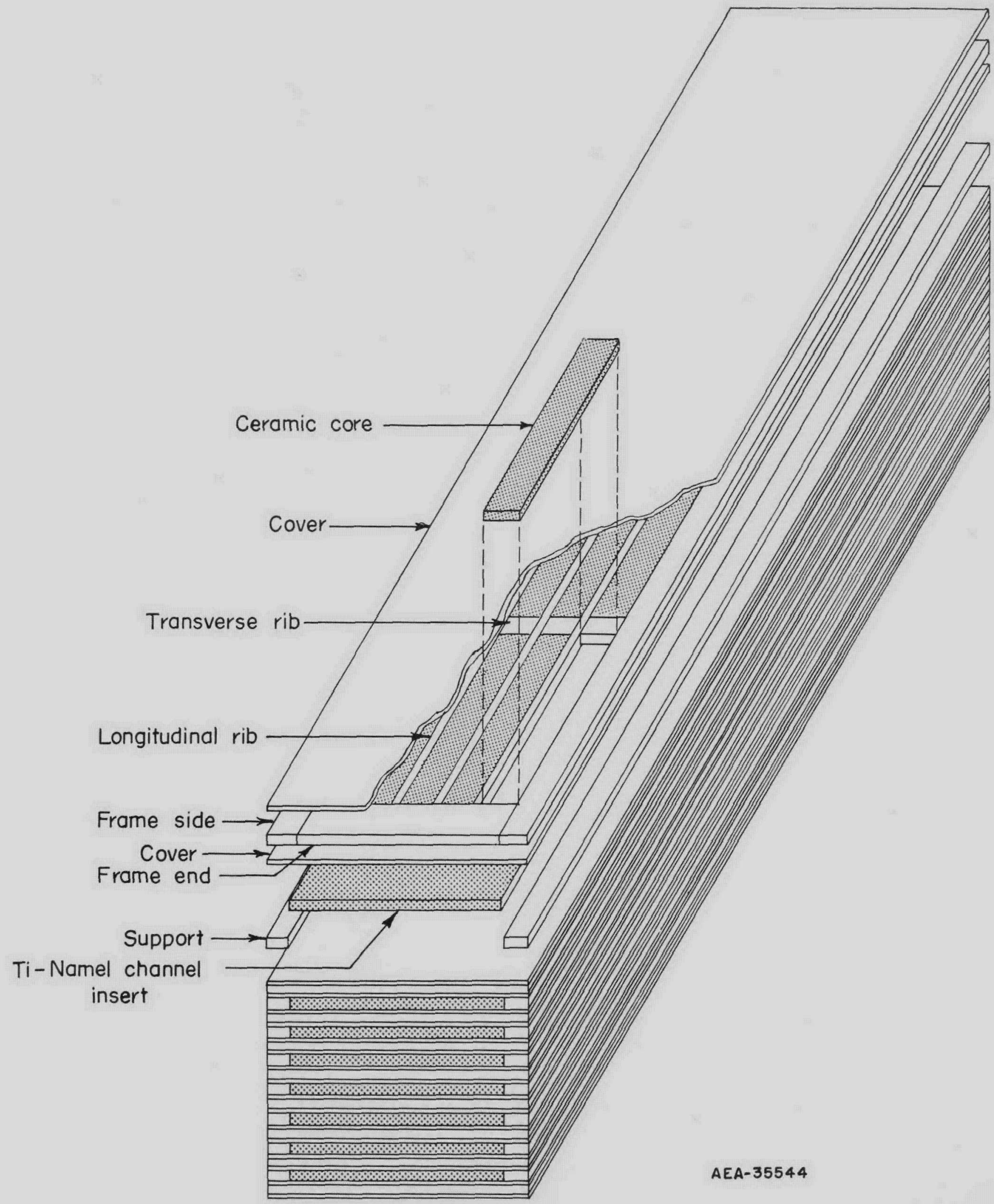

FIGURE 52. DIAGRAM OF A COMPARTMENTED FLAT-PLATE ASSEMBLY 


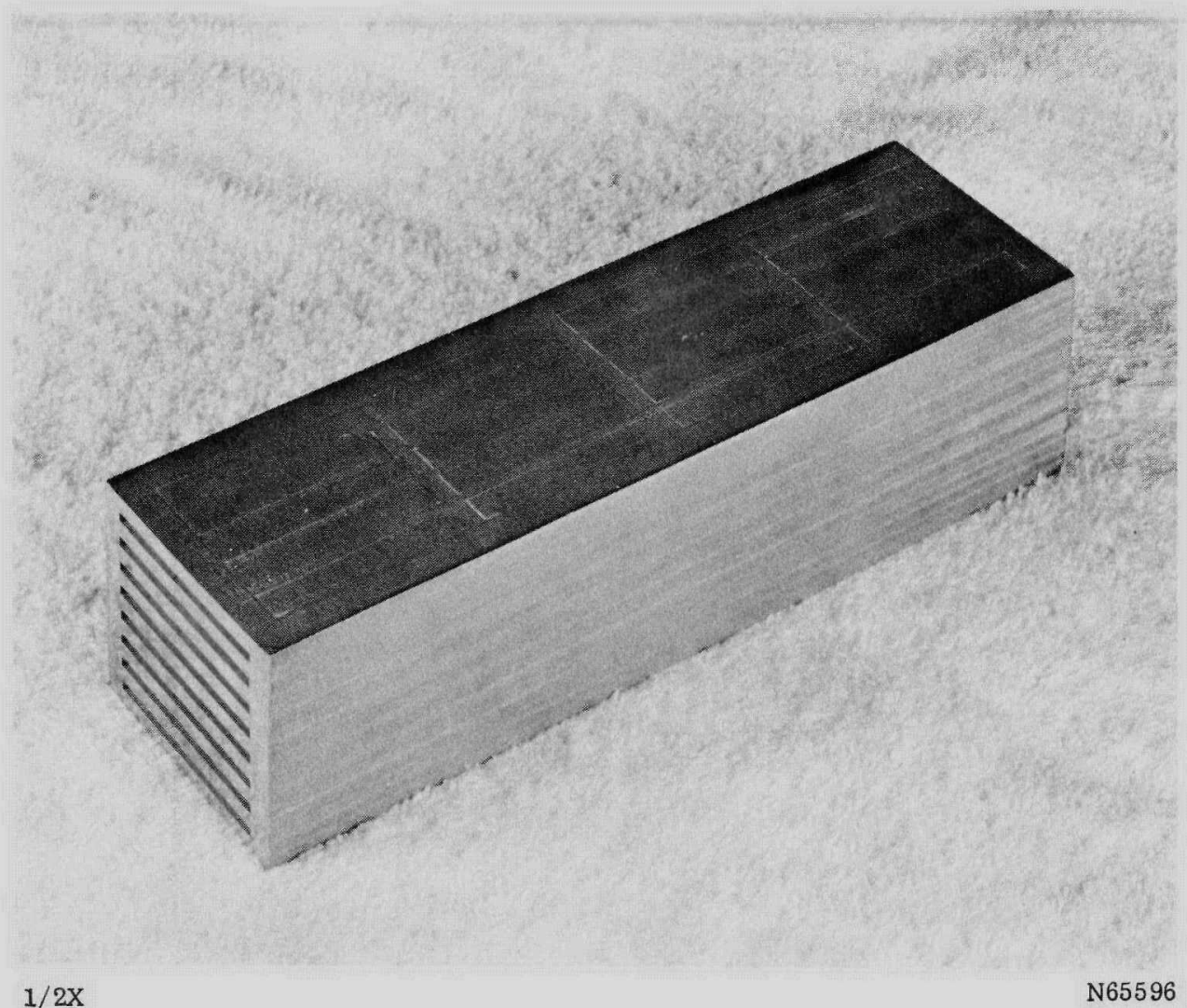

a. Photograph of the 1.698 by 2.000 by $6.875-$ In. Assembly

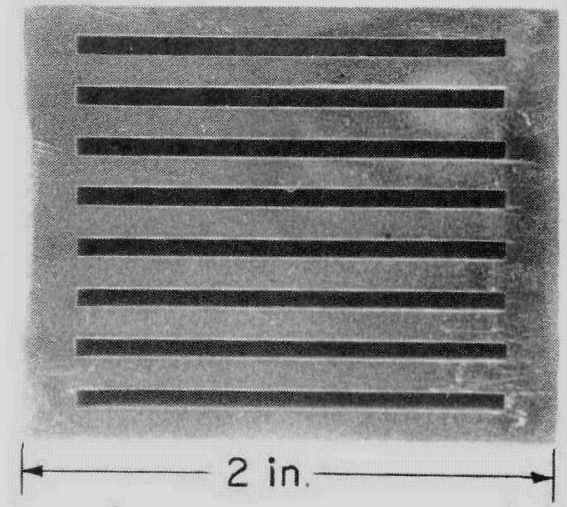

N65597

b. End View Exhibiting the Good Dimensional Uniformity

FIGURE 53. GAS -PRESSURE-BONDED ST AINLESS STEEL-CLAD UO 2 FLAT -PLATE ASSEMBLY WITH NINE COMPARTMENTED FUEL PLATES BONDED AT $2100 \mathrm{~F}$ FOR 3 HR AT 10,000 PSI 
Modified Flat-Plate Design

Two specimens with over-all dimensions of 0.250 by 2 by 3 in. were produced in the form of a corrugated platelet. The container, consisting of two corrugated cover plates and piece frame components, was filled with $\mathrm{UO}_{2}$ powder tamp packed to a density approximately 70 per cent of theoretical. In this approach it was believed that the densification would be achieved while smoothing out the corrugation and thereby result in less deformation of the plate sides and ends. These specimens, however, were unsuccessful due to the fact that the corrugation deformed nonuniformly, warping the plate and producing a very rough surface.

A cursory investigation was conducted to study the possibility of using stainless steel honeycomb material in a compartmentalized flat-plate design. Type 304 stainless steel honeycomb 0.266 in. thick having 1/4-in. cell openings was fabricated from 5-mil sheet. This resulting honeycomb stock was machined to fit into a receptacle measuring 2.000 by 2.500 in., contained in a frame having $1 / 2$-in. -wide sides and a 0.020-in. thick cover. The honeycomb was assembled into the frame and Spencer fused $\mathrm{UO}_{2}$ powder was packed into the cell cavities. A 20-mil cover was placed over the top of the frame and welded into place. The specimen was pressure bonded at $2100 \mathrm{~F}$ for $3 \mathrm{hr}$ at: $10,000 \mathrm{psi}$. The top and bottom surfaces were indented slightly by the honeycomb material, but they were within 8 mils of being parallel with each other. The sides and ends of the frame of this same bonded assembly were found to be bowed in approximately $1 / 16$ in. Half of the specimen was cut for destructive tests and metallographic study while the other half was submitted for a compartmental-leakage test.

Surprisingly good bonds were obtained between the honeycomb and cover plates, as shown by peel tests and metallographic examination. Some contamination was observed in the bonded interfaces, but grain growth had taken place in all interfaces despite the presence of foreign materials. Figure 54 shows exposed edge and top views of this plate. The density of the $\mathrm{UO}_{2}$ core was approximately 90 per cent of theoretical, which is typical of that achieved with fused oxide in other pressure-bonded element designs. The integrity of the compartments was established by internally pressurizing an intentionally defected cell. The defected compartment was pressurized to 1300 psi before an intercompartmental failure occurred. It was interesting to note that this failure did not result in an expansion of the plate cladding. It appeared that failure occurred in the 5mil honeycomb material, as no parting of the bonds was observed when the specimen was examined metallographically. As can be seen in the photomicrographs in Figure 54, piercing of the cell walls by the sharp fused particles occurred in several places; this would tend to weaken this thin material. An additional specimen of this type will be pressure bonded using $\mathrm{UO}_{2}$ powder or powder mixtures characterized by smooth rather than angular particle shapes and using stainless steel powder frame components.

\section{CONCLUSIONS}

The investigations in this phase of the program have further demonstrated the feasibility of utilizing the gas-pressure-bonding method to fabricate low-cost fuel elements. During the course of this work materials requirements and limitations have been studied with respect to uniformity in the final product. At present, a limited amount of further work in these areas is required in order to provide a more complete evaluation of 


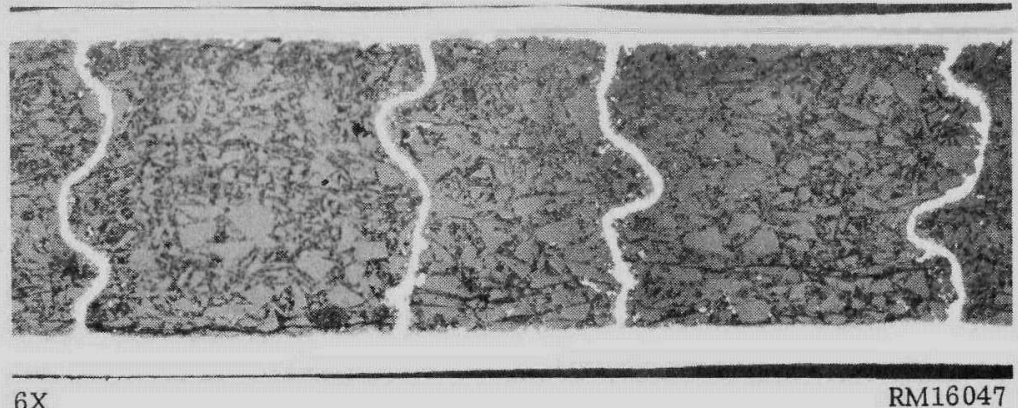

a. Transverse Section Showing the Deformation of the Honeycomb and the Piercing Effect of the Fused $\mathrm{UO}_{2}$ Particles

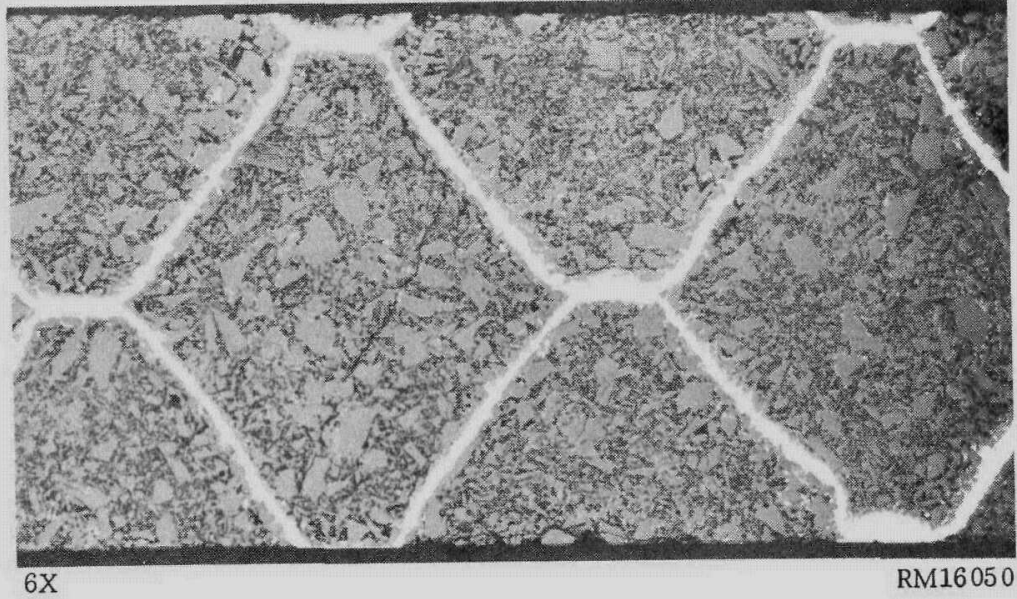

b. Top View of a Section of the Specimen After the Grinding Away of the Cladding

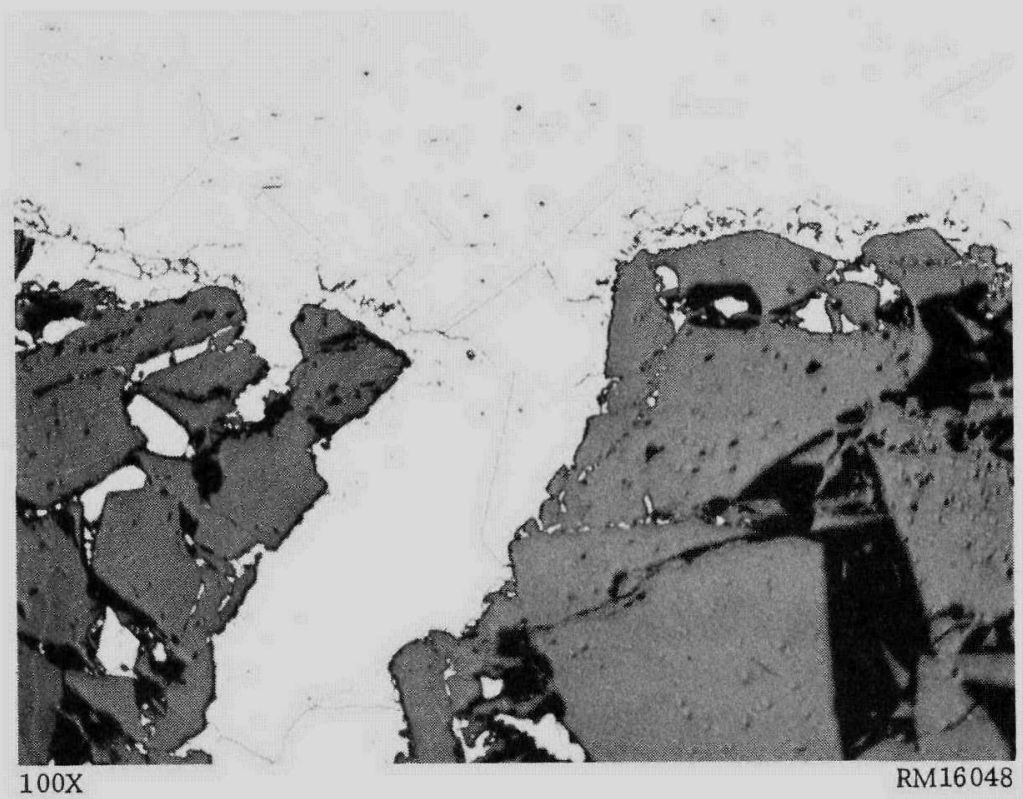

c. A View of the Interface Between the 20-Mil Cladding and the 5-Mil Honeycomb Material

Piercing effect of the fused $\mathrm{UO}_{2}$ particle is evident.

FIGURE 54. TYPICAL SECTIONS FROM A PRESSURE-BONDED ST AINLESS STEEL-CLAD UO 2 COMPARTMENTED FLAT -PLATE SPECIMEN EMPLOY ING A ST AINLESS STEEL HONEYCOMB AND T AMP-PACKED FUSED UO 2 POWDER

This specimen was gas-pressure bonded at $2100 \mathrm{~F}$ for $3 \mathrm{hr}$ at $10,000 \mathrm{psi}$. 
both the materials and process. The conclusions which can be drawn from the present work are summarized as follows:

(1) A variety of uranium dioxide densities prior to pressure bonding ranging up to approximately 86 per cent of theoretical are attainable, depending on the selection of oxide type and compacting procedure.

(2) Pressure-bonded uranium dioxide densities up to 99.5 per cent of theoretical were obtained in this phase of the program. The final densities attainable with the individual oxide types and mixtures have been established.

(3) The most promising oxide material studied consists of a mixture of fused and ceramic grade oxides containing from 30 to $60 \mathrm{w} / 0$ ceramic oxide. Such mixtures possess the densities and activity required for pressure bonding and also represent a low-cost oxide.

(4) The pressure-bonded uranium dioxides appear consistent with pressed and sintered oxide of equivalent density as based on permeability and thermal-conductivity results. It has also been noted that all pressurebonded oxides tend to return to stoichiometry.

(5) Basic fuel-element shapes consisting of rod, tubular, and flat-plate configurations have been fabricated by the pressure-bonding technique. Compartmentalized designs with both the rod and flat-plate elements have been demonstrated. Listed in order of increasing cost the fuel shapes would be rod, tube, and flat plate, reflecting the extent of operations required.

(6) Stainless steel-to-stainless steel bonds are readily achieved with this process; however, further refinement is required to eliminate entrapped oxide from the bonding interfaces.

(7) Stainless steel-80 volume per cent uranium dioxide cermets have been successfully pressure bonded. This material offers unique possibilities in reactor application because of its increased thermal conductivity.

\section{FUTURE WORK}

During Phase III of this program efforts will be directed toward establishing process specifications for the most promising fuel-element designs and ceramic fuel materials. In this regard, it will be necessary to refine the pressure-bonding techniques and compaction procedures to achieve a reproducible uniform product. In view of the results presented in this report, it appears that such work will be concentrated on the use of oxide mixtures used in the basic designs studied to date. Along with this effort, it is intended to also determine preliminary process specifications for similar designs utilizing stainless steel-uranium dioxide cermet and dispersion cores. 
Also during the third phase of this program it will be necessary to complete the compaction and stoichiometry studies presently in progress. These efforts include evaluation of ultrasonic and vibratory packing of "active" oxides and the "activation" of oxides through flash roasting. The completion of these experiments, in conjunction with those results already obtained, will represent a rather complete study of the various powder-compaction methods prior to pressure bonding. It is anticipated that these investigations will be completed early in Phase III so that optimum preliminary processing techniques can be selected prior to selecting final process specifications.

\section{REFERENCES}

(1) Paprocki, S. J., "Progress on the Use of Gas-Pressure Bonding for Fabricating Low-Cost Ceramic, Cermet, and Dispersion Fuels", BMI-1372 (August 25, 1959).

(2) Belle, J., and Lustman, B., "Properties of Uranium Dioxide", TID-7546, Book 2 (November, 1957).

(3) Lustman, B., "Release of Fission Gases From UO2", WAPD-173 (March, 1957).

(4) Eichenberg, J. D., Frank, P. W., Kessel, T. J., Lustman, B., and Vogel, K., "Effect of Irradiation on Bulk UO 2 ", WAPD- 183 (October, 1957).

(5) "Unclassified Research and Development Programs Executed for the Division of Reactor Development and Division of Research", September 1959; HW-62362 (March, 1960).

(6) Tarpley, W. B., "U1trasonic Compaction", NYO-2573.

(7) Scott, R., and Williams, J., "The Warm Pressing $\left(800^{\circ} \mathrm{C}\right)$ of Uranium Dioxide and Uranium Dioxide-Metal Mixtures", AERE-M/R 2396 (1957).

(8) Hall, A. R., Scott, R., and Williams, J., "The Plastic Deformation of Uranium Oxides Above $800^{\circ} \mathrm{C} "$, AERE-M/R 2648 (1958).

(9) Paprocki, S. J., Hodge, E. S., Carmichael, D. C., and Gripshover, P. J., "GasPressure Bonding of Zircaloy-Clad Flat-Plate Uranium Dioxide Fuei Elements", BMI-1374 (August 28, 1959).

(10) Paprocki, S. J., Hodge, E. S., and Boyer, C. B., "Gas-Pressure Bonding of Fuel Assemblies", TID-7559, Pt 1 (August, 1959).

(11) Paprocki, S. J., Hodge, E. S., Boyer, C. B., and Getz, R. W., "Gas-Pressure Bonding of Flat-Plate Fuel Assemblies", BMI-1312 (January 20, 1959).

(12) Van Dusen, M. S., and Shelton, S. M. , "Apparatus for Measuring Thermal Conductivity of Metals up to $600^{\circ} \mathrm{C} "$, J. Research Natl. Bur. Standards, 12, 429-40 (1934). 
(13) Deem, H. W., BMI unpublished information.

(14) Hedge, J., and Fieldhouse, I., "Measurement of Thermal Conductivity of Uranium Oxide", AECU-3381 (1956).

(15) Kingery, W. D., Francl, J., Coble, R. L., and Vasilos, T., "Thermal Conductivity: X, Data for Several Pure Oxide Materials Corrected to Zero Porosity", J. Am. Ceram. Soc., 37 (2), 107-110 (February, 1954).

(16) Evans, E. A., "Fabrication and Enclosure of Uranium Dioxide", TID-7546, Book 2, pp 414-429 (November, 1957).

(17) Paprocki, S. J., Hodge, E. S., Layer, E. H., Wintucky, E. G., Gripshover, P. J., and Carmichael, D. C. , "Further Development of Gas-Pressure Bonding of Zircaloy-Clad Flat-Plate Uranium Dioxide Fuel Elements", BMI- 1436 (May 11, 1960). 